Leonardo Schiocchet, Christine Nölle-Karimi,

Monika Mokre (Eds.)

\title{
AgenCY AND TUtelage IN FORCED MigRATION
}

Selected contributions | ROR-n blog (2016-2019) 

Agency and Tutelage in Forced Migration

Copyright ( 2020 by Leonardo Schiocchet, Christine Nölle-Karimi, Monika Mokre (Eds.) / ROR-n Plattform / ROR-n and Austrian Academy of Sciences. All Rights Reserved.

D.O.I. https://doi.org/10.1553/RoR-n Plattform Vol 02(1) ISSN: 2707-8760 (online) ; 2707-8752 (print)

No part of this publication may be reproduced, stored in a retrieval system or transmitted in any form or by any means, electronic, mechanical, photocopying, recording or otherwise, without prior permission of the copyright holder, except for the inclusion of quotations properly cited.

Published in Vienna, Austria by ROR-n and the ÖAW.

\section{\begin{tabular}{l|l} 
Refugee Outreach & $\mathrm{RO}$ \\
\& Research Network & $\mathrm{RO}$
\end{tabular}}
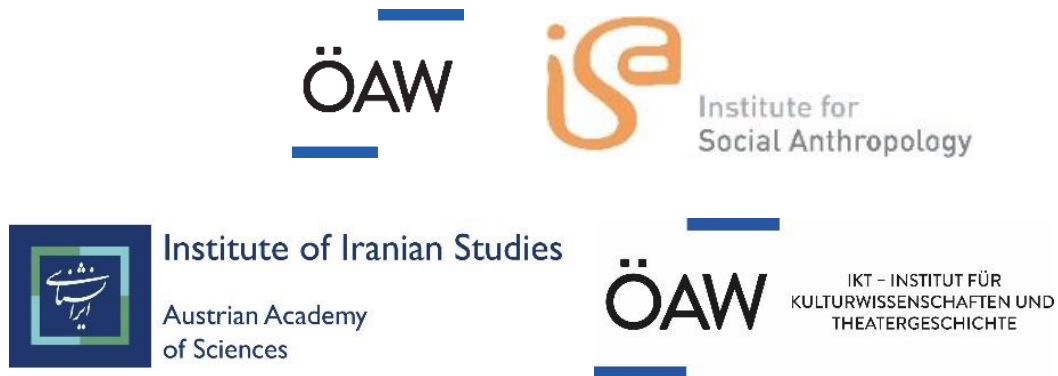



\section{Introduction}

Leonardo Schiocchet, Christine Nölle-Karimi,

and Monika Mokre....

\section{DISPLACEMENT}

1. Many Reasons for Leaving Afghanistan: Social Obligations in Times of Protracted Violence

Gabriele Rasuly-Paleczek

2. There is death in immobility

Khadija Abbasi \& Alessandro Monsutti....

3. Why the lack of research on Iranian emigrants, asylum seekers, and refugees?

Navid Fozi................................................... 25

4. Patterns of Migration in, from and to Yemen

Alexander Weissenburger.....................................32

5. Understanding why smartphones are so essential to refugees

Katja Kaufmann 
6. Forced decisions? How a better understanding of displacement's multiple push-factors may help to reform the global refugee regime

Andreas Hackl........................................................ 43

\section{ENCOUNTERS}

1. Syrian crisis: a very complicated simple question

Ibrahim Sirkeci................................................. 51

2. How Do Lives Become Grievable? On the short summer of migration and the time after

Monika Mokre.

3. Palestinian refugees from Syria and their fate in Europe

Anne Irfan .64

4. Who are the refugees that came to Austria in fall 2015?

Judith Kohlenberger \& Isabella Buber-Ennser. .72

5. Narratives of Asylum Seekers: between coping and integration

Noura Kamal. 
6. "Steps on the way to social integration": Initial social interactions of refugees from Syria, Iraq and Afghanistan with the host society, their relevance, assessment and implications

Josef Kohlbacher

7. Arrival in Austria. Heteronomy and Autonomy in the Experiences of Refugees

Monika Mokre.

8. (We Want Justice for Afghan Refugees Declaration of Afghan Refugees at the Vienna Refugee Protest Camp 2017)

Monika Mokre, for ROR-n 96

9. Against the Wall: Refugees' Artistic Street Performance as Resistant Agency (Berlin)

Amelie Harbisch.

10. Asylum Procedures Shortcomings in Tunisia: What do external borders mean for the EU?

Valentina Grillo.

11. Refugees of the Syrian conflict and the struggle for housing in Brazil

Mirian Alves de Souza \&

Helena de Moraes Manfrinato. 
12. Refugees and the Echoes of the Conflict in the Diaspora (Syrian and Lebanese refugees in Argentina

Silvia Montenegro 125

13. How (not) to scapegoat Refugees: Lessons from Vienna's Election Campaign on Facebook

Liriam Sponholz.

14. Reflections on Migration and Democracy

Monika Mokre....

\section{AGENCY AND TUTELAGE}

1. On Humanitarian Tutelage

Leonardo Schiocchet

2. What is the Problem with Current Perceptions of Refugees as Mere Victims?

Sabine Bauer-Amin.

3. Humanitarianism from Below: Sowa Rigpa, the Traditional Pharmaceutical Industry, and Global Health (Tibet)

Stephan Kloos 
4. Palestinian Refugees in Brazil between Nations and Humanitarian Tutelage

Leonardo Schiocchet. 165

5. The Autonomy of Migration After its Summer

Niki Kubaczek.

6. Volunteers and NGOs in Austria's border management regime, Spielfeld 2015

Lukas Milo Strauss.

7. (Neo-)paternalism and moralism in Austrian language policy

Marija Cubalevska.

8. The Integration of Syrian Asylum Seekers in Austria in Light of Catholic Social Teaching

Pia Jolliffe .196

9. Civil Society in Izmir or how an elusive concept could become useful

Denise Tan .202

10. The Ethics of Struggle: when refugees become hosts of other refugees

Monika Halkort. 208 


\section{The Geopolitics of the Cloud}

Monika Halkort.................................................... 216 


\section{$\underline{\text { Introduction }}$}

Leonardo Schiocchet, Christine Nölle-Karimi, and Monika Mokre

Since 2015, ROR-n has developed invaluable research on forced migration, expressed in lectures, conferences, colloquia, and published material. Some of this material has been specifically geared towards the academic public, while a significant part of our efforts has also been geared towards producing a wider dialogue between academicians, case workers, policy makers, and those engaged in understanding and intervening in forced migration processes at large. ROR-n's blog is part of this latter effort. In addition, the editors of ROR-n Blog have striven to balance out contributions by established scholars and remarkable younger academicians.

ROR-n Plattform is our new Open Source publication series designed to reach out to a wide audience within and beyond academia. Volumes are published ad hoc either in English or German, depending target group and demand. The Plattform features information on various forms of forced migration, including research reports and policy recommendations, informed opinion pieces, guidelines, and interviews.

This issue of Plattform (volume 2, year 1) presents a remarkable selection of contributions to the ROR-n Blog assembled in the course of five years. In the following, 30 authors coming from fields as diverse as anthropology, history, demography, Islamic and Middle Eastern Studies, security studies, political science, and media studies discuss forced migration-related issues. All 30 contributions offered here were written by academicians, based on informed in-depth research and geared to a 
wider public. The material covers a broad range of subjects from Latin America to East Asia, with a distinctive focus on Middle Eastern refugees and Europe.

The book is divided into three parts: Displacement, Encounters, and Agency and Tutelage. These titles organize issues of forced migration heuristically, rather than chronologically. In other words, while the issues discussed in a given chapter may relate to more than one or all categories above, the author(s) may have chosen to highlight and discuss one aspect of forced migration more so than others. These "moments" then - displacement, encounters and tutelage - express a topological rather than topographic organization of the material. They reflect what the editors propose as significant topics of interest to the field of forced migration studies.

The first part of this book, Displacement, groups chapters underlining social processes originating from subjects' immediate response to forced dislocation. This part is composed of five chapters, with contributions by Gabriele Rasuly-Paleczek, Khadija Abbasi \& Alessandro Monsutti, Navid Fozi, Alexander Weissenburger, Katja Kauffman, and Andreas Hackl. Contributions cover experiences of refugees from Afghanistan, Iran, and Yemen as well as general issues related to displacement.

The second part of this book, Encounters, covers social processes relating to the relocation of forced migrants, a situation in which multiple social actors engaging with different traditions of knowledge interact with each other. The concept of encounters we use here is first and foremost tailored to counter the limitations of the "integration" perspective. The latter approach tends to efface the subjects' history or the symbolic and empirical life connections between place of origin and host society. It narrows research questions to answer the question if or 
how forced migrants can participate in the host society, live under its rule of law, or ultimately even become cultural others. By contrast, our encounter perspective aims "to create a broad understanding of representations, social interactions, social organization, and worldviews as they actually are, prior to preconceived notions that generate blind spots concerning the structure of the encounter. To use a medical metaphor, this perspective would be equivalent to producing a general diagnosis before defining the terms of an intervention" (Schiocchet et al, 2020).

This part of the book is composed of fourteen chapters covering a wide range of encounters in their interpersonal, cultural and institutional dimensions. The contributors are Ibrahim Sirkeci, Monika Mokre, Anne Irfan, Judith Kohlenberger \& Isabella Buber-Ennser, Noura Kamal, Josef Kohlbacher, Amelie Harbisch, Valentina Grillo, Mirian Alves de Souza \& Helena de Moraes Manfrinato, Silvia Montenegro, and Liriam Sponholz. Topic-wise, this section includes specific case studies as well as more general reflections on the interactions of refugees (mostly from Syria, Iraq, Afghanistan. Palestine, and Lebanon) with majority societies in Austria, Germany, Tunisia, Brazil, and Argentina.

The third and final part of this book, Agency and Tutelage, groups chapters that relate more directly to issues of refugee regimes and the relative scope of refugee agency they entail. Here, we propose the concept of tutelage as a privileged perspective from which to understand this asymmetric relationship between nation states, international humanitarian reason and intervention, and the experiences of refugees. The concept of tutelage has only rarely been applied to the anthropological understanding of refugees, and more often to the study of indigenous minorities (Paine, 1980; Dyck, 1991; Lima, 1995, 2008; Palmié \& Stewart, 2016) or the impact of international legal regimes on given territories and their populations (Goertz \& Diehl, 
1992; Alston \& Macdonald, 2008; Berman, 2011). Under tutelage, a subject or population is assumed not to have the full capacity of making its own decisions and to be governed by another party that acts as its benefactor. Insofar as refugees do not decide their own fate and do not participate in shaping the policies affecting them, they are by definition under tutelage. Tutelary regimes legitimize the dependency of protectorates, children, indigenous groups, national minorities, refugees, and other subjects perceived as not capable of deciding for themselves. In denying agency and full political participation and autonomy, tutelage objectifies and depoliticizes (Kohlbacher and Schiocchet, 2017; Schiocchet 2019). Thus, understanding refugee agency in relation to various forms of (tutelary) refugee regimes allows us to locate an important source of asymmetry and to identify new, more equal alternatives.

This part of the book comprises eleven chapters, written by Leonardo Schiocchet, Sabine Bauer-Amin, Stephan Kloos, Niki Kubaczek, Lukas Milo Strauss, Marija Cubalevska, Pia Jolliffe, Denise Tan, and Monika Halkort. Contributions discuss tutelage, humanism, and solidarity theoretically as well as in case studies on Tibet, Brazil. Austria, Turkey, North Africa and the Horn of Africa.

In bringing together these three fields of inquiry, the present volume opens up promising approaches to forced migration. We hope that the research questions, methods and perspectives presented here will facilitate a focused and productive discussion on the issues at hand.

\section{References}

Alston, Philip. \& Macdonald, Euan. (eds.). 2008. Human Rights, Intervention, and the Use of Force. Oxford, Oxford University Press. 
Berman, Nathaniel. 2011. Passion and Ambivalence: Colonialism, Nationalism, and International Law. The Hague, Brill.

Dyck N. 1991. What is the Indian "Problem": Tutelage and Resistance in Canadian Administration. St John's, Memorial University of Newfoundland.

Kohlbacher, Josef and Schiocchet, Leonardo (Eds.) 2017. From Destination to Integration - Afghan, Syrian And Iraqi Refugees in Vienna (ISR-Forschungsberichte, Heft 47). Vienna: Austrian Academy of Sciences Press.

Lima, Antonio Carlos de Souza (2008), Traditions of Knowledge in Colonial Management of Inequality: Reflections on an Indigenist Administration Perspective in Brazil. World Anthropologies Network (WAN)/Red de Antropologias de/ Mundo (RAM), Electronic journal, 3, pp. 7-29.

- (1995), Um Grande Cerco de Paz. Poder Tutelar, Indianidade e Formação do Estado no Brasil. Petropolis, Vozes.

Goertz, Gary \& Diehl, Paul F. (1992), Toward a Theory of International Norms: Some Conceptual and Measurement Issues. The Journal of Conflict Resolution, 36, (4) (Dec., 1992), pp. 634-664.

Paine, Robert. (ed.) (1980), Ethnology: The White Arctic: Anthropological Essays on Tutelage Ethnicity. Toronto, University of Toronto Press.

Palmié, Stephan. \& Steward, Charles. (2016), For an Anthropology of History. HAU, Journal of Ethnographic Theory, 6 (1), pp. 207-36. 
Schiocchet, Leonardo, Sabine Bauer-Amin, Maria Six-Hohenbalken, and Andre Gingrich. 2020. Refugee Studies in Austria Today: From Challenges to a Research Horizon. Focaal 87 (Mar 2020), pp. 89-103.

Schiocchet, Leonardo. 2019. Outcasts among Undesirables: 117 Palestinian Refugees in Brazil in-between Humanitarianism and Nationalism. Latin American Perspectives, 46(3), pp. 84-101. 


\section{DISPLACEMENT}




\title{
Many Reasons for Leaving Afghanistan: Social Obligations in Times of Protracted Violence
}

\author{
Gabriele Rasuly-Paleczek \\ Originally published in 1/15/2018
}

Most current studies on refugees and asylum seekers coming to Europe focus on the reasons for fleeing, the challenges refugees face during their flight, and their experiences in potential host countries. So far little attention has been paid to the relevance of personal motives (e.g. fleeing to avoid a forced marriage, or to escape an ongoing vendetta) and to the importance of social obligations and relations in the context of forced migration.

When social relations are highlighted at all, they are mostly studied in the context of facilitating the establishment of refugees in their new places of residence (e.g. providing jobs, housing and a first orientation in the new environment), or in connection with transnational networks of refugees and their relatives and friends left behind in former places of residence. A few studies, such as the paper by A. Monsutti et alii entitled "Afghan Transnational Networks: Looking Beyond Repatriation" (2006) and Ch. Berg Harpviken's book entitled Social Networks and Migration in Wartime Afghanistan (2009), highlighted the role of social networks for the reintegration of returning refugees in their former home region and/or in preventing people from becoming refugees at all by successfully securing a sustainable livelihood despite protracted war or civil war.

However, the decision to flee is not only informed by personal concerns (e.g. fearing to be killed by insurgents), but is also closely 
linked to social obligations individuals bear to their social environment (e.g. children, wife, kinsmen, friends). Thus, it seems worthwhile to focus on the intersection of social ties and obligations and the reasons for fleeing, including very personal ones as forced marriage.

In line with other studies, the data on refugees from Afghanistan that were collected in the framework of the ROR-n pilot study that informed the book "From Destination to Integration - Afghan, Syrian and Iraqi Refugees in Vienna " (2017) show that it is usually a combination of causes that influences the decision to flee or to renew a flight.

Frequently, we find a mixture of general security concerns (e.g. increases in local violence, heightening of ethnic and religious conflicts), personally experienced violence (death threats, detention by government and/ or opposition groups, reprisals by Islamic radicals, retaliation for having worked for foreigners), as well as economic and other reasons (e.g. being persuaded by friends to leave the country with them, evading an unbearable domestic situation, fleeing from an ongoing vendetta, being discriminated in current place of residence, e.g. in Iran). However, these flight motives are often closely linked to social obligations.

Despite decades of protracted violence, displacement and economic hardship that have badly affected the resilience and coping strategies of most Afghans, many still exhibit a strong commitment towards fulfilling their social obligations, in particular towards honoring their responsibility for the wellbeing of their family, kinsmen and friends. Thus, protecting the life of family members or offering children a "good life" are among the most important social obligations that - in addition to the aforementioned reasons - inform the pre-flight decision-making process. 
These social obligations are often deemed as more important than one's own wellbeing and safety. Several of our interviewees mentioned that the final decision to flee was only taken when a personal threat (e.g. fear of being abducted, receiving threatening letters etc.) was perceived as not only endangering one's own life, but also that of other family members (e.g. children, parents, brothers, etc.).

An illustrative case is a 54-year-old male Pashtun from Kandahar, whose brother had been killed several years earlier by the Taliban. The interviewee himself fell victim to a suicide attack in which he was severely wounded and lost the vision of one of his eyes. Yet, it was not until his two young children were threatened to be kidnapped for ransom that he and his family left the country.

Offering one's children a better future also forms an important motivation for many refugees, as the following quote from the same interview illustrates: "Since I had been seven years old, blood had been spilled in Afghanistan, until today. When I consider my situation, without education, under no circumstance did I want my children to suffer the same fate. Education is very important!"

The commitment to protect the life of family and kin and to care for their wellbeing does not solely refer to one's own personal flight (e.g. fleeing to minimize potential threats for other family members who stay put). It also extends to the obligation to organize the flight of a relative whose life is endangered or to send a family member away offering him/her better occupational or educational opportunities as in the case of a 21-year-old male Hazara, who at the age of 17 was prompted by his father to leave Iran, where the interviewee and his family were living in precarious circumstances. 
The obligation to support family members, kin or friends focuses mainly on organizing the flight itself. Close relatives (e.g. father, father-in-law, mother-brother, etc.) and friends provide the financial means for the flight and/ or establish contact with a human trafficker, herein often using personal networks to trace a trustworthy smuggler. Yet, the support does not stop here. It is granted throughout the whole flight process by sending money to allow the continuation of the flight, by putting a refugee in contact with acquaintances that may facilitate further movements, or by offering advice for what to do next when a problem appears.

Summing up, our Afghanistan data offer ample evidence that the decision to flee is informed by a combination of causes, such as security concerns, economic as well as personal reasons, and a vast array of social obligations. The relevance of social obligations in the pre-flight decision-making process has oftentimes been neglected in forced migration studies. This research gap should be closed by putting a stronger research focus on the intersection of social obligations and reasons for fleeing when studying forced migrants.

\section{References:}

Berg Harpviken, Christian. 2009. Social Networks and Migration in Wartime Afghanistan. Houndmills, Basingstoke, New York.

Kohlbacher, Josef and Schiocchet, Leonardo (Eds.): From Destination to Integration - Afghan, Syrian and Iraqi Refugees in Vienna. ISRForschungsbericht Heft 45, Vienna 2017; Verlag der Österreichischen Akademie der Wissenschaft.

Monsutti, Alessandro and Collective for Social Science Research. 2006. "Afghan Transnational Networks: Looking Beyond Repatriation." Synthesis Paper Series; Kabul, AREU, August 2006 
http://reliefweb.int/sites/reliefweb.int/files/resources/6A583751 924F6A31492571F400099A52-areu-afg-31aug.pdf

Gabriele Rasuly-Paleczek, holds an MA in sociology and political sciences (1979) and a Ph.D. in Anthropology, Turkology and Islamic Studies (1984), awarded from the University of Vienna/Austria. Since 1985 she is working at the Anthropology Department of that university. She has also been lecturing at a number of other academic institutions. In 1999/2000 she has been a post-doc fellow at the Program in Agrarian Studies, Yale University and in the fall term 2012 a visiting professor at the University of Southern California, Los Angeles. She has done extensive fieldwork in rural Turkey as well as among Afghan Refugees in Pakistan and Turkey. Dr. Rasuly-Paleczek has published a number of articles and books dealing with rural Turkey as well as with local politics and identity issues in Afghanistan. Her latest work - co-edited with Robert L. Canfield - is "Ethnicity, Authority, and Power in Central Asia: New Games Great and Small" (Routledge 2011). 


\section{There is Death in Immobility}

Khadija Abbasi \& Alessandro Monsutti

Originally published in 10/25/2018

Migration of young Afghan to Europe is structured by a moral economy that has a twofold dimension. First, it implies a social system of exchange and redistribution between young migrants and their relatives who stayed behind. It is underpinned by a code of conduct implying mutual obligations and collective responsibilities, by a system of values and solidarity, norms and social obligations that defines their success as migrants. Second, migration is characterized by the high pressure to succeed. Prompted by their quest for autonomy and recognition, the migrants become increasingly aware during their journey that only a few of them will be able to settle down in Europe. The relationships among young candidates to asylum are imbued by competition and jealousy. These young migrants are invested in the double mission of preparing a better future for their family and proving their individual value.

In such a context, many young Afghan migrants share their hopes and frustrations on the cyberspace, across geographical, social and gender boundaries. Migration and the status of forcibly being displaced are recurrent topics and are addressed with ambivalent feelings: suffering and separation, but also opportunity and autonomy. When Afghans talk about their experience of mobility, the term āwāragì is mostly used. It means 'wandering,' 'vagrancy,' while āwāra refers to a person who is in the state of āwāragī, a wanderer, a vagrant. The semantic field also implies the idea of being separated from one's homeland and having to change one's location against one's own will. Ghorbat is another word recurrently 
associated with āwāragi. It describes the status of being a stranger and lonely in a place different from one's homeland. The two terms have negative connotations and are often used interchangeably. Two terms with religious connotation, mohājerat, which means 'migration,' and mohājer, which designates a person who has migrated out of his/her home country, are nowadays much less commonly used than among the previous generations of Afghans who took refuge in Pakistan and Iran. An online conversation between various transnational young Afghans may serve as an example:

- Zari, a female Afghan whose application for asylum in Germany is currently under review, writes on her page on Facebook: "āwāragī means to be born in Tehran, to be thrown away to Kabul, and, to stay in Berlin; but nowhere you live the life."

The post triggered many comments. Zari describes herself as an āwāra who cannot enjoy the journeys imposed on her.

- Shafiqa, newly settled in Australia, reacts: "Stay āwāra as there is death in immobility."

- Zari: "I feel upset when I remember the reality of being an āwāra."

- Shafiqa: "āwāragī is in the blood of our generation. Just imagine! In three decades, we have experienced the misfortunes of three centuries. Despites this, we still should stay alive."

- Zari: "In these three decades, three generations became āwāra and 
the fourth generation is on the way but without home, in suspension, and with no identity."

- Suraya, based in the United States: "Dear Zari, life is not something beyond this. That's life."

- Zari: "Our life is an absolute āwāragī.”

- Hashmat intervenes with a free verse: "We should put the framework of our identity under our arm [as a sign of leaving], as the walls of home have rotted and we are still āwāra in the streets that are not going to warm [welcome] us."

- Zari: "The streets that did not warm us and the rotted walls that could not bear framework of our identity."

- Hashmat: "And if these rotted walls collapse, thousands and thousands of the lost people will rise from under soil."

- Kousha, based in India adds: "āwāragī means to be uprooted."

- Munirah: "I was born in Kabul, granted asylum in Hamburg, but this is just the beginning of my story... Then, I am thrown to Norway everything had to start from scratch - and then I am thrown to England - everything from scratch again -, then I am thrown to Scotland - everything from scratch again - and maybe soon I'll be thrown again to another place. Perhaps life is all about this constant uprooting?" 
- Sadiq: “We are an āwāra generation.”

- Shafiqa: "The generation of being in continual āwāragī, moving from one ghorbat to another. Even if you are not thrown from one land to another, the fact that your mind is uprooted is enough to prevent you to rest in one place, even in the land that has granted you asylum. There is death in immobility."

For transnational Afghans who took part in this conversation, the conventional concept of home does not suit their situation with a multi-local sense of belonging and loneliness. They question the notion of home for a generation who grew up and reached adulthood in mobility. They contest the notion of home for people who were born as refugees in the country of asylum. Shafiqa used a Sufi trope to respond to Zari's complaint of being āwāra: "There is death in immobility." In so doing, she rationalizes her hyper-mobility. Shafiqa and Zari are amongst the generation who were born refugees to Afghan families in Iran. Zari left Iran for Germany and Shafiqa settled in Australia. Both left Iran to Afghanistan in search of home. Both left Afghanistan disappointed and continued migration in search of a better life where their sufferings and exclusion are recognized. But the streets in Germany, Norway, England, Australia, the United States are not welcoming. There is no apparent end to the wandering life of the āwāra generation; āwāragī is not a transient period of life but becomes an ontological status. These young people inhabit mobility. On the one hand, they feel that their plight is not understood by their relatives left back in Afghanistan or the countries of first asylum, Pakistan and Iran. On the other hand, their everyday life is dominated by competition and suspicion among peers, as only a few of them will be able to get a protection status and settle down in 
Europe. The cyberspace acquires a crucial importance for them, it is the realm where they can express themselves much more freely than in face-to-face relationships, address their dissatisfaction and magnify their aspirations.

Khadija Abbasi holds a BA in English Persian translation from Tehran's Islamic Azad University and a MSc in Gender and Development from the London School of Economics. She has recently defended her PhD thesis in anthropology and sociology department of the Graduate Institute of International and Development Studies in Geneva. In collaboration with Alessandro Monsutti, she was involved in a research for the University of Oxford on becoming adult in migration focusing on young Afghans and their experience of mobility and adulthood. Two papers are upcoming out of the last two-mentioned research projects. Currently, she is on her belated maternity leave.

Alessandro Monsutti is Professor at the Department of Anthropology and Sociology, Graduate Institute of International and Development Studies, Geneva. He has carried out extensive field research in Afghanistan, Pakistan and Iran since the mid-1990s, and more recently in the Western countries among Afghan refugees and migrants. He has published as sole author: War and Migration: Social Networks and Economic Strategies of the Hazaras of Afghanistan (2005), Homo itinerans: La planète des Afghans (2018). And several co-edited volumes. 


\section{Why the lack of research on Iranian emigrants, asylum seekers, and refugees?}

Navid Fozi

Originally published in 6/29/2018

A cursory survey of the scholarship and the media coverage on migrants and refugees reveals a curious absence of Iranians despite the fact that they have been leaving Iran on a continuous basis since the Revolution of 1979. Between 1999 and 2013, an annual average of roughly 69,000-138,000 Iranians have sought asylum, while 12,000-26,000 have been assisted by the UNHCR.[1] Since 1979, there has been a steady flow of 15,000-30,000 annual Iranian asylum seekers through Turkey, the main transit country neighboring Iran. Data on Pakistan and the Independent Kurdish Region of Iraq, the two other neighboring transit states, are hard to come by. Combined with regular emigrants, the Iranian diaspora has reached a community of about six million, mostly residing in North America, Europe, and Australia.

While some statistics exist, research is extremely meager. Inquiries are mostly conducted by members of the Iranian community, focusing on specific political groups. The first fifteen years after the Revolution saw asylum seekers representing the former political system, as well as members of the Communist Tudeh Party, and the People's Mojahedin Organization of Iran (PMOI). Draft evaders followed during the Iran-Iraq War in the 1980s. In addition to these violence-driven exoduses, members of the Baha'i religious community have been escaping persecution since those early years. The last two decades have witnessed a periodic addition of converts (Christian, Baha'i, and Zoroastrian), practitioners of Erfan-e Halgheh 
(Cosmic Mystics), Kurdish Yaresan (Ahl-e Haqq), and Sabians. Furthermore, groups identifying themselves as lesbian, gay, bisexual, transgender, and queer (LGBTQ), social activists; and political dissidents formerly belonging to the ruling elites have sought asylum outside of Iran.[2]

It is important to note that none of these groups have picked up arms or resorted to violence, with the exception of the PMOI in the immediate years after the Revolution and during the Iran-Iraq War. Whereas malicious persecutions and summary executions characterized the extrajudicial revolutionary mood, violence subsided substantially in later years as the ruling class sought to reestablish Iran's membership within the international community. Subsequently, soft modes of harassment without paper trails became a routine practice, for instance, denying documents such as subpoena and official sentences when summoning Cosmic Mystics and Christian converts to court, and preventing Baha'is admission to, and expelling activists from, universities. Brutal methods were reserved for those who contested presidential elections and collectively came to be known as Green Movement in 2009.

Provided the continuous state persecution of such diverse groups of Iranians, what are the reasons for the paucity of academic research on Iranian asylum seekers? A case in point is a recent volume on refugees in Austria that only addresses the Syrian, Iraqi, and Afghan refugees.[3] Could it be that physical violence is perceived as an integral constituent of 'refugee' as a recognized legal category, implying that those not affected directly do not deserve academic inquiry either? Or, as one of the reviewers of this piece commented, the lack of academic research may be due to the "current visibility and sheer number" of Afghan, Syrian, and Iraqi refugees. Nevertheless, the oppression of religious minorities and political 
dissidents in the Islamic Republic of Iran has been discussed for forty years. Even if their cause is not as visible, western countries have been receiving Iranian asylum seekers and migrants since the Islamic Revolution and their existence is publicly known.

This lack of coverage could also be linked to an assumed categorical division between the so-called 'fake' and 'real' asylum cases. Such an assumption, for instance, entails that, similar to many claimants from other countries, Iranian asylum seekers acquire certain religious, political, or gender identities in order to build an asylum case. Even if there exist questionable cases, shouldn't such a phenomenon itself arouse a sense of academic inquiry instead of total dismissal? Those who promote such a division of cases could ask why Shici Muslims are changing religion to escape a government that is founded upon Shici traditions and jurisprudence. Those attacking claims of the LGBTQ communities should acknowledge the equally pressing question of why members of the traditional Iranian culture that frowns upon any sexual behavior violating principles of heterosexual relations would want to fake gender identity. Other inquires could explore why a country that is not involved in direct wars, has regular presidential and parliamentary elections, and is internationally engaged, produces such diverse and continuous flow of asylum seekers? How does the purging of minorities in Iran fit in and contribute to the historical homogenizing project of the Shi'i state?

Finally, what about cases the veracity of which even the skeptics cannot deny? The Yaresan community consists mostly of ethnic Kurds who practice a religion different from Islam. While some of them are Shicatized and identified as Ahl-e Haqq, many, mostly concentrated in the westernmost regions of Iran, do not identify as Muslims. They follow the teachings of Sultan Sahak, who was a 14thcentury religious leader. They have a distinct social structure, sacred 
literature, as well as music and musical instruments, and go on pilgrimage to their own local sites.[4] The Yaresans have suffered since the formation of the Islamic Republic, not just for their religion, but also for their Kurdishness. They have been accused of treason and denied government jobs as well as higher education. As they are labeled as Satan-worshipers, their places of worship have been desecrated and their rituals have been banned. While they have used Turkey as a transit country to seek asylum, the Independent Kurdish Region of Iraq has been their main route to Europe.[5]

The Baha'is are another minority group who follow an indigenous religion that began in 1844 in Iran. They come from diverse backgrounds, religiously and ethnically, and are mostly the descendants of early converts who followed Ali Muhammad Shirazi known as the Bab (1819-1850), a young prophet who challenged the Shi'i religious hierarchy by claiming to be the Twelfth Shi'i Imam. When he was killed by the Qajar dynasty in 1850, most of his followers turned to Mirza Hosayn Ali Nuri known as Baha'u'llah (1817-1892). Their suffering has been continuous since the inception and only increased in the post-Revolution period. Accused of being foreign elements and spies, many Baha'is were killed in summary courts and purged from jobs and schools. Their homes were burnt, their cemeteries are still bulldozed, and their religious practices are banned. Baha'i youth are deprived of higher education and Baha'i businesses are regularly shut down. As mentioned earlier, they have been leaving Iran since 1979.[6]

Another relatively recent phenomenon is the growing number of adherents of contemporary Persian mysticism, Erfan-e Halgheh. The founder, Ali-Mohammad Taheri has received a death sentence that was later lifted as a result of domestic and international pressure. However, coinciding with the rising numbers of Christian and Baha'i 
converts and the decline of Shici hierarchy, his followers, are abused and jailed. Their centers and classes are deemed illegal and shut down.[7]

Iranian asylum seekers and refugees might not neatly fit within the scholarship on refugee camps and those fighting genocide, and there may exist questionable cases. Nevertheless, their flight poses important questions regarding the domestic Iranian context, engaging international refugee regimes, asylum processes, border crossings, as well as diaspora identity formation.

\section{Notes:}

[1] Statistic Data on Iranian Refugees and Asylum Seekers. Updated 2014. http://www.irainc.org/iranref/statistics.php

[2] See, for example, Fathi, Asghar. Iranian refugees and exiles since Khomeini. Costa Mesa, Calif.: Mazda Publishers, 1991; Ghorashi, Halleh. Ways to survive, battles to win: Iranian women exiles in the Netherlands and United States. Nova Publishers, 2003; Koser Akcapar, Sebnem. "Re-Thinking Migrants' Networks and Social Capital: A Case Study of Iranians in Turkey." International migration 48.2 (2010): 161-196. Moallem, Minoo. "Iranian Immigrants, Exiles and Refugees: From National to Transnational Contexts." Comparative Studies of South Asia, Africa and the Middle East 20.1 (2000): 161-164.

[3] Kohlbacher Josef and Schiocchet, Leonardo (Eds). From Destination to Integration: Afghan, Syrian and Iraqi Refugees in Vienna (2017). 
[4] Hamzeh'ee, M. Reza. The Yaresan: A Sociological, Historical and Religio-Historical Studyof a Kurdish Community. Berlin: Klaus Schwarz (1990); In Persian: Safizádeh Borehkeii, Seddiq, Neveshteha-ye Parakandeh Darbareh-ye Yaresan: Ahl-e Haqq [Scattered Essays on Yaresan, Ahl-e Haqq. Khorrami Printing (1982).

[5] There is a lack of academic research on all aspects of Yaresans' life in part due to their secretive practices. My information is based on fieldwork research that I have conducted in western Iran in 2005 among the Yaresan of Guran region (Fozi, Navid. "The hallowed summoning of tradition: Body techniques in construction of the sacred tanbur of western Iran." Anthropological quarterly 80.1 (2007): 173-205), as well as in Turkey among the asylum seekers of the group. See, also, The Danish Immigration Services. Ministry of Immigration and Integration. Iran: The Yaresan. (2017); Kurdish news agencies have in recent years provided some reports: Rudaw. Kurdish Kakai flee state 'discrimination' in Iran. (2015). http://www.rudaw.net/english/kurdistan/09092015

[6] Momen, Moojan. "The Babi and Baha'i community of Iran: A case of "suspended genocide"?." Journal of Genocide Research 7.2 (2005): 221-241. Affolter, Friedrich W. "The specter of ideological genocide: The Baha'is of Iran." War Crimes Genocide \& Crimes against Human. 1 (2005): 75-114. Kazemzadeh, Firuz. "The Baha'is in Iran: Twenty years of repression." Social Research (2000): 537-558.

[7] Among many instances, there are several reports regarding the persecution of Erfan-e Halgheh membership listed on the Center for Human

Rights in

Iran: https://www.iranhumanrights.org/tag/erfan-e-halgheh/ 
Navid Fozi has just concluded a nine-month fellowship at the Harvard Law School's Islamic Legal Studies Program and in September 2018 will assume a position as an assistant professor of cultural anthropology at Bridgewater State University's Department of Anthropology. Fozi has conducted fieldwork in the US with Mexican undocumented migrants, in Iran with Zoroastrians and the Ahl-e Haqq, in Malaysia with the Iranian diaspora, and in Turkey with Iranian asylum seekers. His latest book is entitled Reclaiming the Faravahar: Zoroastrian Survival in Contemporary Tehran (Leiden University Press, 2014). 


\title{
Patterns of Migration in, from and to Yemen
}

\author{
Alexander Weissenburger \\ Originally published in 11/30/2018
}

While the civil war in Syria has received ample coverage in Western media, this is far less true for the ongoing conflict in Yemen. Without perceptible repercussions to the Western world, there is little interest in the fallout of this conflict of close to fifteen years. It entails no terrorist threat to European capitals and, due to Yemen's remoteness, hardly a refugee reaches Europe. Yet, far away from the glare of Western cameras, Yemen has to deal with its own displaced population, and, moreover, remains a hub for regional migration from the Horn of Africa.

\section{Yemen and the Horn of Africa}

In 1980 the Yemen Arab Republic became - and remains to this day the only country on the Arabian Peninsula to sign the 1951 Refugee Convention as well as the Protocol Relating to the Status of Refugees of 1967.[1] However, already before the 1980s, Yemen accepted refugees from the Horn of Africa. While the first group of new arrivals fled the Eritrean War of Independence from the 1960s onwards,[2] later refugees came primarily from Somalia. In 2002, the UNHCR registered over 70,000 refugees in Yemen, 92\% of whom originated from Somalia. Estimates, however, suggest that the actual number of migrants in Yemen far exceeded 300,000.[3] By 2013, the Yemeni Transitional Government reckoned the number of refugees to be between 600,000 and 800,000 . These large numbers of migrants, including refugees as well as asylum seekers and illegal 
immigrants,[4] led to revisions in Yemen's previously rather liberal migration policies. At the same time, the so-called "War on Terror" caused migrants to be increasingly seen as a security threat.[5]

Nevertheless, migration to Yemen continued unabated. By 2013 Ethiopians constituted the majority of migrants to Yemen and made up $83 \%$ of the approximately 120,000 new arrivals of 2016. Migrants pay smugglers several hundred Dollars (between 100 and $500 \$$ ) to cross the Gulf of Aden and then several hundred more to reach Yemen's northern border. For another $800 \$$ they are smuggled across the border to Saudi Arabia, which remains the main destination for the migrants. Since 2015, with the current war in Yemen, the way into Saudi Arabia has become more difficult and a new route opened up with migrants crossing the Red Sea in Northern Yemen in order to reach Sudan and from there travel on to Egypt, Libya and, finally, to Europe.[6]

On their way, migrants face horrible conditions. Besides the overall deteriorating situation in war-torn Yemen, migrants are frequently mistreated by their smugglers. Since the trafficking of humans - often alongside the smuggling of weapons and oil - has become such a lucrative business, the smuggling networks have no interest in migrants making the journey on their own. Migrants are therefore often forced to use these networks,[7] in which case they are completely dependent on their smugglers, who frequently abuse their power. Migrants are forced to hand over money, held to ransom, sexually abused and tortured in order to extort money or contact information of relatives, who are then pressured into sending money in exchange of the release of the captive. A Human Rights Watch report states that this happens at a systematic scale with camps in deserted areas run mainly by Yemenis.[8] 
Due to the worsening security situation in the country, African migrants as well as Yemenis increasingly leave Yemen. While the African migrants return home,[9] the Yemenis are left with only few options. The countries on the Horn of Africa are not attractive and Arabic countries are hard to reach due to the blockade imposed on Yemen by the Saudi-led coalition. Nevertheless, there are several thousand refugees from Yemen living in countries such as Somalia, Eritrea and Egypt, and, most importantly, Jordan. While the UN has registered 12,500 Yemenis in Jordan, their actual number could easily be twice as much.[10] The number of Yemenis looking for a better life abroad is likely to rise as the situation deteriorates. For the time being, however, their number is easily dwarfed by the three million internally displaced persons (IDPs).

\section{Internal Displacement in Yemen}

Internal displacement in the case of Yemen is intrinsically linked to the ongoing crisis. The current conflict in Yemen has its roots in the early 2000s when Husayn al-Huthi, an Islamic scholar and agitator belonging to the Zaydi denomination of Shiite Islam, founded the Huthi movement in the northern province of Sa'da. His Islamist and anti-Western rhetoric put him in conflict with the Yemeni government, which tried to subdue the movement. Between 2004 and 2010 the northern provinces of Yemen saw six rounds of war between the government and the movement. By the end of the last round, 250,000 people had been displaced in the province of Sa'da alone.[11]

In 2011, the Huthis participated in the Arab spring uprising and took part in the transition process after Ali Abdallah Salih had resigned as president. When the new government under President Abd Rabbo Mansur Hadi failed to meet the population's expectations, the Huthis 
exploited the popular anger and marched south, taking Sanaa in September 2014. President Abd Rabbo Mansur Hadi fled first to the southern Yemeni city of Aden and then to Saudi Arabia. In March 2015, the aforementioned coalition under the leadership of Saudi Arabia began to intervene in Yemen, with the declared goal of reinstating President Abd Rabbo Mansur Hadi. The coalition keeps bombing Huthi controlled territory, including civilian infrastructure, agricultural areas and cultural heritage sites, while simultaneously preventing humanitarian aid from entering the country by sea and air.

Mainly due to the blockade, Yemen - which has to import around $90 \%$ of its main food staples - today faces what the UN calls the world's greatest current humanitarian catastrophe. $60 \%$ of the population are food insecure and 8.4 million people (around 25\% of the total population) are at risk of starvation.[12] Besides hunger, diseases and fighting, the population faces corruption and political as well as economic oppression, by all actors in the conflict. With the crisis most severe in the countryside, where what little arrives in terms of humanitarian aid in Yemen is harder to distribute, people flee to the cities and especially the safer regions of the country.

Between 2014 and 2018 the population of the relatively safe province of Marib in central Yemen rose from around 350,000 to more than 1.5 million. The impact is obvious. Hospitals and schools are overwhelmed, as is the housing market. While IDPs are also housed in camps, many are from the middle class and can afford to rent accommodation in the city. This increase in demand severely pushed up rent prices, adding to the strain on the local population. The same problem is seen in the southwestern province of Ibb, where people took refuge from the fighting in the city of Taizz.[13] 


\section{Closing Remarks}

With no end of the conflict in sight, the situation of the population is set to deteriorate further in the coming months, with the number of refugees from, as well as within, Yemen likely to rise. It can only be hoped that the increasing public interest in the crisis following in the wake of the murder of journalist Jamal Khashoggi in October 2018 puts pressure on the relevant political actors to effect at least the lifting of the blockade in order to alleviate the misery of the Yemeni population.

\section{Notes:}

[1] Until 1990, Yemen was split into the Yemen Arab Republic (YAR) in the north and west of the country and the People's Democratic Republic of Yemen (PDRY) in the south and east. After unification, the new state remained subject to all international treaties the former YAR had signed.

[2] Thiollet, Helene: From Migration Hub to Asylum Crisis: The Changing Dynamics of Contemporary Migration in Yemen, in Why Yemen Matters: A Society in Transition, edited by Helen Lackner, Saqi Books, London 2014, 281.

[3] Hughes, Nesya H B: Yemen and Refugees: Progressive Attitudes Policy Voids, Forced Migration Review January 2003, 36-38.

[4] Thiollet, Helene: From Migration Hub to Asylum Crisis, 280.

[5] Thiollet, Helene: From Migration Hub to Asylum Crisis, 275-276. 
[6] Tinti, Peter: Migrant Smuggling: Paths from the Horn of Africa to Yemen and Saudi Arabia, Africa in the World Report 7, Institute for Security Studies November 2017, 16.

[7] Abdiker, Mohammed: Yemen: the Deadly Migration Route the World is Ignoring, CNN, 20 June 2018, https://edition.cnn.com/2018/06/20/opinions/yemenmigration-iom/index.html, accessed on 24 October 2018.

[8] Human Rights Watch: Yemen's Torture Camps: Abuse of Migrants by Human Traffickers in a Climate of Impunity, 2014, 37-47.

[9] UNHCR: As Yemen Conditions Deteriorate, Somali Refugees Look to Return Home, 19 May

2017, http://www.unhcr.org/news/briefing/2017/5/591ea2554/ yemen-conditions-deteriorate-somali-refugees-look-returnhome.html, accessed on 24 October 2018.

[10] Luck, Taylor: Yemenis Join the Line of Refugees Seeking Help in Jordan, The National, September 18, 2018, https://www.thenational.ae/world/mena/yemenis-join-theline-of-refugees-seeking-help-in-jordan-1.771577.

[11] Brandt, Marieke: Tribes and Politics in Yemen, New York, Hurst, 2017 p. 326.

[12] https://news.un.org/en/focus/yemen, accessed on 15 November 2018.

[13] Tuzayid Adad al-Najihin ila Madina Ma'rib, al-Jazeera, 13 March 2016,

http://www.aljazeera.net/programs/newsreports/2016/3/19/\%D 8\%AA\%D8\%B2\%D8\%A7\%D9\%8A\%D8\%AF\%D8\%A3\%D8\%B9\%D8\%AF\%D8\%A7\%D8\%AF\%D8\%A7\%D9\%84\%D9\%86\%D8\%A7\%D8\%B2\%D8\%AD\%D9\%8 
A\%D9\%86-\%D8\%A5\%D9\%84\%D9\%89-

\%D9\%85\%D8\%AF\%D9\%8A\%D9\%86\%D8\%A9-

\%D9\%85\%D8\%A3\%D8\%B1\%D8\%A8, accessed on 24 October 2018; al-Yaman.. al-Nazihun yarfa'a Ijarat al-Sukun 550\% bi-lManatiq al-Amina, al-Arabi al-Jadid, 3 September 2016, https://www.alaraby.co.uk/economy/2016/9/3/\%D8\%A7 \%D9\%84\%D9\%8A\%D9\%85\%D9\%86\%D8\%A7\%D9\%84\%D9\%86\%D8\%B2\%D9\%88\%D8\%AD\%D9\%8A\%D8\%B1\%D9\%81\%D8\%B9\%D8\%A5\%D9\%8A\%D8\%AC\%D8\%A7\%D8\%B1\%D8\%A7\%D8\%A A-\%D8\%A7\%D9\%84\%D8\%B3\%D9\%83\%D9\%86-500\%D8\%A8\%D8\%A7\%D9\%84\%D9\%85\%D9\%86\%D8\%A7\%D8\%B7 $\% \mathrm{D} 9 \% 82-$

\%D8\%A7\%D9\%84\%D8\%A2\%D9\%85\%D9\%86\%D8\%A9, accessed on 24 October 2018.

Alexander Weissenburger holds an MLitt in Middle East, Caucasus and Central Asian Security Studies from the University of St Andrews and an MA in Islamic Studies from the University of Vienna. During his studies, he travelled to various countries in the Middle East and studied Arabic in Cairo for a year. He was an intern at the Austrian Institute for International Affairs and currently works as researcher at the Austrian Academy of Science's Institute for Socialanthropology, where he writes his PhD thesis on the ideology of the Huthi movement in Yemen. 


\section{Understanding why smartphones are so essential to refugees}

\section{Katja Kaufmann \\ Originally published in 9/26/2016}

"Most of people here, they think we are so rich, because we have a smartphone and like this phone they say: You are so rich, why you come to here, what are you doing here? But they don't know it is so important in our way." (Male Syrian refugee, aged 22).

In the last couple of months, pictures of forced migrants arriving on shores or at train stations; standing in front of camps or official buildings, have been omnipresent in the European media. One feature particularly caught the media's attention: many refugees were seen with smartphones. This has been grist to the mill of those Europeans who don't want to open their borders and their societies to foreigners. They ask bluntly: "Why should we shelter people who can afford expensive gadgets?".

Although smartphones have been advertised and spoken of as luxurious lifestyle gadgets for listening to music, and recently for playing Pokémon GO, these phones are nowadays essential everyday information and communication tools. This is true in the wealthy Northern hemisphere (cf. Ling, 2012); and (perhaps to an even higher degree) elsewhere where people only have the smartphone to rely on in everyday life (cf. Donner, 2015). So it is no wonder refugees count on their multifunctional daily companion as well.

In early 2016, I conducted thirteen qualitative interviews with Syrian refugees who had arrived in Austria in 2015 and had used a smartphone in their journey. As a communication scholar, I was 
eager to learn more about the details of smartphone use in this specific situation where scarce resources in combination with fastchanging conditions, stretch the use of information and communication technologies (ICT) to the utmost and at the same time make them so valuable.

For the refugees I interviewed, the smartphone was their 'trusted friend', their 'weapon', their 'manager'. They were convinced they wouldn't have got to Europe and Austria without it. So for some of them electricity was even more important than food. The GPS function that worked without an active Internet connection let them know where they were - on the boat crossing the Aegean; in the Serbian woods; in a truck crossing the Hungarian border. Facebook groups and trusted people who had completed the journey provided advice and details on routes, resources, administrative procedures.

As well as these functional aspects, the smartphone was emotionally essential to the refugees because it allowed them to stay in touch with their family in Syria, or spread across several countries. Talking to and updating each other; sending pictures and voice messages, became their way of 'doing family' despite the harsh conditions. For the refugees journeying into the unknown, this was a source of strength and motivation to survive - literally as well as psychologically. Indeed, on many occasions a picture was worth a thousand words, when refugees were able to send 'selfies' depicting them safely on the shores of Europe as proof of life to their relatives.

"I only took one picture when we arrived to Greece, because it was the most important thing, that we are not dead in the sea. So I took only one picture with my brother and I sent it to my other brother, that we are safe." (Female Syrian refugee, aged 20) 
After the often dramatic journey to Europe, these proofs help refugees both to recall what they underwent, and thereby to cope with the intense, surreal experience.

"Like to remember what we have done, how we did it, how was we looked, now what we are looking in face. Because when you look at your face at that time, you cannot recognize yourself. It's so hard. [...] Now, when I look at photos I just laugh or I just thank god we finished this journey." (Male Syrian refugee, aged 32)

So for refugees who have to leave their past and start an uncertain life, the smartphone is a place to keep memories and connections alive. Also, it allows them to document and share this turning point in their lives, thus making it part of their life stories.

"We keep right now a lot of memory in it. We keep a lot of bad memory and a lot of good memory. Until now, I have the first photo, when I came here to Austria and until now, I have the last photo, I go out from my country, from Syria." (Male Syrian refugee, aged 25)

The aforementioned is only a sample of what my research revealed about a much deeper relationship between refugees and their smartphones than the media portrays. I have learnt about the many creative ways in which people in such a life-threatening situation make the most of these devices and benefit from their use in practical as well as emotional ways. Next, I am going to research how smartphones are useful to refugees upon arrival in Austria. After all, the exceptional, challenging, draining conditions do not cease with the application for asylum. It seems very likely mobile phones play a central role in the next phase too. This is when getting acquainted culturally, geographically and above all linguistically - in order to start a new life far away from known structures may not be lifethreatening, yet is demanding. Only new research will tell. 


\section{References:}

Donner, J. (2015). After Access. Inclusion, Development, and a More Mobile Internet. Cambridge, MA: The MIT Press.

Ling, R. (2012). Taken for Grantedness. The Embedding of Mobile Communication into Society. Cambridge, MA: The MIT Press.

Katja Kaufmann is postdoctoral researcher at the Institute of Geography, University of Innsbruck, and guest researcher at the Institute for Comparative Media and Communication Studies (CMC), Austrian Academy of Sciences and University of Klagenfurt, Austria. Katja holds a $\mathrm{PhD}$ in Communication Science from University of Klagenfurt. In her PhD project, she studied the meaning and use of smartphones by Syrian refugees on their journey to Europe and after arrival in the city of Vienna. Her research interests include the development of qualitative and mixed mobile methods as well as ensuing research ethics. 


\section{Forced decisions? How a better understanding of displacement's multiple push-factors may help to reform the global refugee regime}

Andreas Hackl

Originally published in 5/31/2018

Refugee status implies that people were forcibly displaced from their home country, while migrants in search of work are often perceived to move primarily for economic reasons. Interviews conducted with Iraqi, Syrian and Afghan refugees in Austria reveal how refugees are not merely forced out by persecution and armed conflict: they are often forced to make informed decisions to flee for a combination of social, economic and political reasons (Hackl 2017). Focusing on these decisions and their diverse motivating factors can help us understand forced displacement as a more complex social process than the often-invoked binary opposition between political refugees and economic migrants.

This adds another element to recent calls for reforming the global refugee regime on the grounds that it tends to prevent the forcibly displaced from working, denies them a sense of autonomy, and bases humanitarian protection on an idea of direct "persecution" that was born out of the Second World War (The Guardian, March 22, 2017). Amid highly complex violent conflicts, mostly in failed states characterized by war economies and recurring instability, appeals for an adapted approach are gaining ground. What can we learn from refugees recollecting memories of their own "forced decisions"?

One lesson is that violence, state "dysfunctionality" and socio- 
economic problems often coincide. Not only guns and threats, but also sectarian clientelism, the deaths of family members, the inability to carry out one's profession, or the refusal to comply with militias can lead to forced decisions. A lack of financial resources caused by war may drive women into situations where their only choice is to marry a Taliban affiliate, or they run the risk of falling into the hands of smugglers and into modern forms of slavery.

In the strict legal sense, a refugee is a person who is unable or unwilling to return to his or her country of nationality, "owing to well-founded fear of being persecuted for reasons of race, religion, nationality, membership of a particular social group, or political opinion." This means that those who decide to leave a country because they can no longer maintain themselves without, for example, joining or supporting an armed militia, do not directly fall under this definition; neither do those who have simply lost all their property, belongings and family members. Recent cases have shown that there is flexibility in the refugee protection regime. As Syria has reached a general level of lethal violence, individuals receive general protection and refugee status quickly, or at the very least they cannot be returned home. At the same time, Iraqi and Afghan asylum seekers have much higher rejection rates and are frequently sent back.

While certain cases conform to the pure concept of forced displacement, there are many other refugees who face insecurity because of economic problems and persecution. The book chapter this post is based on (Hackl 2017) covers stories of persons in Iraq, who simply were no longer able to do their job or remain where they had previously lived. Moving to other areas within Iraq often brought about new dangers. And especially for young men, the question was often: join militias, or flee? There was no alternative. 
Some of the accounts also indicate that a simple sectarian explanation of persecution, e.g. Shia against Sunni Muslims, does not always make sense. Many members of the same group may be forced to leave because they do not want to put their skills at the disposal of related militias, who need engineers, doctors, or journalists.

The interviews with refugees in Austria also indicated that generalized violence often leads to specific vulnerabilities, which are different for women and men. What is more, violence and economic problems reinforce each other:

A Kurdish man from Tikrit in Iraq related how war and violence gradually made daily life impossible. He used to work for an Egyptian company in another Iraqi city, often welcoming visiting delegations and taking them across the border in and out of Erbil, Kurdish Iraq's capital. He said, "With the rise of ISIS it became difficult for us. On the one hand, the bombings, on the other, ISIS demanding that young men fight for them." He added that he tried to live with his family in Kirkuk, but one day the company he had worked for withdrew from Iraq. "So we sat there in Kirkuk, four young people without work, without anything." They sold their cars to get by, but one day, he decided to move to Europe, citing the ongoing explosions and the lack of jobs.

Often it is not only the potential of persecution that matters, but the fact that running a normal business can become dangerous. Economic life becomes impossible. A 50 year-old Yezidi woman witnessed the gradual implosion of all aspects of her everyday life before she left Iraq. She had run her own business as a professional cosmetician in the centre of Baghdad for over ten years. She said: "I had a house. I had a car. My life situation was excellent. But recently 
our life began to worsen." Militias in Baghdad threatened and persecuted her, and the arrival of ISIS made things even more difficult. At the time when ISIS-followers began to threaten her because of the cosmetic salon, she discovered that she had cancer and moved to Lebanon for medical treatment. Remembering the last years of her time in Iraq, she summarised the carnage:

“We didn't really live. We were like machines. We fought for our life every day (...) so that we could continue somehow. I went to work and something blew up close by, there were attacks and explosions. It meant that I might have died any moment. (...) When I arrived at my cosmetic studio, I had to reckon that militias might attack and kill me any moment. At home, I locked the door and prayed to the prophets of all religions that they protect me and help me to survive until the next day. Psychologically, we reached the breaking point. We were already destroyed."

Against this backdrop, what can one learn from the many intertwined layers of displacement explored throughout this analysis?

The first insight is that the reasons for displacement and seeking refuge are rarely one-dimensional. Second, economic and political reasons cannot be sufficiently isolated from other factors in many cases. In some instances, political violence makes work and public life impossible. In other cases, the nature of one's work triggers violence, and in yet other situations, one's profession is in demand by violent actors who put pressure on individuals to comply. Third, the distinction between voluntary and involuntary migration is important; but it is equally important to acknowledge that sometimes people take forced decisions based on multiple intersecting push-factors. 
Gaining a better understanding of how these different dimensions of displacement intersect will underpin future efforts to reform the global refugee regime. Here, the focus should not solely be on the support of refugees after their arrival in Europe or elsewhere. The points of departure are equally important. We should not only ask how refugees can get access to work, but also how exactly they lost access to work, security and a meaningful life in their home countries, as a consequence of pervasive violence, or of one of its side-effects.

\section{References}

Hackl, Andreas. 2017. "The Many Faces of Displacement. Pervasive Violence and the Dissolution of a Liveable Life in Iraq, Syria and Afghanistan," in Kohlbacher, Josef and Schiocchet, Leonardo (Eds.), From Destination to Integration - Afghan, Syrian And Iraqi Refugees in Vienna (ISR-Forschungsberichte, Heft 47). Vienna: Austrian Academy of Sciences Press.

The Guardian. March 22, 2017. Available at [https://www.theguardian.com/world/2017/mar/22/whydenying-refugees-the-right-to-work-is-a-catastrophic-error]

Andreas Hackl is a social anthropologist based at the University of Edinburgh, and a member of ROR- $n$. His research interests are cities, inequality, displacement and migration, urban studies, and the wider Middle East region, with a particular focus on Israel/Palestine. He also worked as a journalist and humanitarian analyst based in Jerusalem. 


\section{ENCOUNTERS}




\title{
Syrian crisis: a very complicated simple question
}

\author{
Ibrahim Sirkeci \\ Originally published in 3/23/2016
}

The current migration crisis we face in Europe is the biggest crisis since the last biggest crisis. In about three decades we have seen millions of Kosovans, Bosnians, Kurds, Somalis, Yemenis, Sudanese, Afghan and others fleeing their homes. Syrians are perhaps too close geographically and a little too many. Europe largely failed to embrace and be proud of its tradition of being a sanctuary for those in need of refuge. Politics and media operate on short term parameters and unfortunately these influence the public opinion more than the science and facts can do. Yet, we have to emphasise the facts over and over again.

First of all, not only Syrian asylum seekers but all migrants are driven by the forces of conflict, discomfort, disagreements, tensions and the like. Nobody moves unless there is something discomforting. This is why there are very few migrants in the world. Only $3 \%$ of the world population live outside the countries where they were born. That is 243 million out of 7,349 million. Syrian refugees represent even smaller fraction. So far the total number is 4,8 million and only about 1 million arrived in Europe. This equates more or less what the Gallup Poll predicted before 2011.[1] This means the current conflict in Syria has just speeded the process while the migration pressure was already there. 
In several conferences and lectures I have explained this already but migration crisis we face today is due to three deficits: demographic deficit, development deficit and democratic deficit. One of these deficits is enough to trigger migration but countries like Syria usually have all three. A few facts to remember; Syrian government have not been the most democratic and denied even basic citizenship rights to some groups including Kurds. Despite some oil reserves, Syria has been relatively poor with per capita income below $\$ 5,000$ [2] accompanied by large income inequality. [3] Its population has been fast growing with high fertility rates creating more employment pressure and more emigration pressure. Unless you address these issues in Syria and elsewhere, migration crisis will continue.

Most of the talk recently revolved around money. Either it was the cost of hosting refugees or the amount of Euros to bribe Turkey to keep them there. One way or another Turkey will have enough resources to house Syrian refugees. The cost of accommodating a refugee varies but often it is absorbed in totals. In other words, one can only spend as much as she has access to. Per capita cost to Turkish citizens is about $\$ 100$ a year in terms of sharing public resources/services. The total estimated costs are less than $3 \%$ of Turkish GDP. Due to limited number of Syrians arrived in Europe, this figure is much smaller for the EU's $\$ 18.5$ trillion GDP. Some even argues that two cents levy on petrol prices will solve the problem forever.

Nevertheless, the wrong assumption here is that having these movers is a burden, a costly ticket. The fact is they contribute much and create much. They pay taxes, they create value too. According to a report, Syrians were the owners of $2.4 \%$ of newly established businesses in Turkey in 2014. Syria is used to be one of the largest 
remittance receiving countries. Now I believe much of these remittances go to Turkey, Jordan and Lebanon, where $90 \%$ of refugees are. To help, companies like Ria Money Transfers offered zero fee transfers to Nepal[4] responding to the call by World Bank's Dilip Ratha.[5] May be we should repeat the call for Syrians. This would perhaps send some positive waves.

\section{Syrian Refugees, (з мacc 2016, иннск)}

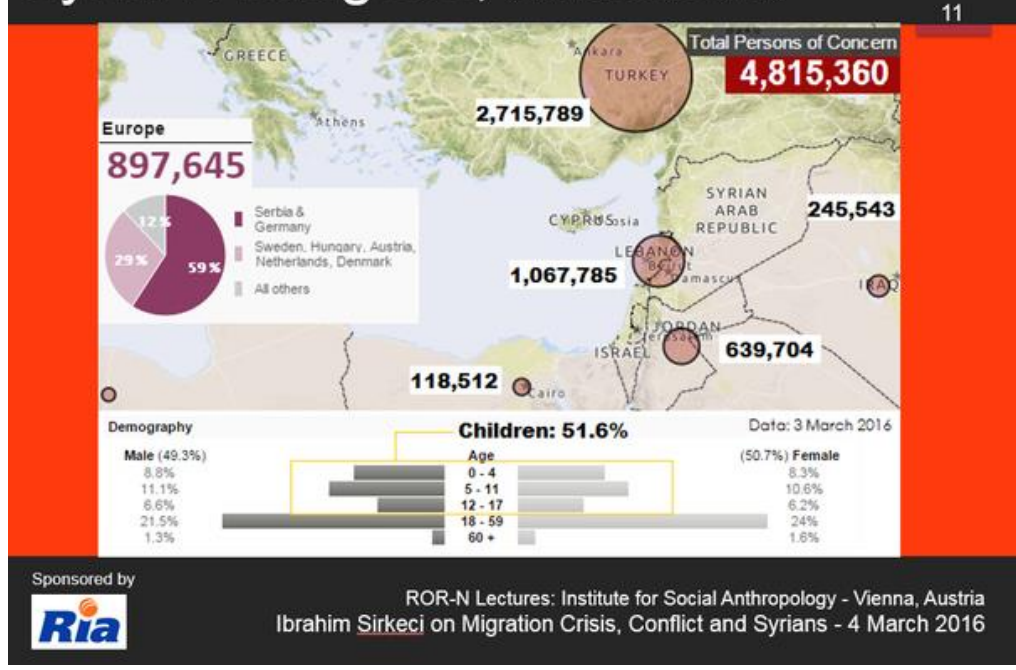

\section{Notes}

[1] See Sirkeci, I., \& Esipova, N. (2013). Turkish migration in Europe and desire to migrate to and from Turkey. Border Crossing, 2013(1), $1-13$.

Retrieved

from http://www.tplondon.com/journal/index.php/bc/article/vie 
$\underline{w} / 89$

[2] See http://tplondon.com/journal/index.php/bc/article/viewFil e/373/294

[3] See http://carnegie-mec.org/publications/?fa=43355\&lang=en

[4] See http://riafinancialblog.com/2015/05/14/remittances-tohelp-reconstruct-nepal-ria-continues-to-offer-zero-service-feeglobally/

[5] See http://blogs.worldbank.org/peoplemove/help-nepal-waiveremittance-fees-and-open-door-wider

Ibrahim Sirkeci is Ria Professor of Transnational Studies \& Marketing and Director of Centre for Transnational Studies at Regent's University London (http://www.regents.ac.uk/rcts). Sirkeci holds a PhD from University of Sheffield and BA from Bilkent University. Before joining Regent's in 2005, he worked at the University of Bristol. His research covers migration, ethnicity, remittances, labour markets and integration. Sirkeci's research has been funded by the World Bank, Ria Money Transfers, and British Academy among others. He is the chair of Turkish Migration Conferences, the 4th will be hosted at the University of Vienna (12-15 July 2016) Sirkeci is also the editor of several journals including Migration Letters, Border Crossing, Kurdish Studies and Remittances Review. He authored several books on migration including Cultures of Migration, the Global Nature of Contemporary Mobility (U. of Texas Press, 2011), Migration and Remittances during the Global Financial Crisis and Beyond (The World Bank, 2012), Turkish Migration, Identity and Integration (TPLondon, 2015), Conflict, Insecurity and Mobility (TPLondon, 2016). 


\title{
How Do Lives Become Grievable? On the short summer of migration and the time after
}

\author{
Monika Mokre \\ Originally published in 9/5/2016
}

After the short summer of migration of 2015 came the long fall, winter, and spring of frustration and reflection focusing on one question: How could it happen that the discourse on refugees changed so dramatically during a very short period of time? How did welcome culture become walls-up policy in the course of a few months?

Certainly, this question is justified. Let's just take a random but striking example: Do you remember the photo of the dead Syrian baby at the Turkish shore, a photo you could see all over the world in September 2015? You probably do. Do you also remember the dead Syrian baby in the arms of a rescue team member whose picture was taken in May 2016? You probably don't because you actually never saw it unless you happened to surf in very specific Facebook and chat groups. It never made it into mass media.

So, it makes sense to ask about the reasons for the change of discourse - but the question is posed the wrong way. What is happening now is normal - normal in the way that normality has been understood since $9 / 11$ at the latest: What we are confronted with now is the normal state of exception of contemporary politics. As the equally ominous as clear-sighted political theorist Carl Schmitt put it, the sovereign is "the one who decides on the state of emergency"[ii]. And for quite some time now, the sovereign has made ample use of this possibility, starting with the US who declared 
a state of emergency by the then-President George Bush in 2001 which has not be withdrawn so far[iii]. In more recent years, other countries like France have followed suit[iv]. While up to now the usual reason for a state of emergency has been the danger of terrorist attacks, these days, Austria is in the process of declaring a state of emergency due to not manageable "refugee flows“[v]. Circumventions of human rights, migrant and refugee rights etc. by measures „situated at the limit of law and of politics“[vi] have been normal for quite some time. What was not normal, was the summer of migration, the welcome culture (which, since then, has become a four-letter-word).. Thus, the question should probably be: How did the summer of migration become possible?

But, in a way, it is also peculiar to ask about the conditions of possibility for universally accepted and legally binding rights to be actually applied. To ask about the conditions of possibility for human decency. To ask under which conditions a dead Syrian baby can be seen as a dead baby and, thus, as a tragedy.

So, let's again start from a different angle: How is it possible to override fundamental universal values in a seemingly legitimate way? How is it possible that lives do not have the same values and that some lives have no value at all?

Judith Butler[vii] describes the problem astutely: „Such frames are operative in imprisonment and torture, but also in the politics of immigration, according to which certain lives are perceived as lives while others, though apparently living, fail to assume perceptual form as such. Forms of racism instituted and active at the level of perception tend to produce iconic versions of populations who are eminently grievable, and others whose loss is no loss and who remain ungrievable. The differential distribution of grievability across populations has implications for why and when we feel 
politically consequential affective dispositions such as horror, guilt, righteous sadism, loss, and indifference." (p.24) Populations that are not grievable are, above all, populations understood as threatening: "Consequently, when such lives are lost they are not grievable, since, in the twisted logic that rationalizes their death, the loss of such populations is deemed necessary to protect the lives of ,the living'." (p.31).

For many years now, refugees have been ungrievable, seemingly threatening populations. They have been framed in this way - and, as Butler remarks, to be framed in English also means "to be set up, or to have evidence planted against one that ultimately ,proves' one's guilt." (p.8) So, this is the normal state of affairs: The state of emergency proclaimed due to refugees framed as guilty for coming, guilty of being terrorists, guilty of threatening our lives.

But how was this frame broken in August 2015? Several causes or, at least, triggers could be named here[viii]: Due to the huge numbers of refugees entering the country Hungary was unable to deal with the situation, even in its usual way of imprisoning refugees. Thus, as imprisonment did not work, refugees managed to find their way out of Hungary, to Austria and Germany - flight helpers were active and their prices reasonable. Maybe due to the normative force of this factual situation the German Office for Migration and Flight announced on August, 25th, that no Dublin deportations from Germany to Hungary would be carried out for Syrians. This became known among refugees before it was even official. And on September, 27th, a lorry with 71 dead refugees was found in Eastern Austria. Probably, this was the point at which Austrian civil society saw the situation as unbearable. And this is interesting in itself: Why is it more tragic, more outrageous when refugees die on Austrian soil than when they die in the Mediterranean? Which kind of weird patriotism is at work here, even for people who would never 
call themselves patriots? How does the non-grievable refugee become grievable when s/he happens to die on „our" territory?

In any case, the death of these 71 people raised more consistent questions as to the responsibility of the Austrian government for the situation of refugees. And the government reacted even before accused: Apart from making the (rather absurd) statement that the refugees were already dead when the lorry crossed the HungarianAustrian border, the government also immediately named the culprits for this terrible deed: smugglers, human traffickers [ix]. And a huge police action against human trafficking was started. Thus, the refugees were stuck in Hungary - and Hungary was stuck with the refugees. So, at one point, the Hungarian police left the railway stations in Budapest and, thereby, made it possible for refugees to board international trains. Refugees came to Austria who did not stop them but sent them on their way to Germany. At the same time, Germany and Austria pressurized Hungary to stop the refugees. Hungary tried - and failed. Hundreds of refugees walked towards the Austrian border. And due to the power of these images, Germany and Austria decided to open their borders. For some time. For a very limited amount of time. But still.

These are the facts - to which one should probably add that there were huge differences between German and Austrian „welcome culture" during this time: While Germany accepted a very high number of refugees, Austria mostly helped them to find their way to Germany, distributing water and food in the main railway stations and showing them the next train to Germany.

Still, given the size of the country, also a considerable number of refugees stayed in Austria. In provisional camps. In soccer stadiums. In gyms. In schools. This situation could well have re-enforced the common understanding of refugees as a threat. But it did not. 
Instead, the camps were crowded by people who wanted to help. It was regularly announced that no more donations should be brought as there were no more storage facilities. At the railway stations you could see men in suits and ties and women in high heels buying half of the supplies of a supermarket and distributing them among refugees. And a surprising high number of people announced via Facebook that they now had a Syrian protégé/e, adoptive child, very good friend and how much happiness this brought to their lives.

The ungrievable lives of refugees had suddenly become valuable. Well, the lives of some refugees. Mostly, the welcome culture welcomed Syrians. And, maybe, this limitation was important to discern one group of refugees that people could deal with when confronted with an otherwise anonymous and threatening "flow of refugees". War refugees. Mostly well-educated as the media emphasized. People who did well in their country before the war and wanted to go back as soon as the situation had improved.

Probably, this assessment is too cynical and too focused on rational judgement. Probably, many or, even, most people are not without empathy for suffering of other human beings. But, at the same time, they are afraid. Concerning their own tiny privileges. Concerning their own modest life standard. And, even, concerning their own national or regional culture - whatever that might mean but, obviously, it means something or different things for different people. And, thus, it feels good to see fear overruled by empathy for a short period of time. To see people as people and not as the enemy. To see suffering as suffering and not as a threat. And to help.

But, obviously, helping is not enough. Or even problematic. Helping cannot take place at eye level. Helping can be patronizing. Helping can make one person strong because another person is weak. All this is unavoidable - but it should be kept in mind for helpers to stay 
cautious and modest. When seeing a criminal led to death penalty the Christian reformer John Bradford said, „there but for the grace of God goes John Bradford“. In the same vein, helpers could easily be in the situation of refugees but for the mercy of birth in a specific part of the world they are not.

Refugees need help. But they should not need help. They should have rights, warranted by the Declaration of Human Rights and the Geneva Convention. Maybe, in a globalized world of exploitation of the Global South by the Global North, they should be granted still more rights than enshrined in these documents. But even the so far established rights are usually not recognized, at least not universally, not even by many helpers and supporters. Very frequently, entitlement to a legal status, to social security, to a "normal life“ (as protesting refugees phrased it in November 2015) are not linked to universal rights but to individual merits: niceness, intelligence, gratefulness, willingness to integrate. It is a symptom of a racist situation when non-whites are only accepted when they are nice, intelligent etc. while whites are accepted because they are white. Or, when non-citizens need to display personal virtues to be accepted while citizens are accepted by virtue of their passport. And a state of acceptance or toleration on the basis of being nice, intelligent, grateful etc. is a precarious one - as soon as you are not nice, you are out.

Obviously, the problem behind all this is nationalism. Or the concept of the nation, in general, the extraordinary success of the construction of national identities[x]. Politically, national affiliation constitutes the main difference between us and the others. Between the citizens and the non-citizens. The citizens are entitled to be here, the non-citizens are allowed to be here - if everything goes well. Even the term „welcome culture" points towards this difference: We who are entitled to be here welcome you. On our terms and as long as we 
consider it appropriate. You are the guest, you have to be polite and modest - and as long as you play by these rules we shall welcome you; this is the difference between the welcoming part of 'us' and the populist and radical right part of 'us' welcoming you under no circumstances.[xi].

So, it should not come as a surprise that the period of the welcome culture ended so soon. This period was not enough to really change the discourse on migration. Not because it was not long enough but because it was not radical enough. In order to change the discourse on migration it is necessary to change the discourse on the nation. To downgrade the importance of national identities. To overcome national borders. To focus on the ways in which people can live together - people who live together anyway, artificially (but no less emotionally) separated by their passports. This seems like a long shot but, in fact, it is probably what will happen anyway - due to the normative force of the factual, of migration which will not be stopped by border regimes.

Border regimes do not stop migrants, migrants come to Europe in spite of border regimes, but the stricter the border regimes the more migrants die at borders. And the summer of migration was not enough to end that. But the summer of migration was enough to help some thousands of refugees to get to Germany. To travel relatively safely. To arrive at relatively safe places. To make their lives relatively more safe. The loss of their lives was perceived as a loss and, therefore, this loss was prevented. And the lost life of a Syrian baby became grievable and has been grieved. This is not nothing.

\section{Notes}

[i] I would like to thank Cornelia Hülmbauer for proof reading as well 
as Leonardo Schiocchet and Cornelia Hülmbauer for their comments that greatly improved the text.

[ii] Schmitt, C. (1922/2004), Politische Theologie. Vier Kapitel zur Lehre von der Souveränität. Berlin: Duncker\&Humblot, p.13

[iii] See

e.g.: http://sputniknews.com/us/20150919/1027228017.html, retrieved 2016-07-22

[iv] See e.g. http://foreignpolicy.com/2016/07/16/francesperpetual-state-of-emergency/, retrieved 2016-07-22

[v] See e.g. http://www.spiegel.de/politik/ausland/oesterreichinnenminister-warnt-vor-notstand-wegen-obergrenze-a1095474.html, retrieved 2016-07-22

[vi] Agamben, G. (2002), The State of Emergency, http://www.generationonline.org/p/fpagambenschmitt.htm, retrieved 2016-07-22

[vii] Butler, J. (2009), Frames of War. When is Life Grievable? London/ New York: Verso

[viii] See for the history of the summer of migration: http://bordermonitoring.eu/ungarn/2015/09/ofhope/, retrieved 2016-07-22

[ix] See

e.g.: http://diepresse.com/home/panorama/oesterreich/4807792/ A4Fluchtlingsdrama_Ein-Lastwagen-voller-Leichen, retrieved 201607-22

[x] Cf. e.g.: Anderson, B. (1991), Imagined Communities: Reflections on the Origin and Spread of Nationalism. London/ New York: Verso 
[xi] See e.g. Sayad on the requirement of "politesse" of migrants; Sayad, A. (2015), Immigration und "Staatsdenken", in: Mennel, B./Mokre, M., Das große Gefängnis. Wien: transversal, 35-64, here: 48-49

Monika Mokre is a political scientist and senior research associate at the Austrian Academy of Sciences Institute of Culture Studies and Theatre Studies as well as member of ROR-N. She teaches in various contexts, e.g. at the Webster University Vienna and, in spring 2016, as a visiting professor at the Institute of Political Science at the University of Vienna. Her current main interest as a researcher and as a political activist are asylum and migration policies. 


\section{Palestinian refugees from Syria and their fate in Europe}

Anne Irfan

Originally published in 2/2/2017

The European response to the Syrian refugee crisis has dominated much of the continent's recent political discourse. Yet this has included almost no discussion of the estimated 100,000 Palestinians who have fled Syria since the conflict began. Prior to 2011, 560,000 Palestinians were registered as residing in Syria without citizenship.[1] They were largely the descendants of the generation that had fled Palestine in 1948, and over the decades they had become well-integrated into Syrian society. Despite not holding citizenship, they enjoyed many of the same rights as their Syrian neighbours, and were significantly better-off than their counterparts next door in Lebanon.[2] Since 2011 this situation has been turned on its head - and the Palestinians' lack of Syrian citizenship has become pivotal to their fate.

The plight of Palestinian refugees from Syria has become especially pertinent in Europe over the last two years. While the majority of refugees from Syria have sought shelter in neighbouring countries,[3] Jordan and Lebanon closed their doors to Palestinians in January 2013 and May 2014 respectively.[4] As a result, increasing numbers of Syrian-born Palestinians have looked to Europe as an alternative place of refuge.[5] UNRWA, the UN Relief and Works Agency for Palestine refugees, estimates that at least 60,000 Palestinians from Syria have now fled the Levant, and that a significant number of these have gone to Europe.[6] The difficulties Palestinians face in acquiring European visas mean that many have 
done so clandestinely by sea, risking arrest, detention, exploitation and even death. On occasion, Palestinian refugees from Syria have been found on stranded boats and subsequently detained.[7]

Despite this, very few Europeans are aware of the existence of Palestinian refugees from Syria, or of the distinctive nature of their plight. Accordingly, European policies towards them are characterised by confusion and inconsistency. The standard European framework, known as the Common European Asylum System (CEAS), is rarely applied consistently for anyone, and certainly not when it comes to the Palestinians.[8] Palestinian refugees from Syria might be recorded as 'stateless', 'unknown nationality', 'Palestinian' or 'Syrian', depending on exactly when and where they register.[9] As a result, there is only limited data available about the situation of Palestinian refugees from Syria in Europe today, and it is unknown how many have been granted asylum. This in turn impedes a full assessment of the problems facing them, and has created more uncertainty for those desperately seeking refuge.

What is known is that Palestinian refugees are even more disadvantaged than their Syrian counterparts. The little data that is available shows that Palestinians are less likely to be granted asylum in Europe than other refugees from Syria, with a higher proportion of their applications remaining pending over a long period.[10] European government policy on Palestinian refugees is often opaque; the UK Home Office, for example, has refused to clarify whether they are included in its Syrian resettlement plan.[11]

Even when governments are transparent about their policy positions, this does not always guarantee clarity in practice. Both the German and Swedish governments have stated that they treat 
Syrian-born Palestinians on the same basis as refugees with Syrian citizenship.[12] Yet in practice there can be exceptions to this. While Sweden is aligned with most other EU states in not forcibly returning refugees to Syria,[13] its policy has a loophole whereby Palestinians from Syria who had formerly lived in Iraq can be returned to the latter.[14]

Similarly, the Greek government's 2013 Order suspending the expulsion of Syrians does not apply to non-Syrian-nationals previously resident there. There have also been reports of Palestinian refugees from Syria being turned back at the Bulgarian border with Turkey, and their asylum applications being ignored.[15] Even in Germany, there are sometimes discrepancies at the local level. If officials are unaware of the status of Syrian-born Palestinians, there may be disparities in how they are classified even within the same country, with some registered as Syrian and others are given an indeterminate status.[16]

The question remains of why Palestinians are treated so differentially. Some of this is down to their statelessness. As Palestinians do not hold Syrian passports, it can be harder for host states to verify that they are refugees fleeing the Syrian war, and are therefore eligible for resettlement schemes. In some cases, there are concerns that their statelessness makes them more likely to become 'long-term' refugees, with no obvious home to return to. Collected testimonies recall Palestinians being detained for unusually long periods in Greece because there is no country to deport them to.[17]

However, the Palestinians' statelessness is by no means the only reason for their differential treatment. Palestinian refugees are also rendered particularly disadvantaged by their unique international classification. Since 1950, they have received services from the UN 
Relief and Works Agency for Palestine refugees (UNRWA). They have consequently been excluded from the mandate of the UN High Commissioner for Refugees (UNHCR), on the grounds that they are covered by another UN body.[18] As a result, they are ineligible for potentially crucial services from UNHCR, including travel documents and formal verification of their status. While UNHCR has intervened to assist Palestinian refugees in certain situations, such interventions have taken place on an ad hoc basis. Officially speaking, the Palestinians lack the formal eligibility for UNHCR services that all other refugees can claim.

The repercussions of this distinction are significant. UNRWA has a much more limited scope than UNHCR. It registers Palestinian refugees in the Middle East and provides them with emergency relief and long-term health and education services. Yet unlike UNHCR, UNRWA is not mandated to provide protection or to pursue political solutions to the refugees' plight. As a result, Palestinian refugees suffer from a 'protection gap', whereby they are the only group of people in the world who are not provided with protection by the UN - and are therefore uniquely vulnerable.[19]

This state of affairs has had a host of negative consequences for Palestinians fleeing Syria today. It means that they lack formal protection in a situation where they desperately need it. Their combination of statelessness and ineligibility for UNHCR services means that Palestinian refugees are too often falling through the gaps - especially in Europe, where UNRWA does not operate. Moreover, any European resettlement plan that is coordinated with UNHCR automatically excludes Palestinian refugees. In September 2015, for instance, the then UK Prime Minister David Cameron announced that the UK would accept 20,000 Syrian refugees over a 
five-year period. As these 20,000 refugees will be identified through UNHCR, Palestinians will be automatically excluded.[20]

The problems facing Palestinian refugees from Syria are significant and in several ways exceptional. Even otherwise laudable European responses to the Syrian crisis have often failed to take account of the complex Palestinian plight. Yet its complexity makes it imperative that the Palestinians are included in refugee response plans from the beginning, so as to avoid the confusion and inconsistencies that have come to dominate the situation as it currently stands.

\section{Notes}

[1] UNRWA, Syria Regional Crisis: Emergency Appeal 2016. Retrieved from http://www.unrwa.org/sites/default/files/2016 syria_emergency appeal.pdf

[2] Qandil, M. (2012). The Syrian Revolution and the Palestinian Refugees in Syria: Realities and Risks. Al Jazeera Centre for Studies. Retrieved from

http://studies.aljazeera.net/mritems/Documents/2012/5/2/2012 52132022536734The \%20Syrian\%20Revolution\%20and\%20Palest inian\%20Refugees\%20in\%20Syria.pdf

[3] Orchard, C. \& Miller, A. (September 2014). Forced Migration Policy Briefing 10: Protection in Europe for Refugees from Syria. Oxford Refugee Studies Centre. Retrieved from https://www.rsc.ox.ac.uk/files/publications/policy-briefingseries/pb10-protection-europe-refugees-syria-2014.pdf 
[4] Human Rights Watch. (2014). Jordan: Palestinians Escaping Syria Turned Away. Retrieved from https://www.hrw.org/news/2014/08/07/jordan-palestiniansescaping-syria-turned-away

Amnesty International. (2014). Families ripped apart as Palestinian refugees from Syria denied entry to Lebanon. https://www.amnesty.org/en/latest/news/2014/07/familiesripped-apart-palestinian-refugees- syria-denied-entry-lebanon/

[5] Abu Moghli, M., Bitarie, N. \& Gabiam, N. (October 2015). Palestinian Refugees from Syria: Stranded on the Margins of Law. Retrieved from https://al-shabaka.org/briefs/palestinian-refugeesfrom-syria-stranded-on-the-margins-of-law/

[6] Bolongar, K. (March 2016). Palestinian Syrians: Twice refugees. Retrieved

from http://www.aljazeera.com/indepth/features/2016/03/palest inian-syrians-refugees-160321055107834.html

[7] Morrison, L. (2015). Egypt: A Desperate Refuge for Palestinians Fleeing the Syrian Conflict. Al Majdal, 57, 19-23.

[8] On CEAS see: https://ec.europa.eu/homeaffairs/sites/homeaffairs/files/what-we-do/policies/europeanagenda-migration/backgroundinformation/docs/20160713/factsheet the common european asy lum system en.pdf

[9] UNHCR (June 2014). Syrian Refugees in Europe: What Europe Can Do to Ensure Protection and Solidarity. Retrieved from: http://www.refworld.org/docid/53b69f574.html 
[10] Orchard, C. \& Miller, A. (September 2014). Forced Migration Policy Briefing 10: Protection in Europe for Refugees from Syria. Oxford Refugee Studies Centre. Retrieved from https://www.rsc.ox.ac.uk/files/publications/policy-briefingseries/pb10-protection-europe-refugees-syria-2014.pdf

[11] Bolongar, K. (March 2016). Palestinian Syrians: Twice refugees. Retrieved

from http://www.aljazeera.com/indepth/features/2016/03/palest inian-syrians-refugees-160321055107834.html

[12] Ibid.

[13] UNHCR (June 2014). Syrian Refugees in Europe: What Europe Can Do to Ensure Protection and Solidarity. Retrieved from: http://www.refworld.org/docid/53b69f574.html

[14] Orchard, C. \& Miller, A. (September 2014). Forced Migration Policy Briefing 10: Protection in Europe for Refugees from Syria. Oxford Refugee Studies Centre. Retrieved from https://www.rsc.ox.ac.uk/files/publications/policy-briefingseries/pb10-protection-europe-refugees-syria-2014.pdf

[15] Ibid.

[16] Bolongar, K. (March 2016). Palestinian Syrians: Twice refugees. Retrieved

from http://www.aljazeera.com/indepth/features/2016/03/palest inian-syrians-refugees-160321055107834.html

[17] Ziadah, R. (May 2016). Journeys of Dispossession: Palestinian Refugees from Syria Confronting Fortress Europe. Retrieved 
from http://www.darkmatter101.org/site/2016/05/16/journeysof-dispossession-palestinian-refugees-from-syria-confrontingfortress-europe/

[18] Article ID of the 1951 Refugee Convention excludes 'persons who are at present receiving from organs or agencies of the UN other than the UNHCR protection or assistance'. The Palestinian refugees registered with UNRWA are the only group to whom this applies.

[19] Akram, S. (2001). Reinterpreting Palestinian Refugee Rights under International Law. In: N. Aruri (Ed.). Palestinian Refugees: The Right of Return. London: Pluto Press. 165-194.

[20] https://www.theguardian.com/world/2015/sep/07/uk-willaccept-up-to-20000-syrian-refugees-david-cameron-confirms

Anne Irfan is Departmental Lecturer in Forced Migration at the University of Oxford, where she is part of the Refugee Studies Centre. Her research focuses on Palestinian refugee history and the evolving role of UNRWA and the UN. Her work has been published in Journal of Refugee Studies, Journal of Palestine Studies, and Forced Migration Review, among others. She is currently launching a new project on the emergence of the global refugee regime in the period after the Second World War. 


\title{
Who are the refugees that came to Austria in fall 2015?
}

\author{
Judith Kohlenberger \& Isabella Buber-Ennser \\ Originally published in 1/10/2017
}

Across Europe, the time between late summer and fall 2015 became rapidly known as the so-called 'refugee crisis', exposing us to daily pictures of large numbers of forced migrants crossing the borders to the EU on foot or by train. Between July and December, roughly 60,000 asylum applications were filed in Austria, amountingaltogether to 88,098 applications by the end of the year.[i] Most of these asylum seekers fled from persecution, war and torture in their home countries Syria, Iraq and Afghanistan, which account for $71 \%$ of all asylum applications in 2015.[ii]

Contrary to popular discourse and tabloid media reports, however, the forced migrants who arrived in Austria in fall 2015 were far from a homogenous group, nor were they a random sample: Research has impressively shown that the Syrians, Iraqis and Afghans who sought refuge in Austria display very specific socio-demographic characteristics, from educational levels and professional qualifications to attitudes and values. To tailor civil society efforts, NGOs' relief services and national integration policies to the specific aims and needs of forced migrants, the question should thus not only be How many are coming?, but more significantly: Who is coming?

Moving beyond counting heads to studying what's in these heads in terms of knowledge, training and skills is exactly what a recent quantitative study at the Wittgenstein Centre for Demography and Global Human Capital (IIASA, VID/ÖAW, WU) tried to 
achieve. DiPAS (Displaced Persons in Austria Survey) was launched in October 2015 under the supervision of Wittgenstein Prize laureate Wolfgang Lutz, with the aim of uncovering the socio-demographic characteristics of asylum seekers in Austria. The survey, the first of its kind in Austria, was carried out among displaced adults, mostly from Syria, Iraq and Afghanistan, who had recently arrived in Austria. Face-to-face interviews were conducted in seven NGO-run refugee shelters in and around Vienna to question respondents about their origins, education attainment and professional experience, marital status, attitudes and values as well as their future plans. The survey yielded 514 completed interviews and also gathered information on respondents' spouses and children, which allowed for the analysis of 1,391 persons altogether.

This analysis showed that asylum seekers who entered Austria in summer and fall 2015 are well-educated, hold less traditional values than their compatriots and have a predominantly middle-class background, when compared with respective data from the countries of origin.

About a quarter of respondents from Syria and Iraq had obtained a post-secondary degree. This corresponds to the percentage of people with a specialized high-school diploma ("Fachmatura") or a higher education degree in Austria. Nearly half of the forced migrants in the sample completed an upper secondary education. This percentage is considerably higher than among the general population in their respective home countries, where the figures are closer to $10 \%$ (Afghanistan) and 20\% (Syria), respectively.[iii] 


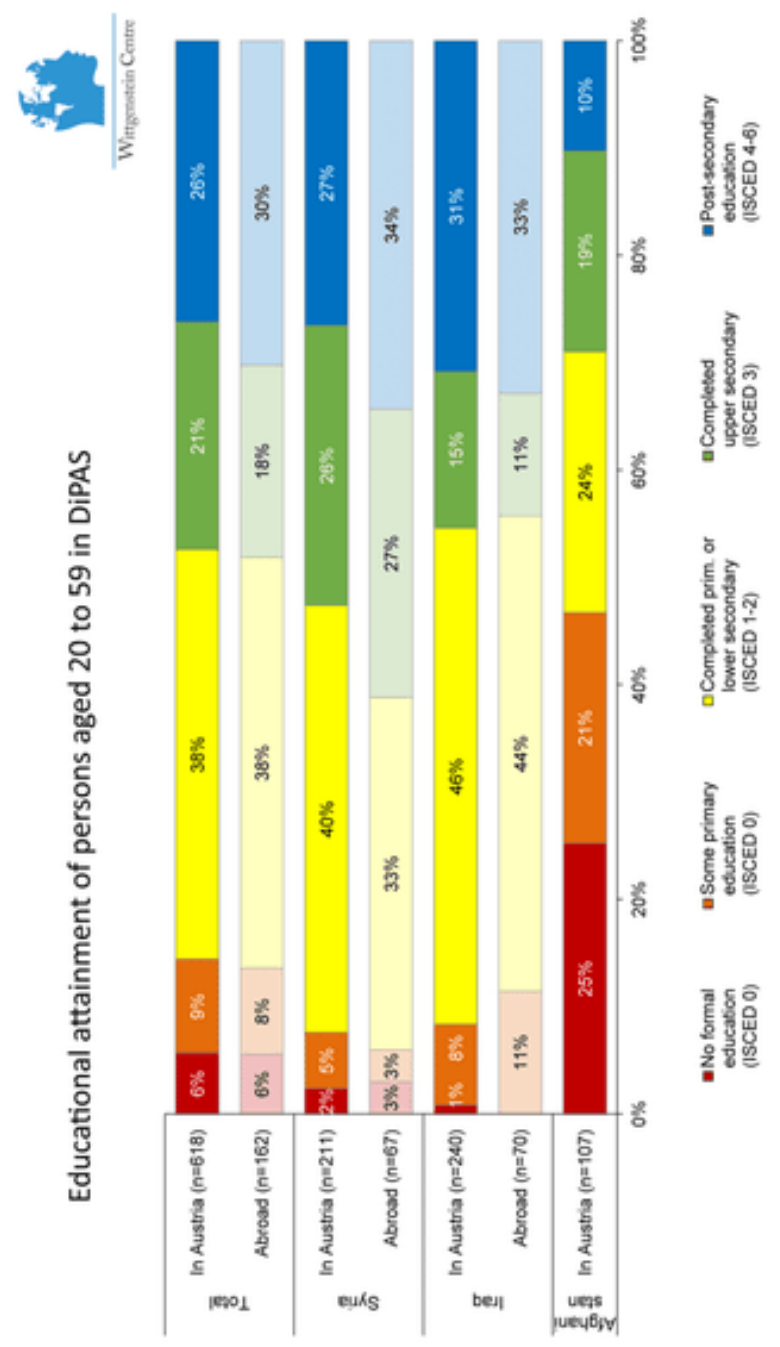


Socioeconomic factors furthermore indicate that a large share of respondents came from middle-class backgrounds before the humanitarian crisis forced them to flee their countries. Home ownership was very common: Four-fifths of respondents lived in their own or their family's house before they had to flee. The majority of respondents indicated that they had to pay between US $\$ 2,000$ and 3,000 for their journey, which roughly corresponds to the average annual income in Syria and Iraq before the crisis propelled heavy inflation and falling exchange rates.

Results further show that the surveyed population comprised mainly young families with children, particularly among Syrians and Iraqis. When extrapolating the number of children or partners still in their home country, the potential for family reunifications can be estimated, ranging at 38 (nuclear) family members per 100 refugees. Sensible international policy measures for safe and quick family reunification are pertinent, not least because, for the majority of forced migrants, their resettlement may very well be a permanent one: Two-thirds of respondents do not intend to return to their home countries, mostly because of the perception of permanent threat. The intention to return is highest among Syrian respondents, which may indicate particularly strong ties with and a high emotional attachment to the home country. 


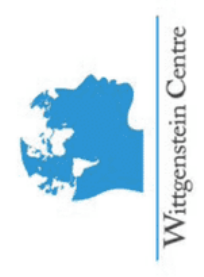

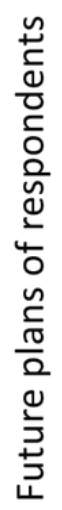

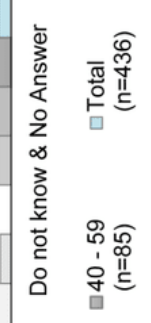

ิㅡㅇ

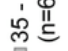

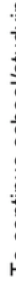

.

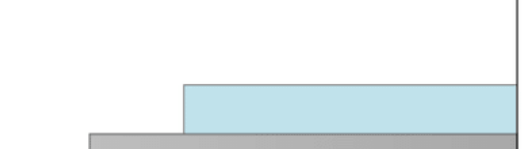

은

ผ ำ

मेत्

읻

ㅁ

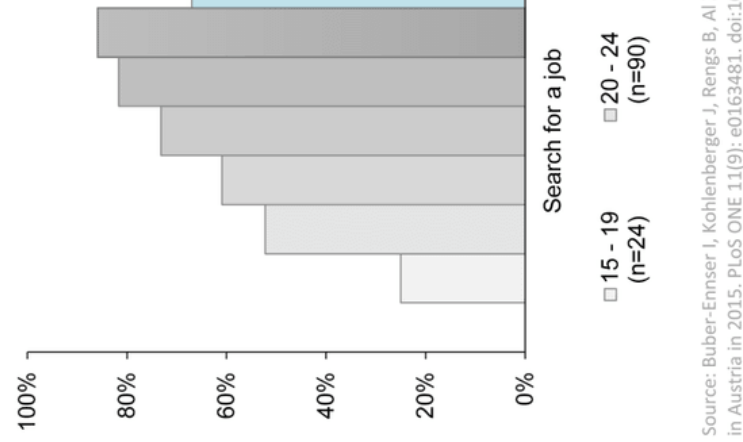


Concerning plans for their future in Austria, most respondents intend to search for a job, which correlates with high levels of previous employment experience, especially among male asylum seekers. Quite consistently, this result is age-specific: In the relevant age groups of 15-19 years and 20-24 years, the majority of respondents wish to complete their education before entering the Austrian labor market. This may suggest an appreciation for the value of (higher) education for one's personal and professional future, an interpretation supported by the overall high levels of education among older respondents.

The data collected for DiPAS allow for many more insights on who the forced migrants from fall 2015 are, ranging from respondents' religion, their levels of religiosity and self-assessed health to attitudes and values on issues of gender equity and household task sharing. The more we learn about the demographics of recent refugee arrivals to Austria, the better, faster and more efficiently resources can be directed to those in need. While DiPAS is only a small, yet significant piece of a bigger puzzle, we hope that further country-specific, as well as international, comparative studies will soon all contribute to establishing a more differentiated, individualized picture of refugees in Europe. Only such a nuanced picture can do justice to the complexity of forced migrant experiences, their hopes and needs.

\section{Notes}

[i] BMI. Asylstatistik 2015 [Asylum statistics 2015]. Vienna: Austrian Federal Ministry of the Interior; 2016. Available at 
<http://www.bmi.gv.at/cms/bmi service/>. (accessed 13 Dec. 2016).

[ii] Ibid.

[iii] Data provided by the Central Bureau of Statistics (2004) for Syria and the Central Statistics Organization for Afghanistan. No recent representative survey is available for the Iraqi population.

Judith Kohlenberger is affiliated with the Vienna University of Economics and Business (WU, Research Institute for Human Capital and Development) and the Wittgenstein Centre for Demography and Global Human Capital (IIASA, VID/ÖAW, WU). Since fall 2015, she has been working on the Displaced Persons in Austria Survey (DiPAS), which examines the family context, educational attainments, and professional qualifications of asylum seekers and refugees from Syria, Iraq, and Afghanistan in Austria.

Isabella Buber-Ennser is deputy leader of the research group "Demography of Austria" at the Vienna Institute of Demography, Austrian Academy of Sciences, which is part of the Wittgenstein Centre for Demography and Global Human Capital (IIASA, VID/ÖAW, WU). Besides her current focus on fertility and forced migration, she has published on different aspects of ageing, like mental health, cognitive functioning and intergenerational transfers of older persons. 


\title{
Narratives of Asylum Seekers: between coping and integration
}

\author{
Noura Kamal \\ Originally published in 4/24/2018
}

People need much effort to cope with unstable social environments and to get used to changes in their surroundings. But what if individuals were forced to leave their homeland? How will they be able to adapt to the circumstances they face in societies in which they may not even know the language?

War is among the main causes of displacement world-wide. As Edna Lomsky-Feder explains, "The personal memory of war is not homogeneous but, rather, multicolored: Some remember the war as a traumatic experience and others as a heroic event; some recall it as an experience that obstructs personal development, and others as an empowering and fortifying one" (Lomsky-Feder 2004, p. 82). That is, each individual has his/her own way of dealing with crises, and of telling their story. Particularly among refugees, these diverse expressions, or narratives, can provide us with countless aspects of human behavior during crises and in their aftermath. How asylum seekers cope with distress in their new place of living features prominently in the responses of a sample of Syrian interviewees.

As researchers, we must be careful when we reflect upon their stories. However, trying to look deeper into their narratives, highlighting certain aspects in detriment of others, can reveal important aspects of human lives, not least about how people confront the challenges of a journey in search of peace and dignity. But how do asylum seekers cope with war and flight? 
In my contribution to the book entitled "From Destination to Integration - Afghan, Syrian and Iraqi Refugees in Vienna", I analyzed fifteen narrations by Syrians of different generations and affiliations to reflect upon the asylum seekers' experiences of exile. While these narratives vary in expression, they also feature common themes. Most importantly, they express how hard the interviewed Syrians tried to be part of Viennese society and adapt to the obstacles they face in this new context. For many, voluntary work was the first step to overcome the idea that they are asylum seekers and prove for themselves that they can integrate and be part of the local Viennese society. Nonetheless, trying to be independent financially or achieving their personal satisfaction by continuing their education was also a vital aim for many in the sample. For many asylum seekers their self-confidence hinges on their ability to control their own lives and to contribute to the new environment. They much preferred to be productive members of their new society rather than being passive individuals. However, the income generated by regular work means they would lose the social welfare money. Sometimes this is not doable for members of large families, since the working family members' salary cannot not provide for the whole family. If a man, for example, starts working, his wife and children at working age will stop receiving social benefits. Given this obstacle, they decided to contribute to their integration by engaging in social voluntary work. Many assisted in taking care of new asylum seekers arriving at the main stations in Vienna, such as Hauptbahnhof and Westbahnhof. But there were other forms of engagement as well. Thus a man in his mid-forties explained that during the process of looking for a job he had worked carrying wood for two months.

Despite the Syrian asylum seekers' efforts to integrate into the new society, their experience of flight and exile affected their well-being. 
As Allen Feldman states: "There is no doubt that memories of the past say a great deal about people's attitudes in and towards the present" (Feldman 2006, p. 15). Both men and women tried to find their way to a future that could give them hope and peace. The individual narratives showed that the personal relations and the background of each individual had a strong influence on how they adapted. Their political inclinations likewise affected their ability to cope with their suffering. The narratives reflected the impact of their social and political situation. Not all the asylum seekers from Syria faced the same hardships, whether during the war, or through their journey to Europe. It was easier for an individual with a wide range of relations beyond Syria to come to Vienna than it was for those who had no relations outside of Syria. In addition, political affiliations influenced the amount of support an asylum seeker received in adapting to the new circumstances. Finally, wealthy individuals found their way to Europe faster and easier than those who had a precarious income. It was noticeable from the interviews that traumatic experiences influenced how the Syrian asylum seekers communicated with strangers. Apparently, fear of others belonging to another religion made it harder for them to develop new relations.

The brief answers a married woman with five daughters gave during the interview reflect her fear of being open. This especially came to light at the end of the interview, when she said that, even in Austria, she was afraid of telling others that she is Yezidi. Her brief answers may be understood in the light of David Morris' words that: "the silence of suffering also points to very practical breakdowns of speech (...) the voicelessness of suffering often resembles the quiet retreat of people who live with chronic pain" (Morris 1997, p. 28).

However, in spite of their fears, the persons interviewed asserted strong agency. They were dealing with their experiences and reflecting upon them with a positive attitude. Regardless of their 
different affiliations, social belongings and social standing, Syrians asylum seekers found in Austria a good place to start over, especially the members of the younger generation, who hope to continue their education or to be part of the labor force, and thus want to contribute to their new society. But the members of the older generation found it hard to move forward. An elderly woman said that if the war in Syria came to an end she would definitely return. At the same time, she emphasized that her children would be free to choose their own path.

\section{References}

Feldman A. (2006), Home as a Refrain: Remembering and Living Displacement in Gaza. In: History and Memory, Special Issue: Home and Beyond, Vol. 18, No. 2, pp. 10-47.

Lomsky-Feder E. (2004), Life Stories, War, and Veterans: On the Social Distribution of Memories. In: Ethos, Vol. 32, No. 1, pp. 82-109.

Morris D. (1997), About Suffering: Voice, Genre, and Moral Community. In: Kleinman, A., Das V. and Lock M. (eds.): Social Suffering, Berkeley, University of California Press, pp. 25-45.

Noura Kamal is a social anthropologist and researcher at the Austrian Academy of Sciences Institute for Social Anthropology. She is a doctor in social and cultural anthropology (University of Vienna). Her thesis discusses the scope of agency in Nablus/Palestine under immediate siege and under regular Israeli occupation. Her current research focuses on the Yemeni post-1962 intellectual discourse regarding changes in the perception and understanding of tribes and tribalism in northern Yemen. 


\title{
"Steps on the way to social integration": Initial social interactions of refugees from Syria, Iraq and Afghanistan with the host society, their relevance, assessment and implications
}

\author{
Josef Kohlbacher \\ Originally published in 11/23/2017
}

This post discusses how the refugees interviewed for the study perceived of the receiving context in the Austrian society. It focuses on social contacts of refugees with Austrians. These Austrians may be police officers, NGO representatives, refugee workers, language tutors, and so on. The analysis is based on the assumption that social integration is a process of change and exchange that involves both refugees and people of the host society and which starts immediately with the first contacts, though the extracted material only reflects the refugees' perspective of this interactive process. Thus, I investigated the modes and consequences of interethnic social interactions and the resulting social ties in the refugees' everyday life and path to integration. A qualitative and interpretative research approach was used to understand how refugees relate to social contexts and make sense of them on their path to social embeddedness in Austrian society. The temporal plane of reference is mainly the initial and early phase of stay. In some cases, refugees who had been in Austria longer were included in the analysis -mainly with regard to housing and labor market integration and social ties that have been established for longer-. A broad range of experiences have been represented in the study depending on socio-economic and sociodemographic variables such as gender, education, language 
proficiency and country of origin. At the time of our interviews, the range of interactions with locals spanned from living in a flat together with Austrian friends to a complete absence of social contacts with the local population.

Two main fields could be identified in which weak or strong social ties were particularly important. Both categories are based on the theory of the American sociologist Mark Granovetter, who found that the "strength" of an interpersonal tie is a linear combination of the amount of time, the emotional intensity, the intimacy (or mutual confiding), and the reciprocal services which characterize each tie. So, the best example for strong ties are friendship relations, whereas most neighborhood contacts can be classified as being of weak tie quality:

- The first was social integration including support by Austrians for solving initial problems in Austria, interactions with NGO staff and volunteers, social contacts with German language teachers, meeting people in leisure activities and so on.

- After a longer stay structural integration, in particular housing and labour market integration gained relevance.

Refugees have to develop differentiated strategies in order to solve problems of "arriving" in Austrian society. One of the most important strategies for the interviewees was the search for social support. Refugees, who had lost their family network were very eager to establish new social ties to compensate for the social vacuum. It became clear that among the determinants of establishing social ties individual motivations, sociability and in particular language skills were among the most relevant. 
Those respondents with good German-language skills were likely to fare better in all domains. Social contacts are the best German language training and also the best "antidepressant", as the following quote from an interview with a young Hazara from Ghazni in Afghanistan illustrates: "In this area for example, in the beginning I stayed two years there, I spoke the language a little, but I had troubles and could not really learn, really now after some time I was able to find my way with my friends, I found Austrian friends and I can communicate with them. Now my heart became brighter."

Our material also showed that involvement in education in general and in particular German language courses are a very important way of making new contacts. As mentioned above, "subjective" individual determinants as introversion or extraversion proved to be very relevant. Conversely, among the "objective" determinants, time plays a key role, as the longer one stays the more opportunities she or he has to integrate.

I also analyzed the long-term perspective, which means the relevance of social ties in structural integration. Here housing and labor market integration are the most important fields. In some cases, it turned out that even weak ties proved to be very effective in organizing housing opportunities for the respondents. This can be illustrated by the following quote from an interview with a young man: "My first experiences with Austrians were excellent. Actually, I am sharing a flat with an Austrian. He provided me his flat although he doesn't really know me. He left his bedroom to me and my brother and he himself is sleeping in the smaller room. Though he does not know me, he did this all for me. Not even your close relatives would do this for you. The Austrians are really extraordinarily helpful and very affectionate people". 
In the field of labor market integration our sample mirrored that informal help and social contacts play a minor role. Active support for labor market integration by weak as well as strong ties with Austrians was rarely mentioned. There were only a few respondents, who were very optimistic also in expecting support by Austrian friends for realizing the future plans in labor market career on a longterm perspective.

Now, which were the main factors hindering social interactions? It became clear that language problems were among the barriers which were most frequently mentioned by the refugees. Thus, all our respondents were eager to improve their German by attending language courses and additionally by studying on their own. Xenophobia forms a further barrier but in our sample only few refugees spoke of experiences with explicitly xenophobic attitudes. Some refugees did not refer to explicit xenophobia but rather to a kind of general social distance in human interactions. In the words of an Iraqi woman: "It is true that this country is very progressive, but there is almost no social contact between people. There is no care for each other, there is no empathy or sympathy towards other human beings. There is no friend who suddenly knocks at the door and comes for some coffee."

As ISR researcher I was also interested in the relevance of spatial factors. For many respondents the desire for more social contacts with native Austrians went hand in hand with an explicit preference for living in urban spaces due to better opportunities for social interactions. In this vein, an Iraqi woman said: "In the urban context I will have more possibilities to come into contact with Austrian people. By this it is easier for me to integrate and I will learn the language more quickly. In the countryside I perhaps have to live far from civilization and one has only very few contacts with the Austrian population". One has, however, to emphasize that this 
argument was contradicted by other respondents. So, for example a female respondent from Syria stated considerable differences in the openness for social contacts and in their quality between smaller towns in Tyrol where she stayed before and the city of Vienna: “... the people, they were very nice with me when I was in Tirol, they were very, very nice with me, I have to say. ... But, when I came to Vienna, Vienna is a work city. You could easily not know, what is the face of your neighbor, just near your door and you meet him in the building in the stairs, but you didn't know that he is the person, who is living there. It's a very busy life in Vienna."

As the research project was a pilot and exploratory study, the purposive sampling of respondents with specific demographic characteristics does not allow for generalizations. The study focused mainly on the experiences of refugees who were recent arrivals and did not perceive themselves to have fully undergone the process of re-establishing social networks. Therefore, the findings derived on the basis of the interviews were quite idiosyncratic to this specific group. It will be necessary to investigate larger samples of refugees from various ethnic backgrounds and with different characteristics in order to produce a representative picture of the patterns of building up weak and strong social ties in a receiving society for refugees.

\section{Notes}

This is the second post of our blog post series on From Destination to Integration: Afghan, Syrian and Iraqi Refugees in Vienna, edited by Josef Kohlbacher and Leonardo Schiocchet (2017). This book features results, analyses and interpretations of a pilot study conducted by ROR-n. 
Josef Kohlbacher, DDr. MMag., born in 1958 in Lilienfeld (Lower Austria); graduations in social and cultural anthropology, sociology, German philology, history and Egyptology at the University of Vienna; 1984-1987 researcher at the Vienna Museum of Anthropology (Dept. India and the Himalaya regions), field research stays in Northern and Central India and in Egypt; since 1988 senior researcher at the Institute of Urban and Regional Research of the Austrian Academy of Sciences, since 2006 deputy director; main research interests: labour and housing market integration of immigrants, municipal integration policies, interethnic relations in urban neighbourhoods, residential segregation, refugee studies. 


\section{Arrival in Austria. Heteronomy and Autonomy in the Experiences of Refugees}

Monika Mokre

Originally published in 2/20/2018

Integration (or the lack thereof) certainly is a buzzword in public discourses on refugees. It is frequently understood as a form of assimilation, that is, the obligation of refugees and migrants to adapt to the values and culture of the receiving country. Contrary to this, the Austrian National Action Plan (NAP) defines "integration as a two-way process, which is shaped by mutual appreciation and respect, whereas clear rules secure social cohesion and peace. (...) An integrated society is characterized by social permeability and openness. Such a society allows individuals to shape their lives selfdependently, without being discriminated based on their origin, language or skin colour. Integration aims at participation in economic, social, political and cultural processes as well as compliance with related obligations." [1].

Against this background, it is important to ask how refugees can design their lives in Austria, how can they integrate and be integrated in Austrian society. In my contribution to the book entitled "From Destination to Integration - Afghan, Syrian and Iraqi Refugees in Vienna"[2], I analyzed interviews with refugees from Afghanistan, Iraq, and Syria from the following viewpoints:

1. Knowledge of one's own legal situation

2. Assessment of concrete institutions and organizations

3. Assessment of the Austrian state 
4. Impressions of Austria and its population

5. Expectations for the future

\section{Knowledge of one's own legal situation}

Statements on one's own legal situation could be found in nearly all interviews, related either to the actual situation or to descriptions of first experiences in Austria. More than $25 \%$ of the interviewees made statements showing that they have or had insufficient knowledge about their legal situation. The first experiences in Austria are frequently described as extremely confusing and traumatizing. But, also, legal procedures are unclear and, obviously, in many cases not explained to the applicants.

"I have been here for about 7 months, and *-* till now there is no paper and no information about me, I am waiting, I mean." (Sy18)

This situation of confusion can lead to rather far-fetched ideas on the asylum system in Austria.

S10: "In the meantime, two sons have arrived in Austria. They already got asylum. But I did not, as yet. I do not know why. (...) I think they take the young people, not the old people. (...) The old ones, are *_* beyond the expiration date, I think." (S10)

On the other hand, one has also to mention that nearly $30 \%$ have very good knowledge about their legal situation. This includes people in the asylum procedure and people who already passed the procedure and have now the right to stay in Austria. A few interviewees also mention that they help their fellow country people with bureaucratic questions. 


\section{Struggling with Bureaucracy}

Knowledge about one's own legal situation is only a part of the information necessary to create a new life in a new country. In the precarious situation of seeking asylum, a wide range of support measures are needed in order for the asylum seekers to find their position in society and to be able - at least in the mid-range - to live an autonomous life. This begins with legal procedures to get asylum but also includes lodgings and access to education and/ or work.

Overall, the interviewees took a rather skeptical stance on Austrian institutions and organizations. For those in the asylum procedure and, especially, those who have been in this situation for a long time, this procedure poses the most serious problem. And, also, lack of respect in the procedure is mentioned by the interviewees.

"Yeah, for the people they didn't know, they know about your number, you are a number for them, you are a refugee. He didn't look about your background from where you are coming, from which kind of society, from which level of education (...)." (S13)

But even after a positive outcome of the asylum procedure, many bureaucratic problems remain, above all for people who are not granted asylum but receive subsidiary protection or a humanitarian title. Frequently, they feel subjected to arbitrary treatment by individual officials.

Several further issues play an important role for the ability of refugees to integrate into society. In the interviews, we can find detailed descriptions of the bad conditions at arrival and in provisional camps - especially in the summer and fall of 2015, the time of a huge influx of refugees for which Austria had not prepared beforehand. But also apart from the rather extreme situation in overcrowded and, partly, provisional camps, the interviews show 
that conditions are frequently not satisfying with regard to food, clothing, German courses, and internet connection.

\section{Trust in the State}

Interestingly, the interviewees see the Austrian state in general in a much more positive way than the concrete institutions and organizations they are dealing with. It seems that many refugees have kept their trust in a democratic state and rule of law in spite of their own, frequently negative experiences with procedures, institutions or organizations. Above all, the interviewees emphasize their trust in the rule of law.

"All people are treated equally here, irrespective of where they come from. Everybody has the same rights and duties. A country where human rights are respected and applied. I really have to say, this country deserves my full respect." (I2)

\section{Feeling Welcome}

Furthermore, the vast majority of the interviewees has a positive image of Austria and its population - in fact, the image is much more positive than the one of the state and its institutions. Probably, these very positive assessments of Austria are related to the fact that many of the interviewed refugees arrived during the period of the so-called welcome culture and were interviewed shortly after this time. The interviewers explicitly asked for an assessment of the open, liberal, and multi-cultural character of Austrian society - and the answers to that were unanimously positive. 


\section{What Will the Future Bring?}

The interviews were also evaluated with regard to the expectations of the interviewees for their future. However, there was no explicit question on this issue; people were asked about their hopes for the future but not about concrete expectations. Thus, the number of positive, negative, or ambiguous responses was rather low.

Expectations for the future are mostly related to the present situation. Several interviewees with positive expectations are already working or studying or have concrete plans in this regard. Negative expectations frequently derive from a lack in legal security, e.g. in the case of one interviewee with the (very insecure) status of toleration. Ambiguous statements on the future result from a combination of hopes for one's own career with fears for the family in the country of origin or, conversely, hopes for the children in Austria but an expected career disappointment for the interviewee himself.

\section{Conclusions}

This analysis of the interviews has to be treated with caution for several reasons. For one thing, it is based on a pilot study with a limited number of interviewees and no refined sampling procedure. Secondly, it partly deals with issues that were not at the core of the interviews.

However, even if the analysis is not representative it shows some crucial problems of the Austrian asylum system that need to be addressed. Out of everyday mainstream discourse one might conclude that growing fears and xenophobia of the Austrian 
population pose a major problem to refugees. However, at least at the time of the interviews, Austria and its population were mainly seen in a very positive light. The main problems refugees faced were related to the way in which their legal status and their life were organized by state institutions and state-related agencies. Thus, it is obviously necessary to improve these structures and procedures. Everybody has the right to be informed about his/her rights and there have to be clear-cut procedures known and intelligible to everybody concerned. In the case of asylum seekers dependent on public services, this requirement applies not only to their legal status but also to their right to welfare, education, and work. Social cohesion can only be upheld and further developed when newly arriving people have the opportunity to live an autonomous life as soon as possible.

\section{Notes}

[1] BMEIA n/d:. Nationaler Aktionsplan für Integration. (https://www.bmeia.gv.at/fileadmin/user upload/Zentrale/Integr ation/NAP/Bericht zum Nationalen Aktionsplan.pdf)

[2] Kohlbacher, J./ Schiocchet, L. (Eds.) (2017), From Destination to Integration - Afghan, Syrian and Iraqi Refugees in Vienna. ISR Forschungsbericht Heft 45, Institut für Stadt- und Regionalforschung. Wien: Verlag der Österreichischen Akademie der Wissenschaften, pp. 145-166. 
Monika Mokre is a political scientist and senior research associate at the Austrian Academy of Sciences Institute of Culture Studies and Theatre Studies as well as member of ROR-N. She teaches in various contexts, e.g. at the Webster University Vienna and, in spring 2016, as a visiting professor at the Institute of Political Science at the University of Vienna. Her current main interest as a researcher and as a political activist are asylum and migration policies. 


\section{We Want Justice for Afghan Refugees Declaration of Afghan Refugees at the Vienna Refugee Protest} Camp 20171

Monika Mokre, for ROR-n

Originally published in 9/29/2017

By the end of August 2017, a four-day protest of Afghani refugees took place in Vienna. We publish here the demands of the protesting refugees as well as some background information on their situation[1].

\section{The Background}

According to UNHCR, ", the most essential component of refugee status and of asylum is protection against return to a country where a person has reason to fear persecution."[2](UNHCR 1977) This socalled „Non-refoulement"-principle is enshrined in Article 33 (1) of the Geneva Conventions on Refugees: "No Contracting State shall expel or return ("refouler") a refugee in any manner whatsoever to the frontiers of territories where his life or freedom would be threatened on account of his race, religion, nationality, membership of a particular social group or political opinion." [3]

The principle of non-refoulement also applies to people who are not refugees according to this definition if their lives are threatened in

\footnotetext{
${ }^{1}$ This chapter contains is a policy critique by Monika Mokre, for ROR-n, and the full declaration published by the The Afghan Refugees in Austria of the Vienna Refugee Protest Camp 2017
} 
their country of origin. In this case, they are eligible for subsidiary protection when there are „substantial grounds for the presumption that they are at risk of serious harm in their country of origin and that they cannot take up the protection of their country of origin or do not wish to take it up because of that threat. Serious harm can originate from both governmental and non-governmental players. The following are regarded as constituting serious harm:

- the imposition or enforcement of the death penalty,

- torture or inhuman or degrading treatment or punishment, or

- a serious individual threat to the life or integrity of a civilian as a result of arbitrary force within an international or domestic armed conflict."[4]

To summarize: According to international law, EU legislation and national laws of the EU Member States, people must not be sent to a country where they are threatened by inhuman treatment or death. This is an individual right, based on individual situations which have to be assessed individually.

However, the Asylum Procedure Directive of 2013 (APD) [5] opens up the possibility for Member States to define so-called „safe third countries“: (30) „A key consideration for the well-foundedness of an application for international protection is the safety of the applicant in his or her country of origin. Where a third country can be regarded as a safe country of origin, Member States should be able to designate it as safe and presume its safety for a particular applicant, unless he or she presents counter-indications." According to the Directive, this does not mean that individual asylum procedures will not take place for nationals of these countries, however, the European Commission stipulates: „Applications from nationals of countries on the Safe List 
will be fast-tracked, allowing for faster returns if the individual assessments of the applications confirm no right of asylum. This will:

- increase the efficiency of asylum systems.

- deter attempts to abuse the European Asylum System

- allow Member States to devote greater resources to protection for persons in need."[6]

Faster asylum procedures form certainly a valuable political aim; however, fast-tracking here means a fast negative decision. Both the safe-country-principle and the fast-tracking method stand in a certain tension with the individual right to a fair asylum procedure. After all, there are several countries in this world which are safe for some people but not for other ones, e.g. safe for white people but not for people of color or (in rare cases) vice versa, or safe for cis-gender or heterosexual people but not for homosexual and trans-sexual people.

In addition to these fundamental problems of the safe-countryprinciple, in recent years, the EU and its member states have applied a very broad definition of safe countries. Turkey is a case in point: In March 2016, the EU signed an agreement with Turkey allowing to send back all refugees coming to the EU from Turkey. According to EU leaders, this agreement is in full accordance with international and EU law. However, this assessment has been flawed from the beginning as Turkey only signed the Geneva Convention on Refugees but not the Protocol which means, inter alia, that only Europeans can qualify as refugees in Turkey. Furthermore, since this agreement has been signed, Turkey has frequently been criticized for nondemocratic procedures and human rights-infringements. Accession negotiations with Turkey were, thus, once again stopped - but not the refugee agreement. 
Even more surprisingly, Afghanistan has been dubbed a safe country by the EU already for some years. This definition only became relevant in fall 2016 as, at this time, the EU signed an agreement with Afghanistan promising 1.2 billion Euros in development aid until 2020 as an exchange for Afghanistan to take back deported Afghani nationals. [7] This agreement took place after Afghanistan asked in 2015 the EU Member States not to send people back due to the worsening safety situation there. And the UN Assistance Mission in Afghanistan called the first half of year 2016 the worst in terms of casualties since 2009[8]. Even the European Commission itself published in 2016 that it was „difficult to map out the safe areas due to the unpredictability of the conflict on the ground. "[9]

The EU-Afghanistan-agreement makes it possible for EU Member States to send people back to Afghanistan - by deportation or by voluntary return. Whereas it should be noted that „voluntary“ in this case frequently just means that people prefer to go back voluntarily when the only alternative is deportation.[10] However, obviously, the agreement does not oblige any Member State to send people back. Currently, three states carry out large scale deportations to Afghanistan - Sweden, Germany, and Austria.

Germany, however, stopped these regular deportations to Afghanistan for some months after a bomb attack on the German embassy in Kabul in May 2017. From this time until the end of August "only" criminals, and so-called "dangerous people" were deported it should, however, be mentioned that also these people should enjoy protection of their human rights. By the beginning of September, Germany re-started regular deportations.

In the last few months, Sweden and Austria have not changed their deportation practice. The Austrian government has thereby referred to an expert assessment by Karl Mahringer, CEO of several 
businesses active in Afghanistan, Iraq, and Syria. His opinion has been contested in legal procedures[11], contradicted by other experts and does not correspond to assessments by the UN. Still, it is the base for return decisions to Afghanistan in Austria. The deportation of people to Afghanistan stands in contradiction to international conventions signed by the EU and its member states and rhetorically held in high regard by them. Afghani refugees in Vienna protest against this politics threatening their lives and have published the following declaration:

\section{The Declaration}

"Honorable Prime Minister of Austria, Mr. Christian Kern, Leaders of the European Council, the Council of the European Union, the European Parliament, the European Commission, the European Court of Justice, United Nations High Commissioner for Refugees, and relevant authorities,

Since, the withdrawal of the international military forces from Afghanistan at the end of 2014 the security situation in the country has seriously deteriorated with increased civilian casualties and a growing internal displacement crisis in the country. The Taliban and the Daesh/Islamic State Khorasan now control more territory than at any point since 2001 .

The deadly terrorist attacks on civilians in the past 8 months of this year 2017 and the inability of the Afghan government to ensure their adequate protection show that Afghanistan remains an unsafe country for refugees to be returned to. The capital Kabul has suffered the highest levels of civilian casualties, followed by Helmand, Kandahar, Paktia, Balkh and Nangarhar provinces. The other regions, 
where (high profile) attacks are not frequently taking place, are mostly overcrowded by returnees - especially those who have been forced to leave Iran and Pakistan. Even the relief help by International Organizations is not reaching and cannot cover sufficiently the suffering population and their needs.

On the one hand, Afghanistan is seen as a place where armed groups like the so-called Islamic State pose such a danger that the USA felt compelled to drop the world's largest non-nuclear bomb and has forced the Trump Administration to announced a new strategy on 21 August 2017 that calls for more troops to combat Daesh/Islamic State Khorasan, Al-Qaida, Taliban and other terrorist groups operating in Afghanistan.

At the same time, the Afghan government is not capable of reducing harm to civilians, due to corruption and warlords' control over key government security positions; civilians received higher levels of casualties, confirmed by various valuable reports issued by United Nations, Amnesty International and other international organizations.

While civilian casualties remain high, with women and children suffering the worst of the violence, we the Afghan Asylum seekers are forced to return to such a country!?

In issuing this declaration, we put forth the following demands and kindly request the concerned Austrian and EU authorities to respect our rights taking into consideration the international instruments, the EU conventions protocols related to human rights and refugees as follows:

1) Immediately put a halton deportations to Afghanistan, because Afghanistan is not a safe country. 
Considering the volatile security situation of Afghanistan we demand an end to asylum decisions influenced by the inhuman commitment or agreement between the government of the Islamic Republic of Afghanistan and the EU, which fundamentally violates the Convention \& Protocol Relating to the Status of Refugees (1951, 1967). We - in collaboration with humanitarian organizations emphasise that Afghanistan is no safe place for Afghans to return. We want the Austrian government to take a diverse set of official reports into serious consideration giving them a higher priority - and not only mentioning them, such reports as from UNAMA, Amnesty International, and other human rights organizations from 2016/17 compared to singular assessments such as the Mahringer Gutachten.

We are convinced that it is necessary to consider the rise of casualties across the country in suicide attacks; bomb blasts, militant attacks, and rampant violence from both political and criminal elements which serve as a sign of the inability of the state to maintain the security of the vast majority of the population. In this light, we request that both the Austrian government and the European authorities review Afghanistan's safety and security situation anew and acknowledge that Afghanistan cannot be considered a safe country.

2) Immediately reconsider and reevaluate all asylum cases which were rejected based on singular reports - like the Mahringer Report -- as a Basis for Safe return to the Country. Presupposition: Afghanistan is not a safe country.

The Mahringer Report portrays Afghanistan - especially Kabul - as safe enough for a return. However, its assumption about safety rests solely on the major metropolitan centres. While, according to some estimates, there exists a perpetual war in thirty of the thirty three provinces of the Islamic Republic of Afghanistan, today we can no 
longer speak of safe centres as the capital itself is a continuous war scene. Recently, Herat, Nangarhar, Kabul, Paktia, and other urban centres have become a target of the Taliban and Daesh/Islamic State Khorasan where not only military personnel, but also children and elderly have become victims of vicious massacres of civilians. The guideline of UNHCR for protection of refugees from Afghanistan (UNHCR Eligibility Guidelines for Assessing the International Protection Needs of Asylum-Seekers from Afghanistan) has to be taken more seriously and consequently applied. The high amount of internal displaced persons and the lack of economic resources followed by the high jobless rate make a survival in Kabul and a new settlement of former refugees impossible and this procedure is risking their survival. The core of reasoning of the Mahringer report - the traditional supportive networks from former times, has been destroyed by war, conflict, poverty and corruption. Several reports dissent the Mahringer report - not only referring to his estimation of minimum income for survival at Kabul, but also the chances for returnees finding an accommodation or a job and getting support by a social network. Moreover, the networks of anti-government elements - such as the Taliban or the Daesh/Islamic State Khorasan and others are frequently underestimated, as they are acting nationwide in Afghanistan. Consequently, the persecution of concerned persons is crossing provincial borders - and so cities like Kabul cannot offer a safe alternative.

Furthermore, the Islamic Republic of Afghanistan is suffering from chronic corruption and internal divisions that perpetuate a state which propagates instability and insecurity. This has further deteriorated the condition of the average residents of Afghanistan. Therefore, it is a threat to the safety of Afghan asylum seekers to be deported to Afghanistan as the country poses a constant threat to the life of its inhabitants. According to the Convention on the Status of 
Refugees this is a "well-founded reason" to not return to Afghanistan.

\section{3) Provision of qualified interpreters for both the initial interview and the appeal process}

Lack of qualified interpreters has been a major source of misunderstanding and miscommunication which has led to asylum case rejections. It is necessary to have a clear oversight of interpreter staff in the initial interview process, as well as the appeal process in case of initial rejection. This means: adequate training and education of interpreters; ensuring adequate accountability of interpreters through secondary evaluation of the initial interview for appeal process (availability of audio recording and transcripts of the interviews for appeal reevaluation), and of course, has the asylum claimant been sufficiently informed in advance about the right to decline a specific interpreter due to biases perceived by the claimant.

\section{4) Provision of Legal Support for the adequate understanding of refugee rights by the asylum applicant.}

According to the Convention \& Protocol Relating to the Status of Refugees $(1951,1967)$ "a refugee shall have free access to the courts of law on the territory of all Contracting States." (1951 Convention, Chapter II, Article 16) Free access must be interpreted as access to appropriate understanding and representation wherever necessary. Access to legal counsel for the initial asylum interview and throughout the process with adequate interpretation is a right. This right - affordable legal counsel - should be extended to the instance of the highest court.

We need more access to information and judicial advice in our native languages; a quicker handling of our cases; the recognition of our refugee status; and the right to family reunion on timely manner. 
5) Provision of education facilities for children, young adolescents fifteen (15) years of age and older, as well as, young adults for better integration

It is commonly an accepted conclusion among scholars and professionals that integration is directly tied to education of children, youth, and young adults. It is to this end that we request that education - in public schools, as a necessary part of integration -will be available to all refugees - also for those who are over 15 years old and their compulsory school attendance has ended. Vocational training for young adults, as well as language classes for all ages are fundamental to a cohesive integration.

We will continue our protest until all deportations are halted!

Sincerely,

The Afghan Refugees in Austria of the Vienna Refugee Protest Camp 2017“[12]

\section{Notes}

[1] The background information was compiled by Monika Mokre of the editorial team of ROR-N.

[2] http://www.unhcr.org/excom/scip/3ae68ccd10/note-nonrefoulement-submitted-high-commissioner.html

[3] http://www.unhcr.org/3b66c2aa10

[4]http://www.bamf.de/EN/Fluechtlingsschutz/AblaufAsylv/Schut zformen/SubsidiaererS/subsidiaerer-schutz-node.html

[5] http://eur-lex.europa.eu/legal-

content/EN/TXT/HTML/?uri=CELEX:32013L0032\&from=EN 
[6] https://ec.europa.eu/home-

affairs/sites/homeaffairs/files/what-we-do/policies/european-

agenda-migration/background-

information/docs/2 eu safe countries of origin en.pdf

[7] https://eeas.europa.eu/sites/eeas/files/eu afghanistan joint w ay forward on migration issues.pdf

[8] http://politheor.net/afghanistan-a-safe-third-country/

[9] http://politheor.net/afghanistan-a-safe-third-country/

[10] https://www.tagesschau.de/inland/freiwillige-ausreise-

103.html

[11] See

e.g.:

http://www.ris.bka.gv.at/Dokumente/Bvwg/BVWGT 20170623 W $2552149686100 /$ BVWGT 20170623 W255 21496861 00.html

[12] http://no-racism.net/article/5236 


\title{
Against the Wall: Refugees' Artistic Street Performance as Resistant Agency
}

\author{
Amelie Harbisch \\ Originally published in 7/8/2019
}

While there is an extensive literature analyzing the depiction of refugees (in the media and in government-issued documents), the refugees' own agency in their self-representations remains a blind spot. The following analysis of an artistic street performance by a Berlin refugee theater group shows how the refugee actors performatively react to mainstream discourses about them.

\section{Performing (Against) the Wall}

The topic of the street theater performance is "the wall". The performance does not have a title, it was performed only this one time. It is inspired by a scene in an entire theater play that was shown a total of six times, three times already half a year before this street performance and another three times a month after it. The four performers are dressed in overalls painted with bricks, as if they were a wall themselves. The bodily expression of the performers underlines this concept of "person as a wall", as they are moving pressed against the wall and pretending to be held back by a wall around their bodies. Through this combination of kinesic code and contact code (movement and relation to the surroundings, Jaworski/Thurlow 2011), they seem to be trapped in a wall and at the same time forming it. The different parts impersonated are, firstly, a businessman, who wears a tie, holds a bundle of fake money and talks into a phone, repeating stock market lingo like "sell now!"; 
secondly, a border police officer wearing a police helmet; thirdly, a soldier wearing a helmet and holding a fake machine gun; and, fourthly, a public office servant, who holds a stamp and mimics a stamping movement while repeating such phrases as "Declined!" and "We only need skilled workers". These roles refer to the dominant depictions of refugees in the media: refugees are criminals that have to be controlled by the police, and they are only acceptable as useful labor force.

The theatric performance refers to the discourse surrounding bordering, walls and refugees. The connection between "wall" and "refugee" has become famous in the context of Donald Trump's plans for a border wall between the US and Mexico, but also in the visual media discourse on the erection of border fences and walls in various countries on the Balkan route during the European "refugee crisis". Further associations are sparked by the famous photos of (attempted) fence-crossings by refugees in Melilla.

\section{"Nobody Gives Us a Voice, We Take It"}

The group I have researched is part of a theater in Berlin that is built on the idea of a community theater (anonymized to protect my sources). The proclaimed aim is to have no hierarchy. Based on direct democratic and bottom-up processes, employees and youth players decide together. The mission statement is to address social and political issues from the perspective of marginalized youths. The group consists of refugees and non-refugees working together under the motto, "Nobody gives us a voice, we take it!", as stated on the group's website. The concept is that of a self-organized collective with the purpose of self-expression and resistance to sexism and racism, among other things. In this context, the "ideal refugee" is a person that is proactive, political and uses art to express his/her 
political resistance. This ideal in itself is regularly re-negotiated and challenged by participants in weekly group meetings. Important points of discussion are the inability to fulfil this ideal because of limited German language skills and the need to avoid confrontations with the police.

\section{Setting the Scene: Walls Past and Present}

The broader historical context of the theater performance derives from two overlapping stories. First, the historical depiction of refugees in relation to walls: refugees have regularly been shown either behind walls and fences, or in the process of crossing them. This portrayal creates a greater distance between the viewer and the depicted people, highlights the perceived "irregular" character of the forced migrant, and creates an undertone of suspicion towards people who cross well-established (b)orders. Second, Topography of Terror in Berlin and Checkpoint Charlie are the performance sites, and they have a story to tell. The group chose the Located at the longest extant segment of the outer Berlin Wall, The Topography of Terror is an indoor and outdoor history museum located on the former site of Nazi regime office buildings. Checkpoint Charlie is the best-known former crossing point between East and West Berlin and a tourist attraction today. Both sites tell stories of walls and dictatorships that have already been overcome. As tourist sites, they serve both as a place of political education and a source of revenue through folklorist displays of the past: at Checkpoint Charlie, tourists pay to be photographed with people dressed up as former border soldiers. 


\section{Conclusion: Challenging the Borders of the Political}

We see here an instance of a conscious form of agency under the preconditions (scope conditions) described by Hopf (2018): A group of "liminars" are not socialized into seeing the touristic sites as places to talk about the walls that have been overcome. In that sense, they enter the field of tourism "from the outside". The performance uses resources and implicit rules of street theater along with resources from the "refugee experience". They display the duality of the wall: It is an object with the agency of keeping people out, defining inside and outside and establishing distance. In the performance it is also deconstructed as something created by the people on the inside.

The performers create a new understanding of "what a refugee is" by making themselves visible as explicitly political subjects. In this manner, they counter the understanding that political participation is the exclusive prerogative of citizens. This perception is fostered in particular by the humanitarian discourse, which defines "refugees as being incapable of autonomous decision" (Schiocchet 2019), constructs bureaucratic and humanitarian agents as the only conceivable political actors (Malkki 1996), and defines refugees as "bare life" stripped of political agency (Agamben 1998).

The theater performers "reconfigure the materiality of public space, and produce, or reproduce the public [and political] character of the material environment" (Butler 2011). The aim is not to change a depoliticized place created by the historicization and marketization of the history of walls into a political place. Instead, they show that the attempt to depoliticize the question of walls is political in itself. As these results were not the explicit conscious goal of the group, there is unconscious agency attached to it (see Hopf 2018 for the fact that one cannot know all the consequences of one's subversive acts). 
What is more, the performance ironically juxtaposes the nexus of tourism, political education, and the narrative of walls long since overcome on the one hand with the experience of the majority of people that walls are very much alive on the other.

Such street performances show how refugees gain agency in resignifying the great medias' image of "the refugee" by challenging and ironically recoining characteristics assigned to it. Because state borders and the concept of citizenship remain barriers to the official institutions of political participation, the performance also points out that "politics" are not only enacted in state-centered (international) organizations and institutions, but in the streets as well.

\section{References}

Agamben, Giorgio (1998): Homo sacer. Sovereign power and bare life. Stanford, Calif.: Stanford University Press (Meridian : crossing aesthetics).

Butler, Judith (2011): Bodies in Alliance and the Politics of the Street. Available online: http://eipcp.net/transversal/1011/butler/en. Hopf, Ted (2018): Change in international practices. In European Journal of International Relations 24 (3), pp. 687-711. Jaworski, Adam; Thurlow, Crispin (2011). Gesture and Movement in Tourist Spaces. In Jewitt, Carey (Ed.), The Routledge handbook of multimodal analysis (pp. 253-262). London: Routledge.

Malkki, Liisa H. (1996): Speechless Emissaries. Refugees, Humanitarianism, and Dehistoricization. In Cultural Anthropology 11 (3), pp. 377-404.

Schiocchet, Leonardo (2019): Palestinian Refugees in Brazil between Nations and Humanitarian Tutelage [Blog post]. Retrieved from 
http://www.ror-n.org/-blog/palestian-refugees-in-brazil-betweennations-and-humanitarian-tutelage1.

Amelie Harbisch is a doctoral student at the Otto-Suhr-Institute for Political Science of the Free University Berlin. Her research within the framework of the Berlin Graduate School for Global and Transregional Studies (BGTS) deals with the performative self-making of refugees against the visual media discourse about them. Her research interests include visual discourse analysis, Practice Theory, Foucault and performativity/performance approaches in the study of forced migration. 


\section{Asylum Procedures Shortcomings in Tunisia: What do external borders mean for the EU?}

Valentina Grillo

Originally published in 6/14/2016

In the last years, the European Union (EU) has pursued a geopolitical strategy that, as far as migration is concerned, has had serious impacts in its neighbouring countries. In the frame of the EU's foreign policy, North Africa is one of the three areas of interest. This contribution highlights European migration policies, and the making and maintenance of European external borders through the example of Tunisia. In particular, it engages the following questions: what do the external borders mean for the EU and what are their impacts for refugees in Tunisia?

Following EU's interest in curbing forced migration into Europe, in March 2014 Tunisia signed the Mobility Partnership (MP) agreement with the EU. Before committing to the partnership, Tunisia had already signed the 1951 Geneva Convention relating to the Status of Refugees and its 1967 Protocol. Moreover, regional instruments provided protection for asylum seekers and refugees, as well: Tunisia had signed the Convention Governing Specific Aspects of the Refugees Problems in Africa (the OAU Convention) that extends the notion of refuge to situations of civil war. It was against this background that, on March 3, 2014, international organizations and the EU committed themselves to develop a more comprehensive asylum system in Tunisia. Among the measures, the MP outlined a mutual intervention in migration in Tunisia through six sections. While the focus of the agreement is in training local authorities to 
identify those who are able to benefit from international protection and to process their asylum requests, the notion of providing refuge appears to be reduced to the ability to identify refugees. Furthermore, only the first article of the fourth section (art. 24) highlights the necessity to develop national laws concerning asylum in conformity with the 1951 Geneva Convention, and its 1967 Protocol and overall fundamental principles - i.e., non-refoulement (art. 25).

Tunisia has around 1,000 refugees coming mainly from Sudan, Somalia, Eritrea and Libya. Around 10\% of them live in the southern regions of the country, such as in Medenine, Tataouine and Ben Gardene. The lack of an internal organ recognizing refugees and, on the whole, of a national legal system, largely constrains the refugees' lives. For instance, refugees are not allowed to sign any kind of legal contract because by law they are not recognized as Tunisian subjects, and therefore they are not officially allowed to work. Besides, no local or international institution supports them financially.

Refugees in Tunisia live in harsh conditions and only very few told me they expect anything from the asylum system. Ahmad[i], for example, is a novel writer and comes from Sudan. He describes himself as an activist for human rights, for which his life was put under serious risk in Sudan. Due to his political activism, after the explosion of the Libyan Revolution in February 2011, he had to escape along with his family and had no other choice but to take shelter in Tunisia. Like Ahmad, other asylum seekers and refugees I interviewed think of Tunisia only as a transit country. However, only a few refugees still consider to "have the chance" to be resettled in a third country.

Resettlement in a third country has been granted to 2,409 refugees from Choucha refugee camp[ii]. In 2013, nevertheless, the 
emergency situation in Libya ceased to be the focal point in the international scenario and probably for this reason, as a Tunisian stakeholder argued during an interview, resettlement in third countries sharply decreased. Authorities still proclaimed the necessity to develop sustainable human mobility strategies, which lead to the signing of the MP. Nevertheless, no legal improvement has been made so far in the country. As Ahmed underlined several times, the 'inhuman' conditions of refugees' lives and the lack of a way to legally leave Tunisia bring refugees to a dead-end: if they cannot stand the living conditions in Tunisia - that he metaphorically addressed as the 'desert' - refugees have no other choice apart from crossing the Mediterranean Sea with makeshift boats and by any other precarious means.

So, is it possible to keep refugees in Tunisia, where - despite the presence of international actors - there is no formal system of protection and refugees find themselves living in dire conditions? According to its mandate, the UNHCR could expand its competences, and since 2011 it has remained the only accredited organ issuing refugee mandate statuses in the country. According to UNHCR Statute, General Assembly and ECOSOC resolutions, mandate refugees are: refugees within the meaning of the 1951 Convention and the 1967 Protocol, and those who "come under the extended refugee definition within UNHCR's mandate because they are outside their country of origin or habitual residence and unable or unwilling to return there owing to serious and indiscriminate threats to life, physical integrity or freedom resulting from generalized violence or events seriously disturbing public order and who, as a result, require international protection" (UNHCR 2011). The UNHCR's international protection mandate covers the group of persons who might be refugees as defined in regional refuge instruments. UNHCR conducts Refugee Status Determination (RSD) procedures on the basis of the 
1951 Convention, the 1967 Protocol, and, in particular, article 35 of the Convention. With concern to article 35, states "undertake to cooperate with UNHCR in the exercise of its functions; and shall in particular facilitate its duty of supervising the application of the provisions of the Convention". Signatory members of the 1951 Convention and its 1967 Protocol, are bound by agreement to accept UNHCR's authority in providing refuge and to cooperate with them. Even in Tunisia, despite the absence of a national asylum system dealing directly with RSD procedures, the UNHCR is able to issue refugee mandate statuses.

Since 2014, UNHCR offices throughout North Africa have witnessed an increased number of asylum seekers (UNHCR 2016). At first sight, many could interpret this figure as the result of many asylum seekers wanting to stay in the region. However, the asylum seekers' and refugees' difficult living conditions in Tunisia discredit such hypothesis. The fact that refugees are not formally recognized by Tunisian authorities makes both refugees and the difficulties they face often invisible. For instance, Mohamed's experience brings evidence to this point. Mohamed is a 33 years old Sudanese refugee and used to travel from Ben Gardene to Djerba, where he used to work. Once, on the way back to Ben Gardene, he was stopped for a control. Police brought him to prison and refused to recognize the document that, issued by UNHCR, certified his refugee mandate status. When he finally mentioned that he was coming from the Choucha refugee camp, he was released. The precarious condition of refugees in Tunisia does not enable them to settle permanently in this country. Moreover, it leads to complications in fundamental spheres of everyday life, like the job market. Yakub, a 23 years old refugee from the Darfur region, for example, reports having been seriously injured at his boss' command after having complained to him about not having been paid. Yakub was employed irregularly 
because refugees are not entitled to be part of regular contracts in Tunisia, thus no legal contract could have protected him from exploitation.

While the UNHCR started issuing refugee mandate statuses in the country, the EU has not yet put forward any measures in order to develop substantial legal frameworks. But even the UN mandate is limited. While it financially supports refugees only in the north, it has no budget to take care of the refugees in the south. Since the Tunisian government does not cover any costs related to refugees anywhere in the country, this gap is covered by many international organizations, institutions or NGOs, but refugees still face evergrowing challenges to cover basic costs, such as food, health care and shelter.

In conclusion, the political objective promoted by the EU through the MP, that is, keeping refugees in Tunisia, is achieving its aims without the development of an efficacious protection system. At this point, one could argue that the MP's main objective is not the protection of refugees, but the protection of Europe against refugees. In this scenario, external borders have the role of fortifying the European migration apparatus that objectifies migration into categories in order to control and harmonize its management (Feldman 2011). Border management becomes sealing off borders, instead of providing refuge and protection of human rights. Indeed, if the development of a national system of protection is the first step in order to provide refuge as it has been occasionally defended (UNHCR 2001), one can definitively affirm that no protection is provided to refugees living in Tunisia. 


\section{Notes}

[i] Every individual mentioned in this text was given a fictitious name, so as to protect my interlocutors' integrity.

[ii] Choucha refugee camp was established in March 2011 in southern Tunisia in order to shelter 4,000 refugees fleeing Libya. It was officially closed in June 2013.

Valentina Grillo completed her MA in Social and Cultural Anthropology at the University of Vienna (April 2016). Her thesis discussed forms of refugee resistance in Tunisia, building on three months fieldwork she conducted on refugees and the so-called "rejected refugees" in the Choucha refugee camp and Ben Gardene, Tunisia. This research was funded by the KWA programme (Kurzfristige wissenschaftliche Auslandsstipendien). 


\title{
Refugees of the Syrian conflict and the struggle for housing in Brazil
}

\author{
Mirian Alves de Souza \& Helena de Morais Manfrinato \\ Originally published in 3/23/2019
}

In 2016, most asylum requests in Brazil were from Syrians. Governmental data for the 2010-2016-period indicates a total of 3,460 asylum requests and 2,298 recognized Syrian refugees in Brazil. In 2016 alone, 326 Syrians and 57 Palestinians from Syria had their requests for refuge approved in Brazil. While this is a small number if compared to total number of Syrian and Palestinian refugees in the world, how these refugees engaged the housing struggle in Brazil can shed light on the complexity of the Syrian refugee crisis. We prefer to use here the term "refugees from the Syrian conflict", for it considers people affected by the conflict, which started in 2011, and includes Syrians and other national groups affected by the war, like Palestinians living in Syria.

Upon the expansion of the conflict in Syria, representatives of the Brazilian Arab community, with the support and intermediation of sectors of the Catholic Church, contributed to put in place a governmental resolution to facilitate the entry of persons affected by the Syrian conflict to Brazil. This resolution considered other national groups, such as Palestinians living in Syria, extending protection to them. This by no means follows international standards, since most commonly these individuals, although affected by the war, were left out of protection programs.

In large cities in Brazil, such as São Paulo, people affected by the Syrian conflict live in squats organized by social movements. Terra 
Livre[1] is one such social movement. It was founded in 2008 and works by occupying abandoned buildings and terrains with the goal of constructing popular housing. The organization has many occupations in Great São Paulo, which today house a total of more than two thousand people. Since both groups were involved in the struggle for land and home rights, the plight of the refugees from Syrian conflict and of Terra Livre appealed to each other, and some of these refugees went to live in the Leila Khaled occupation[2], organized by Terra Livre with the support of MOP@T[3] (Movimento Palestina para Todos, or Palestine for All Movement in English).

MOP@T is a pro-Palestine movement, formed by Brazilians and Palestinians born in Brazil, which until the occupation used to perform actions aimed at making visible the Israeli occupation and the injustices inflicted on the Palestinian people. This movement was originally founded to help Palestinian refugees coming from the Iraq War[4]as a reaction to the abandonment of such refugees by the Palestinian organizations in Brazil[5]. Throughout the years, the movement's focus became organized around the creation of means to promote the visibility of the Palestinian question in Brazil, especially among social movements and left-wing parties through an internationalist struggle perspective. Although some of its members were Palestinians born in Brazil and others were Brazilians interested in the political questions of the Middle East, its formal objectives and political language had a socialist character, and its relations stretched towards unions, left-wing parties and social movements.

In 2015, MOP@T became aware of Palestinian refugee families that had come from Syria and were living in São Paulo, paying expensive rent for boarding in distant neighborhoods. Considering the strategic importance of Downtown for refugees - where they have access to 
jobs, schools, hospitals and the supporting NGOs - MOP@T asked the housing movement, Terra Livre, for space in one of its occupations. After agreeing on a partnership, sixty Palestinians flocked to the occupation and occupied four stories of the old commercial building.

The occupation takes place in an eleven-story building that belonged to a Brazilian state-owned telephone company. Abandoned for over fifteen years, this building was occupied by Brazilians and foreigners alike. Despite all its infrastructure issues, interlocutors reported that they lived in very precarious situations prior to moving there. The name of the occupied building is a reference to the Palestinian activist, Leila Khaled. The suggestion was made by one of Terra Livre's militants, following the movement's premise of choosing names from notable and politically combative women. The Palestinian Leila Khaled is known in the imagination of the Brazilian left as a guerrilla fighter who in her own time fought for the liberation of Palestine from the occupation of its territory. Until 2016, the Leila Khaled occupation sheltered, Brazilians - mostly lowincome workers -immigrants from Egypt and Peru, and refugees from the Syrian conflict. Multiple senses of belonging are present among refugees of the Syrian conflict, and since most of them are of Palestinian origin, most affirm their national identity and recount their two-fold flight. As argued by an interlocutor: "I'm not Syrian, I'm Palestinian. I am a refugee from Palestine. This is a war among Syrians, my war is the one that expelled my parents from Palestine. (...) Now, I am a refugee, twice."

The occupation provides refugees and other residents with housing and a venue for political participation. In accordance with Brazilian law, foreigners are not entitled to political rights, such as the right to take part in public demonstrations of a political nature. As Helena Manfrinato's research points out, the reception of refugees from the Syrian conflict, especially after the global media coverage of the 
humanitarian crisis in Syria in 2015, emphasized humanitarian issues. Activism and social and political engagement in refugee and immigrants' rights were circumscribed to the environments of political articulation in the context migrants' movements and other groups like MOP@T. With the Leila Khaled Occupation, a window was opened not only for the visibility of the political struggle for housing and refugees' rights, but also for connecting different institutions such as social movements and mosques, Christian charity organizations and volunteers that promoted assistance to vulnerable families.

Concomitantly, Mirian Alves de Souza's research[6]focuses on accommodation policies and actions for refugees of the Syrian conflict and determined that accommodation policy in Brazil is ruled by faith-based organizations, mostly Christian, that receive funds from the Brazilian state through agreements and partnerships with the UNHCR. Thus, the provision of accommodation for refugees in Brazil is couched in the language of compassion and charity. Besides, since state and UNHCR's funds are always minimal, organizations are not obliged to respond to the ever-growing collective demands. By contrast, the Leila Khaled Occupation presents a different scenario. The language used is that of rights, of "class solidarity" and of "solidarity among peoples", instead of compassion in the humanitarian sense. This occupation's existence originates from the recognition that housing is a right to be claimed. To its organizers, activists of Terra Livre (whose red flag can be seen on the buildings' façade), hosting refugees is the duty of the Brazilian state, as refugees do not have access to the city because of "real estate speculation". Cost of living in the city of São Paulo, as well as in the city of Rio de Janeiro, makes it impossible for refugees to stay in Brazil[7].

To conclude, both researches point out that while housing rights are shared by all, Brazilians and non-Brazilians alike, the right to engage 
in political struggle is not guaranteed to foreigners. But for the activists of Leila Khaled, the struggle for housing and for political rights is one and the same. For Palestinian families, to live together as neighbors - like some used to do in Palestinian refugee camps in Syria - achieved an advantage as important as getting affordable housing in downtown São Paulo. It permitted the reconstruction of the camp's modes of socialization in their coexistence and shared everyday life, their mutual help and belonging.

\section{Notes}

[1]https://www.facebook.com/TerraLivreCampoCidade/?fref=men $\underline{\text { tions }}$

\section{[2]https://www.facebook.com/refugiadosnaocupa/}

\section{[3]https://www.facebook.com/movimentopalestinaparatodos}

[4]4: In 2008, 117 Palestinians from the Al Rweished camp - formed after the Iraq War - went to Brazil and settled in Rio Grande do Sul and São Paulo, in cities with large Arab-Muslim communities.

[5] See Hamid, 2015.

[6]This postdoctoral research has been developed since September 2015 at Centro de Estudos em Direito e Política de Imigração e Refúgio (Center for Studies on Immigration and Refuge Law and Policy) of Fundação Casa de Rui Barbosa, through a grant from the Brazilian Ministry of Culture.

[7]Refugees still tend to prefer these cities, mainly São Paulo, because it has a large Arab-Muslim community, which has mosques, and it is where the NGOs of refugee assistance are concentrated. 
Mirian Alves de Souza is Professor of Anthropology at the Universidade Federal Fluminense, Brazil, where she is also researcher of the Center for Middle East Studies (NEOM-INEAC-INCT/UFF). Her postdoctoral research focused on refugee and migration policies in Brazil (Fundação Casa de Rui Barbosa 2015-2017). Most recently, she has dedicated her efforts to the study of Syrians refugees in Brazil, focusing on the negotiation of religious and political identities in the diaspora and the management of organizations involved in the process of refugee protection and asylum.

Helena de Morais Manfrinato is a doctoral student in the Social Anthropology Program of the Universidade de São Paulo and works at the Religion and Public Sphere Research Center (PPGAS/USP). Her research is about Palestinian refugee families in the Leila Khaled urban occupation and its notions of Palestinian diaspora, blood and family, as well as the impact of left-wing movements, humanitarian help and the war frameworks of the Syrian conflict. 


\title{
Refugees and the Echoes of the Conflict in the Diaspora
}

\author{
Silvia Montenegro \\ Originally published in 8/12/2016
}

In June this year, on his return from a trip to the United States where he met Barack Obama's National Security Adviser Susan Rice, Marcos Peña, the Chief of the Cabinet of Ministers of the centreright government ruling Argentina since December 2015, stated that the country will receive 3,000 Syrians. This was officially announced as a commitment by Argentina to help solve the humanitarian crisis triggered by the conflict. However, the news was "read" by some sectors of society as a move by the current government to show its willingness to align itself with the United States. The first two presidents to visit Argentina just a few months after the new government's inauguration, Barak Obama in March and François Hollande in February, had allegedly requested this cooperation. It is as yet unknown when or how this policy, which would significantly increase the percentage of Syrians received so far, will be implemented. After the announcement, the Diario Sirio Libanés published an article warning that this new migration policy had been established by the CIA and the MOSSAD, which may hereafter play a key role in selecting visa recipients, and that this would imply a decrease in the Syrian-Lebanese community's involvement in the implementation of admission programmes.

In October 2014, the previous government headed by Cristina Kirchner had put into force the Syria Programme (Programa Siria), an initiative enabling access to a humanitarian visa for people of Syrian nationality and their families, as well as for people of 
Palestinian nationality who usually live in Syria or would have lived there receiving assistance by the UNRWA. Only 197 Syrians entered the country through this programme, another 286 entered after 2011 through several means, obtaining refugee status, and unofficial figures suggest a total 1,000 Syrians arriving over the last 5 years. In order to launch the Syria Programme, the former government appealed to the local existence of a large, organised Syrian-Lebanese community, with institutions scattered all over the country, declaring that from the beginning the Sunni-oriented Islamic Centre of the Argentine Republic (CIRA by its acronym in Spanish), the Federation of Argentine-Arab Entities (FEARAB by its acronym in Spanish) and San Jorge orthodox church would assist in implementing the programme.

Regardless of the policies executed by the previous government or the current government's plans as regards permitting the arrival of 3,000 Syrians, what I am interested in stressing is that the SyrianLebanese community's perception of refugees has as its backdrop the way in which the conflict is understood at the local level. That most community organisations support the Syrian government and reject the classification of the conflict as a "civil war" is partly true, but there are nuances among positions and arguments should be seen in the light of the community's inner diversity. Not all actors, organisations and mouthpieces participate in the same way; some merely call events for the Peace in Syria, others prefer not to speak up, there are even different views within some entities or a gap between the discourse by some representatives and those they are supposed to represent. We could not reflect such complexity here, but we can emphasise that a significant portion of the community is visibly active and takes a public stance. Which are the broad arguments underlying the nuances? Some support Bashar al-Assad as they consider him a leader who resists in the face of aggression, 
others put forward the "lesser evil" doctrine, meaning that it is better to have him rather than those who might take power should he be overthrown. Therefore, in demonstrations and events since the conflict began it is common to see pictures of Bashar and Hafez alAssad together with Syrian flags and other nationalist symbols. Some religious communities and their leaders, such as Shiite and 'Alawi Muslims, agree on the position of other entities making up the larger space of Arab organisations, such as the Federation of Arab Entities (also because over the last years it has been led by Shiite Muslims), or with institutions such as the non-religiously-oriented Syrian Cultural Association, some of whose leaders support the Qawmi Suri party, and which takes specific actions to help the Syrians received so far. Beyond diversity, these sectors agree that it is a conflict organised by foreign powers, by countries that have historically antagonised Syria and that make up an alliance today (France, Britain and the United States), supported by Turkey, Saudi Arabia and Qatar. Thus, the notions of imperialism and colonialism are part of these arguments. The actors fighting in the armed struggle within Syrian territory are characterised based on the national army/terrorist dichotomy. Another argument relates to how the diaspora imagines the Syrian nation -as a secular country previously characterised by the peaceful coexistence of various religions and expressions of Islam. Moreover, the role of Syria in the context of the Middle East is another aspect seen as the target of external attacks; the aim is to subdue the only party maintaining a frontal opposition to Israel, which used to act as a guardian of Palestinian resistance and, hence, of the great Arab causes. Another point of almost unanimous agreement is the view on the future of the crisis, where extensive optimism prevails concerning a definition in favor of the Syrian government. With or without a transition or a change in government, Syria is expected to succeed in repelling what is merely seen as foreign interference. 
Leftist parties, which in Argentina tend to support demonstrations and events in favor of the "Arab causes", have adopted since the beginning of the conflict a distant attitude from these more actively engaged Arab community organisations. The socialist left making up the Left Front (Frente de Izquierda), for instance, has held public rallies burning pictures of Bashar al-Assad, with speakers labeling the Syrian president as genocidal and dictatorial, denouncing his covenant with the United States, Europe and Russia in order to stay indefinitely in power and to suffocate the rebellion of the Syrian people, spreading this position among university militancy spaces. In May this year, a delegation of the Left Front met with the Argentine Foreign Office to claim greater flexibility for the Syria Programme, requesting that the certificate of good conduct requirement for visa applicants be eliminated and that the Argentine government commit itself to receiving 100,000 Syrians who, from the viewpoint of these leftist organisations, are fleeing Bashar al-Assad's dictatorship.

Clearly, refugee policies and actions fall under the realm of readings of the conflict by local actors, and the government's announcement is already giving rise to new debates and side-taking.

Silvia Montenegro is a researcher at the National Scientific and Technical Research Council (CONICET, Argentina), and professor of anthropology at the Universidad Nacional de Rosario, Argentina. She received her PhD in sociology from the Universidade Federal do Rio de Janeiro in Brazil. Her areas of interest are Muslim identities, relations between religion and ethnicity, the practices of transnationalism, and diasporic communities (of Arab and Muslims in Latin America). 


\section{How (not) to scapegoat Refugees: Lessons from Vienna's Election Campaign on Facebook}

Liriam Sponholz

Originally published in 12/20/2016

In the summer of 2015, Europe experienced what some claim to have been the largest humanitarian crisis in the region in decades[1]. At that time, many thousands of people fleeing conflict regions, particularly Syria, crossed European borders in search of international protection. Their main destinations were Germany and Sweden. The situation transformed Austria into the most important transit country in Western Europe, with its capital Vienna becoming a key focal point. Right at the peak of this crisis, the Austrian capital held its mayoral election. Refugees became the main issue during the election campaign which polarized the Austrian political spectrum.

Facebook assumed a pivotal role in this scenario of polarization. Right-wing populists have instrumentalized it politically in a very successful way[2]. In Austria, the Facebook account of their leader Heinz-Christian Strache is the most popular in the country.

Political communication on Facebook enables nonpublic figures to take the floor as well and enhance the interaction between citizens and politicians[3]. In addition, Facebook in particular works as an arena, where users are virtually urged to take a position on current issues. This feature belongs to the modus operandi of this social networking site as public sphere. In order to trigger the engagement of users, politicians on Facebook must provide messages that generate controversy. Because of that, user engagement is not only feedback, but rather backlash. 
Users can react to posts on the Facebook wall of candidates and parties with likes, shares or comments. Such forms of user engagement require and show different levels and meanings of engagement[4]. In general, a comment requires more engagement from users than a like. Comments are also the main and clearest way to show disagreement.

\section{Learning from Vienna}

Vienna's mayoral election campaign on Facebook was a privileged case for analyzing some hypotheses about media representations of refugees that one can seldom observe empirically in other contexts. As earlier studies show, refugees are mostly depicted negatively in the media, so that the chances of being able to analyse the role of positive representations are extremely rare.

In Vienna's mayoral election campaign, this was not the case. In order to compete with the right-wing populist positions, other parties such as the Social Democrats and Greens posted intensively positive depictions in the wave of the so-called "welcome refugeesculture". As these political forces were the most active in publishing posts, the majority of the posts on refugees of the competing parties and candidates for the office of Vienna's mayor were positive depictions.

On the other hand, the depiction of refugees was not able to counter the representations put forward by right-wing populists. Although Heinz-Christian Strache published fewer posts than the Greens and the Social Democrats, messages on his Facebook wall unleashed far more likes, shares and comments. Depictions of refugees on Strache's Facebook wall were overwhelmingly negative, displaying 
people seeking protection as terrorists and as a threat to the Austrian cultural identity and economy.

\section{Triggering user engagement}

To what extent can such user engagement be attributed to the refugee issue itself?

In all Facebook-accounts of the five main parties and candidates in Vienna's mayoral election (NEOS; Greens, Social Democrats, conservatives and right-wing populists), posts about refugees unleashed more user engagement than posts about other subjects.

Regarding valence, as expected, on the Facebook walls of the Greens, positive depictions of refugees on average got more likes, shares and comments than depictions associating refugees with problems (as, for instance, the causes of the crisis). Nevertheless, this only happened in the case of the Greens and the newcomer party NEOS, keeping user engagement at a lower level.

Considering all posts (and not only those about refugees), in all accounts user engagement was higher by posts providing a depiction of an undesirable or an uneasy situation than by those with positive messages. To sum up: user engagement was triggered by problems. The same occurred with the single posts that received the biggest number of likes, shares and comments in the sample.

Notwithstanding, the "success" of right-wing populists on Facebook is not only due to the refugee issue and its problematization. Parties and candidates are using Facebook for different means in their political communication. 
The visibility of most parties in this campaign on Facebook seemed to reflect the internal party structure, by having one Facebook account on the national, another on the local level and a third one for the candidate, instead of having just one single Facebook wall. This had the effect of dispersing instead of channeling utterances and users from their own political spectrum. Right-wing populists, in turn, presented themselves during the campaign on only one Facebook page (Heinz-Christan Strache). Presenting their political platform on only one page during this campaign facilitated rightwing populists bringing users and positions together in their opinion spectrum where they reacted and articulated amongst each other.

\section{Countering discrimination}

The single post with the highest user engagement besides Strache's page was about a Green Party initiative calling for donations to be made during a speech by the right-wing candidate at a special parliamentary session about the humanitarian crisis. Members of Parliament could make donations to under-age refugees by putting money into a glass urn on the table of the Green Party leader in the plenary session every time the right-wing populist stated something that was untrue. With this action, the Greens re-defined the refugee issue as a power struggle in the host society, and not as the refugees themselves. In a nutshell, the Greens did not unleash more user engagement by positive (unproblematic) depictions of refugees, but by providing a new definition of the problem: it is not refugees, but right-wing populists who are the problem.

In order to understand, why "positive" representations do not work, one must consider that media agenda is first and foremost built up by conflicts[5]. This is an intrinsic feature of media logic and usually 
perceived as "negativity". In order to reach and to stay on the agenda, a media message should activate positions pro- and contra. In other words, it must generate a communication conflict or, as Luhmann[6] would say, bring speakers to utter contradictions. Positive images of refugees usually do not urge speakers in the media to take a position, as unproblematic depictions as a whole.

This media operational bias is not only about refugees. When media contradicts its "nature" and produces positive depictions in controversial issues, even recipients distrust such depictions and become hostile to media[7].

In order to tackle the scapegoating of refugees in public discourse, media and public figures need other issues or problem definitions. In this sense, the "problem" in a humanitarian crisis does not have to be the refugees themselves.

\section{Notes}

[1] Connor, Phillip (2016, August). Number of Refugees to Europe Surges to Record 1.3 Million in 2015. Recent wave accounts for about one-in-ten asylum applications since 1985. Retrieved from http://www.pewglobal.org/2016/08/02/number-of-

\section{refugees-to-europe-surges-to-record-1-3-million-in-2015/}

[2] Spyridou, Paschalia-Lia, \& Veglis, Andreas (2011). Political Parties and Web 2.0 Tools: A Shift in Power or a New Digital Bandwagon? International Journal of Electronic Governance, 4(1/2), 136-155; Strandberg, Kim (2013). A Social Media Revolution or Just a Case of History Repeating itself? The Use of Social Media in the 
2011 Finnish Parliamentary Elections. New Media \& Society, 15(8), 1329-1347.

[3] Sweetser, Kaye D., \& Lariscy, Ruthahn W. (2008). Candidates Make Good Friends: An Analysis of Candidates' Uses of Facebook. International Journal of Strategic Communication, 2(3), 175-198.

[4] Sarapin, Susan, \& Morris, Pamela (2014). When »Like«-Minded People Click: Facebook Interaction Conventions, the Meaning of "Speech" Online, and Bland v. Roberts. First Amendment Studies, (48)2, 131-157.

[5] Cobb, Roger W., \& Elder, Charles D. (1972). Participation in American Politics. The Dynamics of Agenda-Building. Baltimore/ London.

Luhmann, Niklas (1991) Soziale Systeme.Grundriß einer allgemeinen Theorie. Frankfurt a. M.: Surkhamp.

[7] Arlt, Dorothee, \& Wolling, Jens (2016). The Refugees: Threatening or Beneficial? Exploring the Effects of Positive and Negative Attitudes and Communication on Hostile Media Perceptions. Global Media Journal (German edition), 6(1). Retrieved from https://www.db-

thueringen.de/servlets/MCRFileNodeServlet/dbt derivate 000354 90/GMJ11 Arlt Wolling final.pdf

Liriam Sponholz is Senior Postdoc at the Institute for Comparative Media and Communication Studies of the Austrian Academy of Sciences and Alpen Adria University Klagenfurt. After concluding her PhD at the University of Leipzig, she held teaching positions at the University of 
Erfurt (Germany), was guest professor at the Federal University of Santa Catarina in Brazil and at the Complutense University of Madrid in Spain and has also published several articles and books. Her research interests include journalistic objectivity, media conflicts and hate speech. 


\section{$\underline{\text { Reflections on Migration and Democracy [1] }}$}

\section{Monika Mokre \\ Originally published in 5/19/2016}

In the words of the French revolution, democracy is based on three fundamental values: liberty, equality, and fraternity. This wellknown triad forms an aporia if we maintain that democratic rights should be universal: The acceptance of equal liberty of different individuals is based on a quasi-family relation between them[2]. In contemporary democracies, this family relation is called the nation.

Nations are a construction which became necessary in order to create cohesion in large-scale societies[3]. Over the centuries, this construction has proven extraordinarily effective - it is the base of our thinking, our legal system, our rights and the denial of these rights to those who are not nationals. While European integration has somehow blurred the sharp dividing line between nationals and foreigners, it has done so only with regard to other Europeans, thus, adding a supranational limitation to the national one.

Each society needs cohesion - and cohesion is based on inclusion and exclusion[4]. This holds especially true for democracy as selfgovernment of the people as, here, the first obvious question is: Who is the people? The nation state has a clear answer to that, an answer, however, which is less and less adequate to contemporary migration societies: How democratic is a society in which more and more people are subjected to legislation which they cannot influence?

One argument in favor of this existing political order maintains that, after all, there are universal rights, namely human rights and rights derived from human rights, such as refugee rights. However, these rights are not political; they cannot be enlarged or fought for by those 
to whom they apply. [5]And, thus, as we can see nowadays, it is, in fact very easy to take these rights away or, at least, to water them down to a degree that they are no longer recognizable.

Democracy is always, at the same time, particular and universal. The definition of those who should govern themselves, i.e. of "the people" is part and parcel of democracy as an existing political system. On the other hand, the claim for continuous democratization, for enlarging democratic rights is a necessary and essential feature of democracy as an ideal, a horizon[6]. Democracy is, thus, particular in its implementation and universal in its aspirations. Democracy is a promise and a claim - and this claim has been taken up by many movements over time, the suffragette movement, the black movement, the movement for LGBT rights, movements for social rights and welfare for every citizen etc.

Nowadays, movements of migrants and refugees claim their democratic rights. These movements are confronted with nationalist counter-movements. Both groups fight for "their" rights, the rights of its members and the people they (want to) represent. Still, normatively, these fights do not take place on the same terrain. Nationalist movements try to limit rights to specific groups; they defend "their rights" against others who want the same rights. Movements of migrants and refugees question the existing order and their marginalization in this order - and, in this way, they question all forms of marginalization. As every other democratization movement, also these movements are formed by those "without part" [7].

While migrants and refugees are nowadays frequently seen as a danger for democracy, out of these reflections one can come to the opposite result: Those who are excluded from democratic rights further develop democracy by their claim for inclusion. 
Thus, once again, in history, democracy is fought for by those excluded from democratic rights. In the words of Étienne Balibar: "So the Sans-papiers, 'excluded' amongst the 'excluded' (...), have stopped appearing as simply victims and have become actors in democratic politics. They have helped us immensely, with their resistance and their imagination, breathing life back into democracy. (...)The more these demands are understood and relayed by the citizens of our countries, the more political language and practice, today dangerously aligned with exclusive corporate and national interests, will have the chance to find the universality and inventiveness that gives them an emancipating reach for all." [8]

[1] See for a more elaborated version of the arguments in this text: Mokre, M. (2015), Solidarität als Übersetzung. Überlegungen zum Refugee Protest

Camp Vienna, http://transversal.at/books/solidaritaetalsuebersetzung, pp. 73-94

[2] Cf. Derrida, J. (2005), Politics of Friendship, London-New York, p. 6

[3] Cf. Anderson, B. (1983), Imagined Communities: Reflections on the Origins and Spread of Nationalism. London and New York; Gellner, E. (1983), Nations and Nationalism. Ithaca, NY

[4] Cf. Balibar, E. (1990), Die Nation-Form. Geschichte und Ideologie, in: Balibar, E./ Wallerstein, I., Rasse, Klasse, Nation. Berlin, 107-130.

[5] Cf. Arendt, H. (1994), The Origins of Totalitarianism. New York, p. 292

[6] Laclau, E./ Mouffe, C. (2001), Hegemony and Socialist Strategy: Towards a Radical Democratic Politics . London/New York.

[7] Rancière, J. (1995), La Mésentente: Politique et philosophie. Paris 
[8] Balibar, E. (1996), What we owe the Sans Papiers, http://transversal.at/transversal/0313/balibar/en

Monika Mokre is a political scientist and senior research associate at the Austrian Academy of Sciences Institute of Culture Studies and Theatre Studies as well as member of ROR-N. She teaches in various contexts, e.g. at the Webster University Vienna and, in spring 2016, as a visiting professor at the Institute of Political Science at the University of Vienna. Her current main interest as a researcher and as a political activist are asylum and migration policies. 


\section{AGENCY \&}

TUTELAGE 


\section{On Humanitarian Tutelage}

Leonardo Schiocchet

Originally published in 10/24/2017

Most refugees in the world come from the Middle East and Central Eurasia, and most forced migrants in Europe also come from this region. The so-called Summer of Refuge (or Summer of Migration) in 2015, when unprecedented numbers of forced migrants applied for asylum in Europe, made this fact apparent from Portugal to the Balkan Peninsula.

A recent book publication, From Destination to Integration: Afghan, Syrian and Iraqi Refugees in Vienna (2017), edited by Josef Kohlbacher and me, has been devoted to presenting and analyzing experiences of refugees from these regions in their country of origin, on their flight and after their arrival in Austria. This blog post inaugurates a series dedicated to showcasing this book featuring results, analyses and interpretations of a pilot study conducted by ROR-n. The edited volume contributes with in-depth qualitative data on forced migration from the Middle East and Central Eurasia to Europe, by means of discussing how Syrian, Iraqi and Afghan refugees reached Austria and relate to this regional and urban context. Overall, this edited volume offers intimate stories on the disrupted lives of Syrians, Iraqis, and Afghans both prior to deadly conflicts in the region and in exile. It also presents interpretations of sets of in-depth interviews, contributing to several topics in migration and forced migration studies. Research presented in this volume focuses on the unique moment of the first experiences of these refugees in Austria, which is essential to understanding the development of the interaction between refugee and host over time. 
This fresh outlook from the point of view of displaced persons is also in tune with established and contemporary scholarship on memory and agency. Besides, Europe is in dire need of a reexamination of attitudes towards forced migration, and Austria is no exception. Thus, the importance of this timely contribution can hardly be overstated.

Even though each of the chapters in this book contributes to different topics, one topic in particular cuts across all contributions: integration. But what is integration? What are its conditions of possibility? How is it mobilized as discourse and practice? And, what does it leave out of the picture, if anything? These are some of the most pressing questions posed by the Summer of Refuge. As the reader will see in the other posts of this series, each chapter addresses integration, or rather, what I prefer to call "the encounter", between refugees and their hosts by exploring different aspects, nuances, and diverse transdisciplinary competences.

Besides, all chapters in one way or another engage with the principles of humanitarian intervention and the power relations they convey, what we understand as human, humanity and humane, and how we organize society around it. As I argue throughout my introductory chapter summarized here (Schiocchet 2017), the relationship between the two can be in fact surprisingly contradictory, and the concept of "tutelage" lays bare relations of power constitutive of this social situation.

I use the term "encounter" to challenge assumptions entailed by the term integration in a similar way that Lieba Fair and Lisa Rofel engage with the term: 
"These ethnographies explore how culture-making occurs through unequal relationships involving two or more groups of people and things that appear to exist in culturally distinct worlds. The term encounter refers to everyday engagements across difference. Ethnographies of encounter focus on the cross-cultural and relational dynamics of these processes" (2014: 363).

Yet, my discussion emphasizes instead the meeting between migrants, forced or otherwise, and their hosts. My point is not to discredit the importance of the concept of integration in general, only to suggest that encounter is more suitable as an academic tool to investigate how different worldviews influence each other upon contact, which in turn does not take for granted the normative imperative of fitting one term to the standards of the other. While integration remains an important policy tool, academics should first investigate the encounter at large and only then seek answers to integrating policies. This more holistic standpoint, in turn, gears the discussion on the topic toward what Noel Salazar and Alan Smart called (im)mobility (2011). As I develop elsewhere, refugees obliged to cross borders rather than stay at their places of origin, living in overcrowded shelters, and serving as easy prey for war machines surrounding them - often do not feel mobile but immobile even when jumping country-to-country and continent-to-continent.

In part because most refugees feel obliged to abandon their homes to live under another country's rule as a non-citizen, I contend that the refugee voices heard in the study suggest that the encounter between refugees and Austria and Austrians is best understood through the lens of tutelage. The concept of tutelage, in turn, has been only rarely applied to the anthropological understanding of refugees, and more often to the study of indigenous minorities or international legal regimes over given territories and their populations. 
The concept of tutelage lays bare relations of power constitutive of the humanitarian intervention. It is what the works of Michel Foucault (1980) and Liisa Malkki $(1985,1995,1996)$ combined would call a technology of biopower, meaning disciplinary practices determining power relations over life, through which power is exerted asymmetrically across the system of forces at play. Tutelary regimes legitimize the dependency of protectorates, children, indigenous groups, national minorities, refugees, and other subjects perceived as not apt for deciding for themselves. In denying agency and full political participation and autonomy, tutelage objectifies and depoliticizes.

Humanitarianism has its own vernacular politics, which is mobilized not only by the United Nations refugee agency, but also by NGOs, nation-states, the media, and the refugees themselves. Anthropologists working on refugees or on humanitarianism, such as Michel Agier (2012, 2008), Ilana Feldman (2010), and Didier Fassin $(2013,2012)$ have already pointed to the structure of the humanitarian discourse and apparatus. The principles and mechanisms of humanitarian aid depend on accepting nation state sovereignty above all. This, in turn, means that international treaties and "laws" relating to refugees, such as the Geneva Convention and its protocols, not only depend on each state's own agreement and interpretation, but are also contextually subject to nation-state rule in practice. That is, the application of such principles is left to each state's own devices. Institutions such as the United Nations can only suggest resolutions on how to treat refugees, but not enforce them in practice. Accountability and enforcement mechanisms are usually limited to international sanctions, when these are actually put into practice. The decision always lies with the General Assembly, which is in itself composed of UN member states, voting according to their own interests. Humanitarian intervention is thus complementary to 
nation-state sovereignty, rather than an opposite force. As refugees by definition do not fit into any nation-state, they need to be governed by a force external to the nation-state order of the world that, in doing so, reinforces nation-state sovereignty. Tutelage, thus, embodies the power relations at play between refugees on one side and the national-humanitarian order of the world on the other one.

At the base of the nexus between national sovereignty and international humanitarian intervention lies the main principle that humanitarianism should be apolitical. While this principle is most often naturalized as being beyond criticism, it has its limitations. Most importantly, most refugees perceive that the solution for their situation is not simply bed and board or to be taken (or not) to one or another country. The solution, for most, is inherently political. Most Palestinian and Kurdish refugees, for example, want their own country, rather than only food and lodging. As forced migrants, refugees were obliged to leave their countries of origin or else suffer persecution and violence. On the one hand, by treating refugees as mere objects of humanitarian policy, their claims are understood in principle as apolitical. On the other hand, however, refugees are treated by host nation states as a political problem, rather than as humans just like any other citizen. In the national-humanitarian order of the world, thus, refugees are apolitical when they want to be political, and political when they want to be taken as equal to other humans. This tension tends to frame the experience of refugeeness greatly, and has yet to be widely acknowledged by policymakers, humanitarian agents, and scholars alike.

I suggest that humanitarianism is a project entailing the creation of a humanity beyond politics that could never be fully turned into reality, as it is curbed by the whims of nation-states. Such a project cannot exist but within the relative and contextual space given to it by particular nation-state sovereignties. The result is a general policy 
of tutelage that conceals political contextualization and with it the aspirations and lives of the refugees themselves. This, in turn, goes against Hannah Arendt's suggestion that Human rights should be above all political (see, for example, Arendt 1976: 296-297). Supposedly beyond politics, humanitarianism has often been considered beyond criticism too, and thus needs to be taken in scholarly perspective and understood as an ideology in Louis Dumont's sense $(1980,1986)$ - that is, not opposed to truth, but as one truth regime among others.

Nonetheless, my remarks must not be read as effacing the notable improvement humanitarian intervention has ensured for the lives of refugees. It is imperative to keep in mind that the critique of the Humanitarian intervention I present here is academic, only meant to lay bare its mechanisms to diagnose the social situation analyzed. It is also not meant as a critique of Europe or Austria specifically, but of global humanitarian reason and intervention at large.

Only through comprehensive understanding of the socio-political processes at play can we move forward, overcome ideological and policy limitations, and ultimately contribute to the betterment of the refugee situation world-wide. Thus, my aim here was to show that no matter how outstanding this assistance is, it is only palliative to enduring political solutions. To be more precise, my chapter suggests that it is the tutelary character of humanitarian intervention, legitimized as apolitical, which must be rethought and substituted by a more comprehensive, context-aware, practice; a practice that would take refugees as subjects of their own destinies, and assume the inherently political character of refuge situations, refugee subjects, and humanitarian practice itself. 


\section{References}

Agier, Michel. 2008. On the Margins of the World: The Refugee Experience Today.Cambridge: Polity Press.

2012. Managing the Undesirables: Refugee Camps and Humanitarian Government. Cambridge: Polity Press.

Arendt, Hannah. 1976. The Origins of Totalitarianism. New York: Harcourt Brace \& Company.

Dumont, Louis. 1980. Homo Hierarchicus: The Caste System and Its Implications. Chicago: University of Chicago Press.

. 1986. Essays on Individualism: Modern Ideology in Anthropological Perspective. Chicago: University of Chicago Press.

Faier, Lieba \& Rofel, Lisa. 2014. Ethnographies of Encounter. Annual Review of Anthropology, 43, pp. 363-77.

Fassin, Didier. 2013. Why Ethnography Matters: On Anthropology and its Publics. Cultural Anthropology, 28 (4), 621-646.

2012. Humanitarian Reason: A Moral Order of the Present. Berkeley: University of California Press.

Feldman, Ilana \& Ticktin, Miriam (Eds.). 2010. In the Name of Humanity: The Government of Threat and Care. London: Duke University Press.

Foucault, Michel. 1980. Power/Knowledge: Selected Interviews and Other Writings, 1972-1977. Toronto: The Harvester Press.

Kohlbacher, Josef and Schiocchet, Leonardo. 2017. From Destination to Integration: Afghan, Syrian and Iraqi refugees in Vienna (ISR- 
Forschungsbericht Heft 45). Vienna: Austrian Academy of Sciences Press.

Malkki, Liisa. 1985. The Origin of a Device of Power: The refugee Camp in Post-war Europe.Special Paper submitted to the Department of Anthropology, Harvard University, Cambridge.

. 1995. Purity and Exile: Violence, Memory, and National Cosmology among Hutu Refugees in Tanzania. Chicago: University of Chicago Press.

1996. Speechless Emissaries: Refugees, Humanitarianism, and Dehistoricization. Cultural Anthropology, 11 (3), pp. 377-404.

Salazar, Noel \& Smart, Alan (Eds.). 2011. Anthropological Takes on (Im)Mobility. Identities: Global Studies in Culture and Power, 18 (6), i-ix.

Schiocchet, Leonardo. 2017. Integration and Encounter in Humanitarian Tutelage. In Kohlbacher, Josef and Schiocchet, Leonardo (Eds.). In From Destination to Integration - Afghan, Syrian And Iraqi Refugees in Vienna, pp.9-35. Vienna: Austrian Academy of Sciences Press.

Leonardo Schiocchet has a PhD in anthropology (Boston University, 2011), is a researcher at the Austrian Academy of Sciences Institute for Social Anthropology, and a member of ROR-n. His work has focused on the Anthropology of the Middle East, with particular attention to processes of social belonging and subjecthood among Arab refugees in the Middle East, Latin America, and Europe. Many of his writings are available at

\section{https://oeaw.academia.edu/LeonardoSchiocchet.}




\section{What is the Problem with Current}

\section{Perceptions of Refugees as Mere Victims?}

Sabine Bauer-Amin

Originally published in 3/29/2018

When people leave a war-zone and arrive in a new setting, they are often not perceived as a tabula rasa but already have certain connotations attached to them. One common connotation in the late 2010s has been the idea of "victimhood". This idea and its ramifications can be highly conflictual for the affected persons. The strategies they develop to escape the "victimhood" ascribed to them and to regain agency call some of the core tropes of the current humanitarian refugee discourses into question.

How are these current discourses different from earlier ones? Although people had to leave countries that failed to protect them long before the 1951 UN Convention relating to the Status of Refugees (and its additional protocols), it was this so-called Refugee Convention that clarified the rights of refugees in their host countries. The "refugees" represented in this declaration were mostly dissidents from the Soviet Union, hence white, middle class and politically motivated actors who left the Soviet Union based on their own decision. These characteristics together with a focus on political reasons for taking refuge shaped the perception of refugeeness within earlier humanitarian discourses. Over the following decades, this political conception was gradually replaced by a focus on economic reasons, such as poverty, hunger and a lack of alternatives. While these phenomena often appear in the context 
of wars, they originally were not the most prominent features of refugeeness.

The shift was enmeshed with the visual representations about refugee crises that became dominant in the 1980s (ELIE 2014:30; see e.g. IMAGES OF EXILE BY UNHCR 1991). In this context, the people depicted were mostly poor, starving and suffering from harsh economic circumstances in refugee camps somewhere in the Global South. The previously pivotal understanding that becoming a refugee was inherently based on political agency and political reasons was replaced by humanitarian discourses highlighting refugees' dependence on foreign aid and on those countries receiving them. Hence, the prevalent depiction of refugeeness for the last forty-five years has cast them as passive, poor and apolitical victims and not as determined political actors. These pictures of poverty and war merged into a common assumption of what it might be like to be a refugee. However, these assumptions are representational constructions fostered by the changing visual representations and political discourses on refugees.

How are political actors turned into dependent victims in public discourses? This assumption is based on a "myth of difference" between those who are in need and those who can act upon the other's need (JOHNSON 2011:1023). It entails processes of power and dominance that turn the less privileged ones into "suffering victims" who are depending on the intervention of those who can "rescue" them. While the donors and host societies are portrayed as powerful and seemingly acting out of their own humanitarian motives, the refugees are presented as disempowered masses without personal histories, reasons for exile, or political motivations. They are no longer critical figures and dissidents but are forced into a corset of voiceless victimhood without the capacity to act (especially politically) while fully dependent on international 
donations and receiving states. Although this might be the case for a significant number of refugees, it is certainly not for everybody. Instead of this, many people do not want to be portrayed only as the victims of their situation and want to negotiate their new position in society actively.

Through the creation of this fundamental difference, people are essentialized as "naked refugees" and deprived of other possible perceptions. This creates the stereotype of the generic refugee, which in turn is essential to the structure of the contemporary discourses on refugees. This generic refugee became an indexical representation of refugeeness and shapes imaginations in hosting countries. BLEIKER argues that through such representations meanings are introduced into the public (2011:515). The aforementioned constructions inform visual representations and shape wider meanings in the social world. (JOHNSON 2011: 1017). At the same time, they create problematic expectations in the countries receiving refuges and/or donating money.

Why would different social actors mobilize this victimization trope even when not believing in the stereotype it produces? For NGOs and supra-local organizations, victimization plays on an emotional urge to contribute and mobilize funds. For policymakers, it justifies interventions and programs (mostly in the Global South) in the realm of humanitarianism (JOHNSON 2011: 1016). For host countries, victimization contradicts the threat posed by the "dangerous alien" (MALKKI 1995: 11) and his potential for political dissidence. Depicted as helpless and vulnerable beings, refugees become a controllable group whose political agency seems to be limited. For refugees, this trope helps to gain visibility, which is especially important for social movements, oppositional groups and minorities. For minorities in particular, the victimization trope can be weaved 
into claims of protection that might not be guaranteed simply through a 'minority' label.

The victimization trope and its shortcomings have pervasive consequences for the refugees whose profiles do not always correspond to it and the related myth of difference. Differences between the supposed powerful and powerless are not as rigid as the dominant discourses would suggest, putting into question the myth of difference, and, by extension core ideas of refugeeness. One of the most important of these ideas is that refugees give up political agency when leaving their country. As JOHNSON states, political agency is the ability to have an impact on one's own life and on the lives of others. Usually, these qualities are linked to the notion of citizenship. In addition, NYERS states that citizenship is a political identity that entails claims to equal rights, liberty, selfdetermination, individualism and agency (2004: 203). Thus, those being denied these rights become non-citizens. This alleged loss of political agency justifies the often-hostile attitude of host countries towards refugees' political involvement either locally or in their countries of origin. This clearly contradicts the main understanding of refugees as political actors as expressed in the 1951 Refugee Convention. However, as victims of violence, political suppression and persecution, refugees are in fact political actors. This mismatch between the denial of political agency while being de facto political actors often creates tensions with humanitarian agents and host state authorities. Refugees' political agency might undermine humanitarian justifications for conceding legal refugee status (BAKEWELL 2010: 1690). Furthermore, the expression of exile as an intrinsic political decision based on refugee's choice, selfdetermination and agency, rather than on extrinsic reasons, questions the "forced" in forced migration. Over the last forty years, humanitarian discourses have fundamentally changed the 
perception of refugees from political actors to suffering victims and have, in effect, contradicted the original understanding of the Refugee Convention.

In this blog post, I have analyzed the structure of contemporary humanitarian discourses about refugees to show how they drifted away from the ideas enshrined in the 1951 Refugee Convention. Furthermore, these discourses also contradict the self-perception of refugees as political actors. Although there are reasons why social actors use the trope of victimization characterizing the contemporary humanitarian discourses, the myth of difference, on which it is based, creates tensions. Most importantly, stereotypes about refugees that have been fostered through visual representations portraying refugees as "essentialized", passive, and helpless victims. This victimization in turn creates expectations on refugees that are for many hard to fulfill and come at a high emotional cost. An important conclusion is that all too often the humanitarian debate leaves out how refugees experience their victimization and how they struggle to overcome this labeling. This compels us to ask further questions and to critically approach the victimization trope: what if people do not want to be voiceless and apolitical? What if they want to (re-)empower themselves? What if they do not want to be identified with their past and their suffering? What if they do not want to be non-citizens but become equal cocitizens in their new countries of residence? 


\section{References}

Bakewell, O. (2010), Some reflections on structure and agency in migratory theory. Journal of Ethnic and Migration Studies, 36 (19), pp. 1968-1708.

Bleiker, R. (2011), The aesthetic turn in international political theory. Millennium 30 (3), pp. 509-533.

Elie, J. (2014), Histories of Refugees and Forced Migration Studies. In: FIDDIAN-QASMIYEH E., LOESCHER G, LONG K. \& SIGONA N. (eds.), The Oxford Handbook of Refugee and Forced Migration Studies, 23, pp. 22-35.

Johnson, H.L. (2011), Click to Donate: visual images, constructing victims and imagining the female refugee. Third World Quarterly, 32 (6), pp. 1015-1037.

Malkki, L. (1995), Purity and Exile: Violence, Memory, and Hutu Cosmology among the Hutu Refugees in Tanzania. University of Chicago Press.

United Nations High Comissioner For Refugees (UNHCR) (19919, Images of Exile 1991-1991. Geneva, UNHCR.

Sabine Bauer-Amin is a social anthropologist and researcher at the Austrian Academy of Sciences Institute for Social Anthropolgy as well as member of ROR-N. Previously, she has worked on the Middle East with a special focus on youth and issues of identity/alterity. Her current research focus is on the situation of refugees from Iraq and Syria in Austria and beyond. 


\title{
Humanitarianism from Below: Sowa Rigpa, the Traditional Pharmaceutical Industry, and Global Health
}

\author{
Stephan Kloos \\ Originally published in 4/27/2019 \\ (Original article published in 2020 \\ Medical Anthropology 39(2): 167-181 \\ doi.org/10.1080/01459740.2019.1587423
}

Tibet's persistent image of geographical, cultural and political isolation belies the cosmopolitan nature of its history and cultural heritage, including Sowa Rigpa. As the most important symbol of Tibet's national identity today besides Tibetan Buddhism (Janes 2001; Kapstein 2000), Tibetan medicine (Sowa Rigpa) was originally assembled from Indian, Chinese, Persian and Central Asian scriptures and experts from the seventh century onwards. After it had been fully institutionalized as Tibet's own unique science, Sowa Rigpa was re-exported throughout Inner Asia and the Himalayas, playing an important role in the expansion of Tibet's sphere of cultural influence (Schaeffer 2003) that partly still exists today (Kloos 2017). Sowa Rigpa's Mahayana Buddhist ethical claim to work for "the benefit of all sentient beings" (Tib. 'gro phan) was particularly useful in the Ganden Phodrang government's political and economic agenda (Gyatso 2004), articulating a universalist vision that potentially included the whole world. In practice, however, the extent of Sowa Rigpa's world of "all sentient beings" remained limited to the Central Tibetan sphere of hegemonic ambition (including Himalayan areas like Ladakh and Bhutan, as well as Mongolia and Buryatia) until the mid-twentieth century, when Tibet's occupation by China and the Fourteenth Dalai Lama's 
subsequent flight to India in 1959 forced major changes upon the Tibetan world. It was only in exile that Sowa Rigpa's and the Tibetan community's ethical, political, and economic vision expanded to include, in the notion of "all sentient beings," the world in a global sense (cf. Huber 2001; Roemer 2008).

Rooted in its pan-Asian origins, its universalist Buddhist framework, and its historical development until the twentieth century, Sowa Rigpa's contemporary globalization was a gradual process. During the first two decades in exile (Kloos 2008), as much as during the Cultural Revolution in China (Hofer 2018; Janes 1995), Sowa Rigpa's ethics was certainly to "benefit all sentient beings" just as it had been for centuries, but its immediate concern was one of sheer survival: its own survival as a central part of Tibetan culture, and also the physical survival of its Tibetan patients, who were dying in large numbers due to the violent reforms in Tibet, and the unfamiliar climate, poor sanitary conditions, and inadequate biomedical care in India. It was only in 1982 that several events - the first successful production of tsotel (mercury sulfide ash, an important ingredient for "precious pills") in exile, the organization of a popular "Tibetan medicine week" in New Delhi, and the first international conference devoted to Tibetan medicine in the United States - enabled exile Tibetan Sowa Rigpa practitioners to broaden their vision and begin to engage with the world at large (Kloos 2017). This coincided with a shift in the Tibetan exile government's political strategy, which led to an active reframing of Tibetan culture as consubstantial with the Mahayana Buddhist ethics of altruism and compassion (cf. Lopez 1998). Manifested most clearly by Tibetan Buddhism and medicine, these universal values enabled the portrayal of Tibetan culture in terms of a threatened common good worthy of the world's protection and support (Barnett 2001). For this, its value to the world had to be demonstrated, leading the Dalai Lama for the first time to explicitly include, in a 1982 speech to Tibetan doctors and medical students, Indians and foreigners as Sowa Rigpa's 
beneficiaries, pointing out that "the more benefit and service Tibetan medicine renders to humanity, the more it is of service to Tibetan culture. We must understand that this holds strategic importance." (Dalai Lama 2007:17) In later speeches, he noted a "growing global interest in Tibetan medicine," and reiterated repeatedly that Sowa Rigpa should not remain limited to Tibetan society.

The prime institution of Tibetan medicine in India, the Dharamsala Men-Tsee-Khang, serves as a good example for Sowa Rigpa's expanding scope. In several key meetings and a conference in the mid-1990s, the institute decided to strategically focus its clinical research activities on hepatitis, a major health issue especially among the exile Tibetan community; diabetes and asthma, health problems of epidemic proportions in India; and cancer, a cure for which would guarantee international attention (cf. Czaja 2011). If Sowa Rigpa's role and function had largely been restricted to primary health care for refugee Tibetans with little access to other health resources, from the 1990s onwards it thus began to systematically specialize on common, chronic, complicated, or untreatable biomedically-defined diseases of urban, often nonTibetan upper and middle classes. Also in the early 1990s, the then Men-Tsee-Khang director and a senior physician publicly claimed in the US that Tibetan medicine could, at least in principle, cure AIDS. The results of such activities were mixed: while the Men-Tsee-Khang team had to cut short its US tour to avoid a lawsuit, Tibetan clinics opened all over South Asia - and doctors traveled and settled throughout the world - not for their primary health benefits, but their seemingly miraculous cures for problems like asthma, diabetes, arteriosclerosis, or cancer. In fact, almost all Men-Tsee-Khang branch clinics in metropolitan India - Mumbai, Chennai, Bangalore, Ahmedabad, Secunderabad - were established upon the initiative and sponsorship of enthusiastic local Indians who owed their (or their family members') lives to Tibetan medical intervention. Similarly, Sowa Rigpa's accelerating spread in other parts of Asia and 
the rest of the world is largely sustained by its reputation of efficacy in treating complicated chronic diseases and dramatically improving patients' quality of life.

Sowa Rigpa's worlding, that is, its re-envisioning of the global as a singular reference point through multiple, transformative relations with the world (Zhan 2009:7), was best summarized by one Tibetan physician in India who told me: "Although we are refugees, through Tibetan medicine we can help the world." This doctor's sentiment, which was shared by most exile Tibetan physicians I talked to, is doubly revealing. For not only does it point to the extent to which the world has become an integral, defining feature of exile Tibetan medicine, but it also articulates an exile Tibetan "politics of compassion" that can be understood as a particular kind of humanitarianism. Commonly defined as a "way to 'do good' or to improve aspects of the human condition by focusing on suffering and saving lives in times of crisis or emergency" (Ticktin 2014:274), humanitarianism accords moral sentiments such as altruism and compassion a central place in the realm of politics and governance. As Didier Fassin (2012) reminds us, this involves an uncomfortable combination of genuine ethical motivations with political or economic self-interest and power inequalities, without one necessarily invalidating the other. The exile Tibetan case constitutes precisely such an introduction of moral values like altruism and compassion into the political sphere of nationalism (Fassin 2010:269) and market competition, via the ostensibly apolitical nongovernmental institution of Sowa Rigpa (Kloos 2017). Like humanitarianism elsewhere (Ticktin 2006; Redfield \& Bornstein 2010:6), it also reframes (Tibetan) medical expertise as an important vehicle of such moral engagement, and thus as a crucial mode of governing.

The particularity of the exile Tibetans' politics of compassion lies in its subaltern nature: instead of large, well-funded humanitarian 
organizations or rich states of the Global North, in this case it is poor, often stateless refugees who set out to "help the world" with their unique medicine. Lacking official recognition outside a small number of countries, Sowa Rigpa remains invisible to large global health institutions like the WHO or the World Bank, and technically illegal in most of the world. Contrary to the global politics of compassion of the North, carried out by an army of NGOs and large international organizations, the Tibetan version thus largely remains an unofficial (or even clandestine) operation. The relationship of inequality inherent in humanitarianism's usual flow of aid and intervention (Fassin 2012) - from above to below, from the powerful to the weaker - is thus turned on its head. However, just like the humanitarian agents from the privileged countries of the Global North, exile Tibetans are keenly aware of not only the moral, but also the political and economic capital to be earned by helping others. In the Tibetan historical context, this model was known as the "patronpriest" relationship, in which Tibet would provide spiritual/religious guidance in return for foreign political or military patronage (Kapstein 2006). Today, as Tibetan religious and medical experts offer their services around the world, what is at stake are global, regional, and professional hegemonic ambitions, just as occurs in Western humanitarianism. They involve the representation of Tibetan identity and history on the global stage (Kloos 2012), the perpetuation of a Tibetan cultural/religious hegemony in Inner Asia (Kloos 2017), and the control over (parts of) the transnational Sowa Rigpa industry - all legitimized by the genuine intention to help. Sowa Rigpa's development in exile, then, not only testifies to an extraordinary process of globalization, but also constitutes a subaltern politics of compassion - or, in other words, a particular kind of humanitarianism from below.

\section{References}

Barnett, R. (2001), "Violated Specialness": Western Political Representations of Tibet. In: Dodin, T. and Räther, H. (eds), 
Imagining Tibet: Perceptions, Projections, and Fantasies. Boston: Wisdom, pp.269-316.

Czaja, O. (2011), The Four Tantras and the Global Market: Changing Epistemologies of Drä ('bras) versus Cancer. In: Adams, V., Schrempf, M., Craig, S. (eds), Medicine between Science and Religion: Explorations on Tibetan Grounds. New York \& Oxford: Berghahn, pp.265-295.

Dalai Lama (2007), Srid zhi'i rnam 'dren gong sa skyabs mgon chen po mchog nas bod gzhung sman rtsis khang gi sman rtsis las slob yongs la stsal ba'i bka' slob phyogs bsdebs bzhugs so. Dharamsala: Bod gzhung sman rtsis khang.

Fassin, D. (2010), Heart of Humaneness. In: Fassin, D. and Pandolfi, M. (eds), Contemporary States of Emergency: The Politics of Military and Humanitarian Intervention. New York: Zone, pp.317-333.

. (2012), Humanitarian Reason. A Moral History of the Present. Berkeley \& Los Angeles: University of California Press.

Gyatso, J. (2004), The Authority of Empiricism and the Empiricism of Authority: Medicine and Buddhism in Tibet on the Eve of Modernity. Comparative Studies of South Asia, Africa and the Middle East 24(2): 83-96.

Hofer, T. (2018), Medicine and Memory in Tibet: Amchi Physicians in an Age of Reform. Seattle: University of Washington Press.

Huber, T. (2001), Shangri-la in Exile: Representations of Tibetan Identity and Transnational Culture. In: DODIN T. and RÄTHER H. (eds), Imagining Tibet: Perceptions, Projections, and Fantasies. Boston: Wisdom Publications, pp.357-372.

Janes, C. (1995), The Transformations of Tibetan Medicine. Medical Anthropology Quarterly 9(1): 6-39.

- (2001), Tibetan Medicine at the Crossroads: Radical Modernity and the Social Organization of Traditional Medicine in the 
Tibet Autonomous Region, China. In: CONNOR L. and SAMUEL G. (eds) Healing Powers and Modernity: Traditional Medicine, Shamanism, and Science in Asian Societies. Westport, CT: Bergin \& Garvey, pp.197-221.

Kapstein, M. (2000), The Tibetan Assimilation of Buddhism. Oxford \& New York: Oxford University Press.

. (2006), The Tibetans. Malden, MA: Blackwell.

Kloos, S. (2008), The History and Development of Tibetan Medicine in Exile. Tibet Journal 33(3): 15-49.

(2012), Die Alchemie exil-tibetischer Identität: Anmerkungen zur pharmazeutischen und politischen Wirksamkeit tibetischer Pillen. Curare 35(3): 197-207.

. (2017), The Politics of Preservation and Loss: Tibetan Medical Knowledge in Exile. East Asian Science, Technology and Society 10(2): 135-159.

Lopez, D. (1998), Prisoners of Shangri-la: Tibetan Buddhism and the West. Chicago: University of Chicago Press.

Redfield, P. and Bornstein, E. (2010), An Introduction to the Anthropology of Humanitarianism. In: Bornstein, E. and Redfield, P. (eds), Forces of Compassion: Humanitarianism Between Ethics and Politics. Santa Fe: School for Advances Research Press, pp.3-30.

Roemer, S. (2008), The Tibetan Government-in-Exile: Politics at large. London \& New York: Routledge.

Schaeffer, K. (2003), Textual Scholarship, Medical Tradition, and Mahayana Buddhist Ideals in Tibet. Journal of Indian Philosophy 31(56): 621-641.

Ticktin, M. (2006), Where Ethics and Politics Meet: The Violence of Humanitarianism in France. American Anthropologist 33(1): 33-49. 
Ticktin, M. (2014), Transnational Humanitarianism. Annual Review of Anthropology 43: 273-289.

Zhan, M. (2009), Other-Worldly: Making Chinese Medicine through Transnational Frames. Durham \& London: Duke University Press.

Stephan Kloos is director of the Institute for Social Anthropology at the Austrian Academy of Sciences. His recent publications include The Pharmaceutical Assemblage (Current Anthropology 2017) and The Transnational Sowa Rigpa Industry in Asia: New Perspectives on an Emerging Economy (Social Science \& Medicine 2020; with Madhavan, Tidwell, Blaikie \& Cuomu). See stephankloos.org for more information. 


\section{Palestinian Refugees in Brazil between Nations and Humanitarian Tutelage}

Leonardo Schiocchet

Originally published in 5/27/2019

* This post is based on Schiocchet, Leonardo. 2019. "Outcasts among Undesirables: 117 Palestinian Refugees in Brazil in-between Humanitarianism and Nationalism". Latin American Perspectives, 46(3), pp. 84-101. The full article can be found here. A slightly different version of this post has also been published at The Maydan.

In 2007, a group of 117 Palestinian refugees moved from Iraq to Brazil following a resettlement plan involving the UNHCR, the Brazilian government, and the civil society, including international NGOs. In what follows, I highlight some of the experiences of Palestinian refugees and established diaspora in relation to this plan. This, in turn, enables us to access the way the Brazilian nation-state navigated its political meanders and question broad assumptions about humanitarianism.

\section{The Brazilian Political Context}

Since 2003 and until President Dilma Rousseff's impeachment in 2016, the Partido dos Trabalhadores (PT) party's government in Brazil had striven to diminish Brazil's enormous class, gender, and economic inequalities with varying success. From a 2019 
perspective, and in the light of the ongoing systematic dismantling, it may be said that social policies of inclusion reached their apex during the PT (Workers Party) era.

An important component of the Brazilian developmental project during the PT years had been to increase visibility in international politics. This new international orientation, in turn, demanded humanitarian action. The resettlement plan discussed here unfolded within this larger context, and more specifically, that of Brazil's interest in securing a permanent seat in the UN Security Council, which calls for dealing with the world's refugees.

While there is a heated debate in Brazil about the country's indigenous minority policies, much less is known about Brazil's policies regarding non-indigenous minorities, particularly refugees. I will argue that it treated the refugees as migrants, and expected them to integrate just as previous Arab migrants had in the early 20th Century. In the following, I will examine refugee policies during the PT government and relate them to the migrant assumption as a broader national myth influencing state practices.

\section{The Refugees}

Michel Agier has noted that the world's refugees are "undesirable". He states: "They are at the end of the day undesirable, kept apart from the world, far from the city. (...) They are the very figure of a detestable liminality" $(2008,62)$. Yet, the following story concerns a slightly different category of people, for the group coming from Iraq was branded outcast among such undesirables. The resettled Palestinians were a group of 117 refugees who left Iraq for Brazil in 2007 due to the war. Among them were men, women, and children of all ages. Many of the adults worked for the Iraqi government 
bureaucracy at least at some point. Prior to coming to Brazil, almost all of them were temporarily lodged in Rwayshed, a refugee camp in the Jordanian desert close to the border with Iraq. There, they had already developed a reputation for being "undesirable" and unfit for refuge elsewhere, even in comparison to other local refugees. They were among the last to find refuge prior to the camp's closure. Once in Brazil, they were again deemed undesirable, only this time due primarily to a mythical national narrative. This double rejection of being outcasts among "undesirables" has worked against these Palestinians' perceived "integration". Through the lens of this double rejection, I discuss the principles of integration and tutelage, putting the supposed apolitical character of humanitarianism into perspective and showing how mythical-ideological notions of Brazilianness also helped to reinforce and reproduce stereotypes associated with Palestinians.

\section{Humanitarian Tutelage}

After the fall of Saddam Hussein, many refugee camps started to form in Iraq. These camps received refugee groups of diverse ethnicities and religions, and vulnerable due to various political reasons - all of which were connected to the demise of Saddam Hussein's regime in 2003. The refugees were Sunni, Shi'a and Christian Iraqis. They were also Iranians, Kurds, Sudanese, and Palestinians, among other minorities historically living in Iraq at the time of the war. Rwayshed was located in the Jordanian desert, close to the Iraqi border, and thus under Jordanian jurisdiction. The camp there was created in 2003 specifically to receive refugees from all other camps, and to serve as a transitional point between Iraq and the resettlement countries. 
In 2007, the UNHCR aimed at closing Rwayshed and resettling all of its population. For the institution, "resettlement" entails permanent residency in a country other than that of the refugee (UNHCR, 2014). The group of originally 117 Palestinians who landed in Brazil was the last to leave Rwayshed before the camp was deactivated.

The humanitarian agents frequently spoke to me of the resettlement project as a "favor". The benefit was not inclusion through national citizenship at first, but protraction through tutelage, which in turn implies the non-recognition of the autonomy of the subjected, who become then objects of the humanitarian policies. In this model, there are those who are eternally recipients, and those who are eternally "givers". Consequently, the relationship between these terms is always unilinearly asymmetrical, as the recipients are always bound to the givers' favor. Accordingly, once in Brazil, the Rwayshed group discovered that Brazilian citizenship was not unconditional, automatic, and uninterested. It was rather something that they would have to "deserve" in the eyes of the Brazilian government. Far from a gift, the logic was closer to the Weberian protestant ethics: a prize given only to those who were able to demonstrate their successful efforts to "integrate", overcoming inherent difficulties. What "integration" meant, however, was elusive.

\section{"Integration"}

In theory, integration loosely meant to be able to "fit" Brazilian society, and almost every resettlement agent had an opinion on the matter. In practice, CONARE[1] officially decided who would become integrated - and thus who deserved to gain permanent status in Brazil - on an individual basis grounded on relative criteria, such as personal sympathies and especially the display of non- 
confrontational behavior towards the ressettlement agents, the project itself, and all levels of Brazilian authority.

Nevertheless, a discourse recognizing the authoritative character of the tutelage did not always accompany the tutelary intervention. In fact, tutelage often came bound to a critical discourse against the vulnerability of the refugees. The group of Palestinian refugees in question were constructed by CONARE as objects of tutelage because they are restricted not only by extrinsic war impositions (for instance, territorial mobility), but also because they were supposedly incapable of understanding - and thus choosing - what was best for them. Accordingly, what the refugees were incapable of conceiving of in first place is the Brazilian state's heroic act of saving them from the catastrophe that undercut their lives. These Palestinians were thus incapable of judging that their coming to Brazil was a unique opportunity, given the multicultural tradition of the Brazilian nation, and the competence of the state in its treatment of "immigrants". In a interview with one of CONARE's top representatives, I also heard that "in Brazil those who do not integrate are only those who choose not to". Such integration was related to the Brazilian "long tradition" of "receiving immigrants" and, therefore, the non-integration of the Palestinians was an abnormality associated with limitations (social, political, ethnic, religious, or cultural) intrinsic to them and dissociated from the resettlement program or the Brazilian context.

However, the concept of "integration" proved to be very elusive. The criteria could not be found in any text of law, or even in any of the institutions' brochures, websites, or other forms of official discourse. They were not evident or transparent, and the decision was on an individual basis and dependent on a CONARE commissary's judgment. Rwayshed refugees constantly reiterated their unawareness of the conditional character of their Brazilian 
citizenship. The very move to Brazil and the subsequent "integration" into the Brazilian nation were imposed upon the Rwayshed group. Once in Brazil, each refugee had to tackle the Brazilian context in one way or another, either by trying exile or seeking "integration". By conditioning citizenship on integration, and by informally associating integration with both civic duties and cultural expectations, the Brazilian state's integration efforts were instead often perceived by the refugees as "assimilation" and/or "obedience" to all forms of authority to which they were subjected.

\section{Nations and Humanitarianism}

These "undesirables" went to Brazil because no other country accepted them, and they only went there because that decision was imposed on them. The humanitarian discourse not only qualified these refugees as being incapable of autonomous decision, but also denied them the right to desire (to be sent to another country) and to resent the humanitarian agents (for sending them to Brazil). In practice, the refugees could not even choose to remain in Rwayshed, as a few supposedly had preferred. The refugees' ideas about Brazil contrasted greatly with the state's official narrative, which was based on a mythical-heroic description of the nation, of its potentialities, and its natural and social riches.

Among all the promises made and not granted by UNHCR and Brazil, the refugees placed one above all the others: citizenship, which, in this sense, represented more than just a simple chart of common rights and duties. It represented belonging to the Brazilian nation.

Nationality via citizenship is the only possibility of becoming a subject in the contemporary "national order" of the World - to use Liisa Malkki's words (1992; 1995a; 1995b). In practice, even the 
humanitarian agents presuppose that the "human" (in the plenitude of its rights and duties, thus beyond tutelage) is only imaginable within the parameters of the nation-state. This view assumes the ineluctable political condition of the subject. However, this is also precisely what the humanitarian discourse denies by upholding the assumption that it is beyond politics and, thus, beyond ideology. Most commonly, the humanitarian discourse is thought of in terms of an ideological liberal notion of universal human rights associated with a politics of commitment to the just protection of those rights. However, the claim to transcend politics, or the particular interests of nation-states and other political actors, constitutes the very substance of humanitarian politics. By claiming universality, the humanitarian discourse also claims to be beyond ideology. This universal pretension serves to legitimize humanitarianism in both ideological and political terms.

The perlocutionary effects of this denial of particularism (politics and ideology) are vast and manifest. For instance, it precludes the possibility of self-criticism and of being put in perspective: being beyond politics and ideology essentially entails an ontological, outof-the-world position beyond perspectives. Consequently, "problems" - whenever they exist - are always located elsewhere, usually in the object of tutelage or in the not-so-partial host institutions.

\section{National Mythologies through an Asymmetrical Encounter}

While the resettlement agents took for granted that the locals closest to the refugees would be other Palestinians and Arabs, the relationship between these groups proved to be less than harmonious. In addition, the UNHCR entrusted its responsibility to local humanitarian NGOs, who responded directly to Brazilian laws 
and shared nationalistic myths about the country's cosmopolitan potential. Such myths suggested that any difficulty of integration should be justified as resulting from a collective limitation of the ward - and not of the state or nation. The resettlement agents often found such limitations in the "Palestinian culture" - also commonly referred to as the "Arab culture" - in general, but also in the "problematic" condition of these "undesirables", and usually in the confluence between these two factors. Authorities involved in the resettlement argued that since history had shown that everyone else integrated well in Brazil, the unruliness of the Palestinian group had to be attributed to their "culture" and problematic character. The latter characteristic was part of a narrative that had been transmitted from the UNHCR to the NGOs they hired in Brazil, and to the Brazilian government which was aware that they were outcasts among undesirables.

The Brazilian official discourse about the refugees borrowed elements from the humanitarian vernacular, investing the government with morality as it omitted the political character of the decision to receive the refugees, of the resettlement process, and of the actual legal and symbolic status bestowed upon the refugees visà-vis the Brazilian nation. Such supposed (apolitical) morality, besides yielding corporality to the nation, in turn justifies a civilizatory mission - as stated by Hamid (2013). In my opinion, it is this civilizatory mission that motivates a priori the disposition and the disciplinary practices the resettlement projects' agents bring to bear upon the objects of tutelage.

\section{Conclusion}

The Rawayshed refugees resettled in Brazil were affected by scenarios as diverse as those of war-torn Iraq, the ideology of global 
humanitarianism, and Brazilian developmentalist policies. Legitimized through the tutelary regime, the resettlement agents reincorporated and in part unconsciously managed disciplinary practices upon the refugees.

The shortcommings of humanitarian tutelage are hardly ever problematized beyond the accepted consensus. In the case presented, tutelage assumed the refugees' temporary incapacity to govern their lives on their own, evoking the transference of biopower (Foucault, 1988), or the power over subjects' lives, from the refugees to the UN and then to the Brazilian state. Tutelage was supposed to be transitory, ending upon complete integration. It was thus a counterpart to integration. While integration mobilized a mythical-ideological view of the host (Brazilian) nation, tutelage mobilized a bureaucratic regulatory apparatus in line with this view.

The mythical-ideological view of the Brazilian nation was based on the assumption that Brazil is a prejudice-free melting-pot, evidenced especially by how all immigrants there had supposedly "integrated" to form one coherent Brazilian nation, beyond ethnic, racial, religious, and cultural differences (Lesser, 2000: 130-133; Karam, 2007: 157). As such, the Brazilian government expected that the refugees should emulate the supposed behavior of the immigrants of the late 19th and early 20th centuries, generational, contextual, and legal gaps notwithstanding. The conceptual place of the immigrant, and thus of the refugee, was in turn supported by heroic narratives and representations about the history of the immigrants in Brazil, upheld by the state as much as by the immigrants themselves and their descendants. Moreover, it was by dealing with undesirable refugees that the nation maintained its ideals about the Brazilian citizen. Failure to properly "integrate" was then to be solely attributed to the refugees themselves, rather than to the resettlement progam or any of its actors. Thus, when these refugees' 
integration proved difficult, the rhetoric of the outcasts among undesirables evoked stereotypes of Palestinians as bellicose, unruly, and backward, this being the sole cause of the resettlement plan's faililures.

Neither the Brazilian government nor the UN and its NGOs acknowledged the contradiction between humanitarianism and the nation, which I suggest are tacit counterparts. Yet, the disciplinary practices of the resettlement project departed from representations of the Palestinian and especially the Brazilian nation, and about the place of the refugee in what Malkki (1995b) calls the national order of the world. Thus, a humanitarian vernacular was embedded in the Brazilian rhetoric and policies towards the refugees, informing expectations about the refugees' so-called integration. Refugees are not simply immigrants. Yet, on the one hand, in the case presented here, they were expected to conform to an idealized view of those who left their countries voluntarily to live in Brazil many decades ago. On the other hand, they were kept under tutelary control, their voices rarely heard. Rather than treating the refugees as active subjects of their own lives, the resettlement process muted the refugees' voices. While this paradox was evidenced by the Brazilian case, it is by no means solely a Brazilian problem. Rather, it is a broader issue relating to the encounter between the national order of the world and humanitarianism at large.

\section{References}

Agier, Michel. 2008 On the Margins of the World: The Refugee Experience Today. Cambridge: Polity Press.

2012 Managing the Undesirables: Refugee Camps and humanitarian Government. Cambridge: Polity Press. 
Foucault, Michel. 1988 The History of sexuality. Vol 1: The will of Knowledge. London: Penguin.

Hamid, Sônia Cristina. 2013 (Des)Integrando Refugiados: Os Processos do Reassentamento de Palestinos no Brasil [Portuguese]. Doctoral diss., Universidade de Brasília (UnB).

Karam, John Tofik. 2009. Um Outro Arabesco: etnicidade SírioLibanesa no Brasil Neoliberal. São Paulo: Martins Fontes.

Lesser, Jeffrey. 2000 A Negociação da Identidade Nacional. São Paulo: editora da UNESP.

Malkki, Liisa. 1992 "National Geographic: The Rooting of Peoples and the Territorialization of National Identity among Scholars and Refugees". Cultural Anthropology, Vol. 07, No. 01 (Feb): 24-44.

. 1995a. Purity and Exile: Violence, Memory, and National Cosmology among Hutu Refugees in Tanzania. Chicago: University of Chicago Press.

1995b "Refugees and Exile: From 'Refugee Studies' to the National Order of Things". Annual Review of Anthropology. Vol. 24: 495-523.

Schiocchet, Leonardo. 2019. "Outcasts among Undesirables: 117 Palestinian Refugees in Brazil in-between Humanitarianism and Nationalism". Latin American Perspectives, 46(3), pp. 84-101.

UNHCR. 2014 "Resettlement". Accessed Jan 31. <http://www.unhcr.org/pages/4a16b1676.html>. 


\section{Notes}

[1] CONARE, Comitê Nacional para os Refugiados [National committee for Refugees], is an interministerial commission under the Brazilian Ministry of Justice.

Leonardo Schiocchet has a PhD in anthropology (Boston University, 2011). He is a researcher at the Austrian Academy of Sciences Institute for Social Anthropology (ISA), P.I. of the FWF-funded project AustroArab Encounters (2018-2022), editor of Anthropology of the Middle East (Berghahn) and of ROR-n's blog. Since 2006, his work has focused on the Anthropology of the Middle East, with particular attention to processes of social belonging and subjecthood among Arab refugees in the Middle East, Latin America, and Europe. Within this focus, his work has covered themes such as dynamics of suspicion and trust, ritualization, home-making processes, and others. 


\section{The Autonomy of Migration after its Summer [1]}

Niki Kubaczek

Originally published in 8/31/2017

It has been two years that Germany's and Austria's governments opened their borders following the pressure of migration movements. Since then, a lot has changed, and not much for the better. Did the demarcations and enclosures of the nation states win once and for all? How does the present situation differ from the one of 2015? And what has migration got to do with social networks, affect and forms of commons?

On Friday 4 September 2015 thousands of migrants made their way from the train station Keleti in Budapest towards west and hundreds broke out of the so-called reception center, in Röszke.[2] Multiple actions of support followed, which were then celebrated under the term 'welcoming culture' ('Willkommenskultur'). Suddenly, everybody wished to play a part in helping people to arrive or to get further, at least that's how it seemed. Here and there, pictures of furious police officers on the German-Austrian border fighting on the correct interpretation of the border management circulated in the media. Politicians and mass media had wild debates on the proper way of dealing with the cross-border movements. The European migration regime arrived at a crisis point. Borders that seemed unchangeable and unbreakable were suddenly open. A rupture took place, something new was happening.

Not new was the fact that movements along forbidden, illegalized, routes are often accompanied by immense violence, danger and exploitation. Living and moving as a refugee got a lot to do with living 
a life of crisis, in a state of exception, be it before or after 2015. Hence, what was new was not the fact that refugees suddenly lived under extremely precarious and dangerous living conditions. What was new that summer was the obvious crisis of the migration regime, not the bad living conditions of migrants and refugees. This means that the term 'refugee crisis' is quite misleading, when what is at stake is actually the crisis of the European border or migration regime.

Since then, the European nation states try to regain control over this migration regime crisis, that is, over the migration management crisis, at all cost. Restoring the image of normality is sometimes done through the exercise of repression and at other times through the construction of consensus. One moment it's humanitarianism and inclusion, a bit later it's suppression and state legitimized violence which serves as coping strategies. But invariably, these two sides work in parallel and simultaneously, with different intensities. The terms 'welcoming culture' and 'refugee crisis' are in this sense central elements of these nation state operations insofar as they decisively contribute to a very specific striating and stratifying of the multiple events of the summer 2015. As the term refugee crisis locates the crisis 'in' the refugees, thereby distracting from the crisis of the migration regime, also the term and imagination of a 'welcoming culture' establishes one specific perspective and renders other stories and histories invisible and impossible. The notion of a welcoming culture paints an image of national bodies and national cultures of generosity, that invites the Others, the aliens, the maltreated bodies and passive victims to stay. With the normalization of those terms, it seems as if it was up to a few national subjects, like Germany and Austria, and their generosity, to make the summer of migration happen.

This form of storytelling and history writing hides, not just accidentally, some of the most important points I wish to elaborate 
here. What initiated the opening of borders was not a national culture of welcoming, but first and foremost the self-determined and autonomous movements of those that were said they should not have been moving in that way but still did so. The cross-border movements that took place despite all the resistance only then brought into existence actions of solidarity, and support for flight and shelter. Therefore, migration didn't result from a supposedly pre-existing national culture of welcoming but the opposite, was it migration that produced those practices, affects, networks and ways of coming together, forms of commons. A certain sociality and economy bellow the grid of the nation state, fleeing from it and undermining it. What was later named and celebrated as welcoming culture - that is, the many and multiple practices of support and helping people's arrival and moving further, as well as the resulting micro politicizations of the resident population - was therefore not the reason nor the condition, but the result and effect of migration.

This productive and inventive force of cross-border movements can also be read out of a letter written shortly before the summer of 2015 by representatives of the municipality of Alberschwende, a small village in Austria. This letter already implied the politicizing potential of migration: "It brews in the country, it rumbles in the municipality! Through our activity with asylum seekers, we got an insight in the insufficiency of the European asylum system (Dublin agreement). We are no longer willing to join the shoulder-shruggers. We, people on the ground, seem to be more progressive in terms of asylum politics than the discouraged and, in this case, dishonest 'high' politicians" (Gemeinde Alberschwende 2015). This means that not only the migrants were depending on local support, but also those local networks of support depended on the presence of the migrants: If these migrants had not come in the summer of 2015 with their stories, experiences, desires and perspectives, these networks 
of support would simply never have existed. The presence of those who traveled or fled enabled the support networks to hear new stories and histories. They heard stories first-hand, face to face, which they might have heard before through the mass media but had long forgotten behind other broadcasted horror stories.

Therefore, migration brought about a politicization of those that enjoy - seemingly naturally - the rights of the citizen through which a denormalization of the state and the nation took place, irrespective of whether the people affected by this politicization considered themselves as helpers, supporters, activists or voluntaries. Through these forms of connection and of support debates emerged on who should be able to live "here" and under which conditions. Who was to be considered "from here", who should not be living under certain given conditions, and with whom one wants to live were questions that exceeded the limited realm of law. Instead, these questions were discussed in shock, quiet, shame or fury next to the toilet at the railway station, the sidewalk in front of the refugee camp, during a common dinner, or on holidays at the sea.

The present nation state model of distribution of rights and duties, which enables a relatively good life for some while deporting, incarcerating and criminalizing many others thereby making them even more exploitable, suddenly appeared as no longer the only option. Rather, it stood for what it is: just an alternative among better ones. Thus, the summer of 2015 revealed that political conditions are certainly not set into stone. "To question the state through the detour of immigration leads, in final analysis, to 'denaturalize' what is almost considered "natural". As a consequence, the state (or that what is within it), infected as it was by a history amnesia, is getting historized again, which in turn means that we are remembered of the social and historical conditions of its formation" (Sayad 2015: 39). 


\section{De- and Renormalization}

Since this summer of 2015, much effort has been invested in the renormalization of the migration regime. The fantasy of closing and opening of migratory routes proliferates as never before, as if the streams of migration could be opened and closed as a water tap. The ghost of integration is haunting the present as if Kanak Attack, Maiz, 1.März, the many Refugee Protest Camps since 2012, Non-Citizen Conferences, No-Border Camps, Refugee Forums, flight support convoys, smuggling networks, post-migrant theater, Sans Papiers occupations, and many more antiracist and post-national forms of cross-connection of the last years and decades never existed. However, there is something primal to those dreams of control, desires of integration, processing, and job creation that is worth remembering: a force against which to react, that should be governed; a movement that forever differently runs riot, gets carried away, and never lets itself be totally managed. It is a potentiality that will make the water tap leak again and again, no matter how many other taps or how much thread seal tape is added. This resistance, this force, that is continuously challenging government and management, was often referred to as the autonomy of migration. "If necessary, we will find loopholes over mountains, through villages, or through the jungle." [3]

The autonomy of migration does not primarily describe a kind of heroic practice that originates from just neglecting the existing obstacles and controls. Instead, the term autonomy is an attempt to understand the capability of braving control and confinement in a given moment only to escape in the next moment, to maybe come up with an unexpected story in another situation that is capable of distracting supervisors. Just as it is pointless to wrap migrants or migration in imaginations of pity and victimization, it is also absurd to heroicize and romanticize migration. Repeatedly withdrawing 
itself from representation and placement, migration is neither victim nor heroine. It is maybe both, but probably something completely different.

The cross-border movements of people that made their way to a given destination even though they supposedly should have stayed put, crosses as often well as not the secured border lines. Transport is at times expensive and at other times not, sometimes dangerous, other times funny, in one moment quick and full of hope, in the next tough, wearing, deadly and traumatizing. The movements of migration run along very different lines and realities - paths significantly affected by state obstacles, filters and barriers, as well as by violent or pleasant smugglers, by the availability of money, and by information and infrastructure. And all this, depends for sure much on one's friends. The autonomy of migration lies thereby less in a romantic, independent heroism but much more in getting further "partly-in-common" despite all the opposition - "partly-in-common" because the networks of support are not homogeneous communities of unbroken solidarity and collectivity, neither are they free of exploitation and violence. Yet, the existence of these conflictual and ambivalent networks of support, care and exchange are the very condition to migration[4]. Networks of exchange among migrants (in which, as mentioned above, here and there also non-migrants might be involved) are especially important here because they enable migrants to move faster or to arrive despite hindrance and deterrence. The summer of 2015 has shown us that it is possible that those not taking this governance of migration for granted, this distribution of rights, possibilities and affects, become more both in terms of sheer numbers and in terms of differences. At the same time, the summer of migration contradicted this governing and this division in government and governed insofar as it referred to the fact that politics can never be the business of a few professional 
politicians but rather it is an ongoing work on the question of how we, who are here in this very moment, want to deal with each other and the problems we face together.

Whether migration is welcomed, exploited, included or criminalized, she will carry on by finding new paths; "if necessary", as stated above by the person at the Belgrade train station. Its capacity to create forms of connection and of commons that perpetually produces social realities, different than those provided and prescribed by the nation state, is decisive for this resistance and persistence. Autonomy thereby lies in the creative and inventive force of uttering new social networks, narratives, and affective connections that repeatedly undermine, surround, besiege and put under pressure the enclosure of the nation state - whether it is revealed or concealed in a given historical moment.

\section{References}

Gemeinde Alberschwende (2015): Manifest Alberschwende URL: http://www.alberschwende.at/fileadmin/Download/Asylverfahre n-Manifest_und_Aktivit\%C3\%A4ten.pdf [12.09.2016].

Kuster, Brigitta (2017): Europe's Borders and the Mobile Undercommons. In: Texte zur Kunst 105. Papadopoulos, Dimitris / Tsianos, Vassilis S. (2013): After Citizenship: Autonomy of migration, organisational ontology and mobile commons. In: Citizenship Studies 17 (2). 178-196.

Sayad, Abdelmalek (2015): Immigration und "Staatsdenken«. Translated by Birgit Mennel. In: Birgit Mennel and Monika Mokre: Das große Gefängnis. Vienna: transversal texts. 


\section{Notes}

[1] This text is based on an article published under the name dealen, schleppen, willkommenheißen - Kämpfe um Bewegungsfreiheit nach dem langen Sommer der Migration in the edited volume Der lange Sommer der Migration - Grenzregime III 2016 with assoziation-A.

[2] For more details, please visit f.ex. http://movingeurope.org/march-of-hope-3/

[3] This is my translation of the translation of a quote by an interviewee at the central bus station of Belgrade in the summer of 2015.

https://www.welt.de/politik/ausland/article146507736/Wer-diehistorische-Grenzoeffnung-wirklich-ausloeste.html

[4] For more information in this topic see Papadopoulos / Tsianos 2013 or Kuster 2017

Niki Kubaczek is a sociologist, activist and publisher based in Vienna. He is a member of the editorial boards of transversal texts (transversal.at), of the eipcp (http://eipcp.net) of kritnet - Network for Critical Border Regime and Migration Research (http://kritnet.org) as well as of the council of the section for racism and migration research of the austrian association of sociology. Nikis main research interests are antiracism, critical migration research, queer feminist and postcolonial theories, poststructuralism, political theory, social movements studies and questions of solidarity, as well as friendship, difference, affect and commons. 


\section{Volunteers and NGOs in Austria's border management regime, Spielfeld 2015}

Lukas Milo Strauss

Originally published in 7/25/2017

In the coverage of the EU's self-proclaimed 'refugee crisis', some of the most widely circulated images in the Austrian news media concerned the 'breaking through' of refugees at the AustrianSlovenian border in Spielfeld in October 2015. A few containers and mobile fences proved insufficient for containing thousands awaiting entrance under increasingly harsh conditions. The purported state of lawlessness made the successful management of Spielfeld's border crossing a top priority for Austria's center-right government.

Consequently, the modestly equipped border post was enlarged to a full-fledged militarized camp. Replete with search lights, armed vehicles, the distant drone of a helicopter scanning the area with thermal imaging cameras and seemingly endless police barriers, it created a 'state of exception[i]' like no other state intervention at that time. The camp was conceptualized as a "transit camp", meaning those newly arrived were only to be detained on a temporary basis. A bus service was established to forward the refugees to their next destination - usually the German border or the permanent camp at Traiskirchen - as quickly and uneventfully as possible. Large tents were set up to provide rudimentary accommodation. Bag searches and basic identity checks were conducted separately, whereas a full registration protocol was not in place until 2016. 
I began fieldwork in the region in November 2015[ii], at a time when high-security approaches to border management were gaining prominence in the wake of the Paris attacks. Still, despite its militarized set-up and the presence of large numbers of federal police, Austrian Armed Forces, a private security company and the BVT (the 'Federal Office for the Protection of the Constitution and Counterterrorism'), the camp also involved large civil organizations. Red Cross staff were responsible for providing medical aid, handing out pre-packaged travel provisions and beverages, while Caritas Austria handled clothing donations and the enrollment of lay translators. Also, an activist-operated mobile kitchen was striving to provide hot meals for all newcomers. All three non-state organizations relied heavily on volunteer labor. While the bulk of the workload was carried out by volunteers - usually middle-aged men and women from the region professional NGO staff were charged with assigning tasks and supervising work routines.

The camp was organized according to a very tangible hierarchy. Refugee-internees and NGO volunteers were ranked at the bottom, NGO staff and contractors at the medium levels, while the higher echelons were constituted by members of the executive. This hierarchy for the management of large numbers of people in the camp assigned concrete and unambiguous locations and tasks to each group. For refugees, this meant staying in the tents until ordered to proceed to the food distribution or pick-up area, except when using the mobile toilets located in small, fenced-off areas on the sides of the tents. For volunteers, it meant having to pre-register 24 hours before starting their shifts and being subject to identity verification processes at two checkpoints upon entering the camp. Just like other camp personnel[iii], volunteers needed to be identifiable at a glance, with colored vests displaying a unique 
identifying number and their organization. Thus, their assigned tasks and appropriate location in the camp were also made visible. When working a shift, they were expected to stick to their assigned workplaces (food and clothing distribution counters or the kitchen) or a container designated as a common room for NGO staff. They should act only on orders and comply with an extensive set of rules that governed their conduct in the camp, especially their relationship to the refugee-internees. Personal contact was to be kept to a minimum, individual favors could not be granted and volunteers were to stay clear of the refugee accommodation and the border zone. Non-compliance could be punished with immediate expulsion, blacklisting the offender for voluntary work on a nationwide basis and, incidentally, legal prosecution. Some volunteers were subject to non-disclosure agreements, preventing them from discussing any aspect of their work outside the camp.

The structured organization of the camp was reflected in an information hierarchy that provided camp personnel only with a bare minimum of contextual information. Kitchen staff received word only on whether they should continue their work or pause, and usually didn't know how many people they were cooking for, or if the newcomers would be allowed to the food distribution counters or sent straight to the tents (and if so, why). Rumor became a primary source of information for all those excluded from the levels of decision-making. These attempts at 'crowdsourcing' the truth were not limited to volunteers and refugees, but appeared to include lower-ranking security personnel as well. Among the talk of great numbers awaiting entry, fights erupting and guns being seized, some oft-repeated stories acquired the status of self-legitimizing myths, justifying administrative decisions (or, occasionally, justifying ignoring those decisions). An example was the claim that refugees could never be granted WiFi access[iv], because the deceptive 
proximity of Germany in GPS-based mapping services like Google Maps would lead them to believe their final destination to be within walking distance, thus provoking unrest and possibly rioting. Similarly, volunteers would interpret the absence of an order to hand out blankets not as a lack of need for blankets, but as a commanding officer not wanting to deal with "the fuzz" (i.e. the commotion about bedding) - only to be informed that if there was not one blanket for each internee, it would most certainly lead to rioting. These stories acquired both their 'legitimizing' and their 'mythical' qualities against the backdrop of the 'chaos days' and perceived lawlessness that had supposedly reigned at the border crossing prior to the establishment of the camp order[v].

The subordinated status of their work presented many volunteers with the danger of their labor power being separated from their political convictions[vi]. After all, they were contributing to and being directed by the state's border management regime, although frequently skeptical of its intentions. Volunteers often seemed to confront this dilemma by introducing their own ideas whenever supervisors and executives were absent or undetermined on how to proceed. Gaps in the organizational protocol would then readily be filled with their own conceptions of how their work should look like, e.g. how much and which food should be given to each person, what clothes should be handed out to whom and what amount of social interaction and additional services (e.g. charging of cellphones, provision of information ...) should be granted to each 'customer'.

Supervisors and executives were generally aware of this and sought to counter it whenever possible. The volunteers' status as civilians with unclear motivations and agendas - voluntary work lacking the rationale of wage labor - led some policemen and soldiers to regard them as "dangerous subversives", treating them with suspicion and sometimes open hostility. Other perceptions, especially among 
some higher-ranking officials, ranged from considering volunteers a "necessary evil" (as being part of "the civil society" that could not effectively be excluded from state operations) or a "welcome support". Their appreciation of volunteer work was often phrased in disciplinary terms, for example when stating that "the food makes them [the internees] calm down".

To summarize, volunteer work in the militarized setting of the Spielfeld transit camp differed sharply from other situations where volunteer-activists became involved in refugee arrivals (cf. the 'Train of Hope' engagement at Viennese train stations). The joining of civil organizations and a number of diverse government bodies in the hierarchical structure of the camp not only raises questions of governance, it also points to the complexity of state practice in times of crisis, of which civil voluntary work is but one layer. The organizational structure at Spielfeld is by no means self-evident, as even a superficial glance at the transit camps in Šentilj and Bad Radkersburg reveals. Both - Šentilj being Spielfeld's Slovenian counterpart; Bad Radkersburg an Austrian border crossing only $35 \mathrm{~km}$ to the east - exhibited a different structure, with comparatively little police presence, a stronger emphasis on humanitarian concerns, and most noticeably for me, an organizational ethos that promoted the ordinary over the exceptional in the face of crisis.

\section{Notes:}

[i] Agamben, Giorgio. 2014 [2004]. Ausnahmezustand. Frankfurt a. M.: Suhrkamp.

[ii] I conducted participant interviews by volunteering for various NGOs working in the camp. Supplementary data stems from 
informal conversations I had outside the camp, usually with off-duty camp personnel, residents or regional activists. With several interruptions, the fieldwork process lasted until January 2016, when the flow of refugees was redirected to the Carinthian border crossings.

[iii] Seeing as refugees were the only people in the camp not wearing uniforms, it could be argued that in the closed setting of the camp, their everyday clothes took on the meaning and function of a 'uniform for internees'.

[iv] The minor Viennese political party 'Der Wandel' had provided mobile WiFi access points for refugees.

[v] 'Myths' also in the sense that they were employed frequently by people who had never actually experienced the 'troubles.

[vi] Without exception, the volunteers I talked to perceived their work as political contributions in the specific setting of the refugee situation, rather than general philanthropy or conceptions of 'civic duty'.

Lukas Milo Strauss worked as a volunteer for several organizations in Spielfeld refugee camp. He is currently a student of cultural and social anthropology at the University of Vienna. His main research interests lie in the field of political anthropology (and particularly on the anthropology of the state), transnational governance, and the social life of institutions. He has conducted research on corporate social responsibility in the Nicaraguan sugar industry (2103-2015) and on transformations in the Austrian border management regime (2015-2016). 


\title{
(Neo-)paternalism and moralism in Austrian language policy
}

\author{
Marija Cubalevska \\ Originally published in 7/31/2018
}

After mastering often difficult journeys to their destination, refugees face numerous administrative obstacles as they try to adapt to a new life in a different society. As part of Austria's language policy, they have to sign an 'Integrationsvertrag' or 'Integrationsvereinbarung' (=integration contract / integration agreement). This law was issued in 2003 and has since then been amended several times (the last time in 2017). In order to obtain or extend their residency permit, all citizens of third member states who are not part of the EU (including refugees) are obliged to attain a certain level of proficiency in German within a certain period of time and pass classes on Austrian values called 'Werte- und Orientierungskurse'.

In my research I explore the question of how these legislative measures are presented and legitimized. My focus is on the most important institution in this area, the Österreichischer Integrations Fonds (Austrian Integration Fund for, henceforth ÖIF). ÖIF is responsible for implementing the 'Integrationsvereinbarung' and 'Integrationsvertrag' i.e. financing and evaluating educational institutions, organizing the classes on values and conducting both language proficiency and value tests.

The measures contained in the 'Integrationsvereinbarung' and the 'Integrationsvertrag' are presented along (neo-)paternalistic or moralistic lines. Paternalistic lines of argument stress that the measures taken (like the obligation to learn German) are 
implemented for the migrants' own good. Neo-paternalism, as defined by Niku Dorostkar (2012, 77ff), is associated with discourses arguing that people should want to learn German on their own accord instead of being forced to acquire it. Rather than through legal measures, the desired effect is to be reached by helping the targeted individuals to take "the right decision", whereby what is wrong and right has already been defined for them. Stutter/Maasen (2010, 321333) also describe this phenomenon as "crypto-paternalism". In this scenario, paternalism takes the form of a top-down prescribed selfhelp mechanism through which limited autonomy and empowerment can be reached, but only as long as they are used for the "right" cause. This implies that migrants should not only accept the obligation to learn the language; they should also support the measures enthusiastically. In this line of argument, German is often referred to as the language or our language, implying that fruitful communication in Austria cannot occur by means of any other language than German. This moralistic argumentation imagines national communities as culturally singular and homogenous entities. In order to uphold this image, clear boundaries between the own culture and other cultures need to be drawn - any differing cultural expression within one's own defined boundaries is interpreted as a threat to national identity and unity.

A case in point is the ÖVP (Austrian People's Party) election program for the national elections of 2017. It cites a study according to which German is not the primary medium for over $25 \%$ of students attending Austrian schools. According to the same study, $70 \%$ of the students attending middle schools (Haupt- and kooperative Mittelschulen) in Vienna do not use German as their primary language. (Österreichische Volkspartei 2017, 48) The underlying assumption is that people only resort to one language for colloquial speech. Taken at face value, these statements imply that $70 \%$ of the 
kids in Viennese secondary schools only use a single language in their everyday life, and this is not German. They do not admit the possibility of having two or multiple colloquial languages which are used consecutively or even mixed simultaneously.

Perhaps even more problematic than the forced language learning are the courses and tests on values. It is assumed that 'Austrian values' are something that people who are born as Austrian citizens automatically share and uphold, while newcomers have to study and adopt them. But what exactly are these values and who defines them? No official definition of 'Austrian values' has ever been undertaken, which means that the ÖIF gets to specify them. The brochures entitled 'My life in Austria - opportunities and rules' and 'Rot-weißrot-Fibel' outline the basic principles of parliamentary democracy and secularism. They explain some specific Austrian laws and customs, such as the daily 'Nachtruhe' from $22.00-06.00$. They teach basic principles of human behavior and lawfulness, for instance, that it is illegal to hurt another person physically or to use public transport without buying a ticket. The content of this material says more about ÖIF's perception of migrants and refugees than it says about Austrian values. Refugees are unequivocally portrayed as primitive and ignorant of basic democratic principles.

According to Krumm (2002), the 'Integrationsvereinbarung' has nothing to do with integration, but is simply a euphemism for racist policies. Under the etiquette of 'integration' diversity is being suppressed and excluded, elements defined as 'foreign' are being silenced and made invisible. Unfortunately, over the years, this tendency has become stronger.

In ÖIF's publication entitled 'Perspektiven Integration' the racist ideology is even more blatantly visible, 'Migration does not necessarily have to stand in opposition to the social welfare state, but 
is undoubtedly a big challenge for it. If this societal model is supposed to function in times of impactful migration movements, migrants need to identify and feel connected with Austria, the country in which they live and where a new home is being offered to them.' [Wolf: 2017; translation by M.C.].

Here, an artificial contrast between participation in the Austrian welfare state and identification with Austria is created. It implies that migrants per se pose a threat to the welfare state and, by extension, a threat to all Austrian citizens. This argumentation obscures the fact that participating in the welfare state (i.e. paying taxes) is not optional but obligatory for everyone working and living in Austria, regardless of their national or cultural identity. These examples demonstrate how culturally racist policy making in Austria is legitimized by construing a homogenous national-cultural identity for Austria and twisting such concepts as integration.

\section{References}

DOROSTKAR, Niku: Linguistischer Paternalismus und Moralismus: Sprachbezogene Argumentationsstrategien im Diskurs über 'Sprachigkeit. In: Aptum. Zeitschrift für Sprachkritik und Sprachkultur. 8. Jahrgang: 2012, Heft 1, S. $61-84$.

KRUMM, Hans-Jürgen: One sprachen konten wir uns nicht ferstandigen. Ferstendigung ist wichtig. Entwicklung und Tendenzen in der Sprachlehrforschung im Bereich der Migration und Integration. Vortrag im Rahmen des Symposions "Sprache und Integration" Wien am 22.02. 2002 / Institut für Germanistik / Wien. 
STUTTER, Barbara \& MAASEN, Sabine: „Bürgergesellschaft“. Der verdeckte Paternalismus eines politischen Programms. In: Bijan Fateh-Moghadam u.a. (Hg.) Grenzen des Paternalismus. Stuttgart: 2010, S. 318-340.

WOLF, Franz: Sozialstaat und Integration. In: Perspektiven Integration 07/2017. Österreichischer Integrationsfonds

Bundesministerium für Europa, Integration und Äußeres (Hg.): My Life in Austria - Opportunities and Rules. Österreichischer Integrationsfonds Lindenau Productions GmbH / Wien: 2013.

Bundesministerium für Inneres (Hg.): Zusammenleben in Österreich (Rot-Weiß-Rot-Fibel) 2013.

Der neue Weg. Aufbruch und Wohlstand. Programm der Österreichischen Volkspartei zu Nationalratswahl 2017.

Marija Cubalevska is currently studying linguistics with a focus on German as a foreign or second language in Vienna. She is especially interested in the political dimension of language in the context of migration. Currently she is writing her master thesis on how "Austrian values" are being construed and conveyed to refugees during the institutionalized process of integration. She has also been a political activist in Austria and Macedonia for many years. 


\section{The Integration of Syrian Asylum Seekers in Austria in Light of Catholic Social Teaching}

Pia Jolliffe

Originally published in 7/18/2016

The role of religion in conflict and peacebuilding is an established research area within the social sciences1. Faith-based organizations provide forced migrants around the world with humanitarian assistance and social services. Yet, in spite of this fact until the 2000s religious issues were largely ignored by academic research as well as in public debates about forced migration2. Since then studies of refugees and forced migrants increasingly revealed the intersection between religion, spirituality and forced migration. This body of research highlights the importance of religion as forced migrants renegotiate their identities within a continuum of migration, including internal displacement, life within and beyond refugee settlements in first countries of asylum or third countries of resettlement 3 as well as the history and implications of various faithbased humanitarian responses to forced migration 4.

The social teaching of the Catholic Church provides conceptual tools the analysis of the situation of asylum seekers and refugees around the world. In particular, the interrelated principals of the common good, of subsidiarity and of solidarity lend themselves to better understand the phenomenon of forced migration at different levels of society. The principal of the common good refers to the social and community dimension of the individual moral good. It indicates the sum total of social conditions, such as hospitality, education and care, which allow groups or individuals to flourish more fully and more 
easily. Those in government have a responsibility to defend and promote the common good5. At times, civil society needs to complement the State in the promotion of the common good. For example, in 2015, 24,720 people with Syrian citizenship applied for asylum in Austria6. The refugee camp in Traiskirchen (Lower Austria) was the first place where many registered and claimed asylum. The camp can shelter 1,800 people. However, on 1stAugust $2015,4,500$ people were living there in a precarious situation7. As a consequence, a range of local civil society initiatives sprung up to assist refugees and bridge between them and the Austrian population. Also different faith communities became active in delivering hospitality and basic care for those in need of protection.

For example, in July 2015 during the Islamic month of fasting ("Ramadan"), the Islamic community in Traiskirchen organized after sunset daily meals for 2500 asylum seekers and refugees without asking for their religious affiliation8. It is important to bear in mind that "institutionalized networks of giving and receiving are also always structures of unequal distributions of power, structures welldesigned both to mask and to protect those same distributions" and accordingly there "are always possibilities of victimization and exploitation bound up with participation in such networks9". In this respect, Monika Moikre draws attention to the tensions and frictions that arose between the feminist and anti-racist engagement of Austrians who developed personal intimate relationships with refugees of different cultural and/or religious background10.

The basis of the principal of subsidiarity is that organizations of higher order should assist ("subsidium") smaller organizations and societies of people: "Subsidiarity, understood in the positive sense as economic, institutional or juridical assistance offered to lesser social entities, entails a corresponding series of negative implications that require the State to refrain from anything that would de facto restrict 
the existential space of the smaller essential cells of society. Their initiative, freedom and responsibility must not be supplanted." 11 In regards to the protection needs of refugees and asylum seekers, the principal of subsidiarity may imply an expansion from the statecentred framework provided by the 1951 Convention relating to the Status of Refugees towards an approach to protection that incorporates refugees' perspectives on their own needs and circumstances. Indeed, intersectionality of social categories shapes individual Syrian needs for different forms protection. Syrians not only differ in terms of their religious affiliation, but also in terms of their education, social status and political affiliations. Whether or not a man or a woman grew up in rural or urban parts of Syria often determines whether or not they had access to schooling. Whilst most men and women from urban areas are literate and often hold diplomas from institutions of higher education, those who come from rural areas - in particular women - arrived illiterate.

Accordingly, these groups have different needs for their integration into Austrian society. For example, the Sovereign Military Order of Malta specializes on assisting highly skilled asylum seekers and refugees. Volunteers of the Order of Malta organize German language classes in cooperation with the St Ephrem Syrian-Orthodox church which has been in Vienna since 1974. The Syrian asylum seekers who are members of this community typically come from urban areas such as Damascus, Homs and Aleppo. They are often highly skilled and educated: most adult men and women hold university degrees in medical sciences or in engineering. If they want to work in Austria, e.g. as engineers and doctors, the recognition 'nostrification' - of their Syrian degrees is necessary. In turn this process includes a language test to ascertain the applicant has mastered the specialist vocabulary for their professional field. In the long absence of such state-sponsored courses, local Maltese Order 
volunteers who are medical doctors or engineers regularly meet Syrian professionals for language training. They also seek placements to participate in local hospitals and clinics.

The principal of solidarity, emphasizes the interdependence between individuals and peoples at and across the micro, intermediate and macro levels of society. It is a moral and a social virtue because it marks a firm determination to commit oneself to the common good and is placed into the sphere of social justice. For example, across the Archdiocese of Vienna, the Roman Catholic organisation Caritas mediated between asylum seekers, refugees and parishes who were able to offer flats. The assignment of individuals or families to parishes was independent of asylum seekers' religious affiliation: "If someone says he would only like to accommodate a Christian family, we answer that we cannot arrange that because peoples' religious affiliation is first not being registered and second not a criterion for exclusion for us. We say, we want to help human beings, independent of their religious affiliation" (Interview, Caritas, 8 February 2016).

Thus faith-based organizations complement the Austrian State; sometimes they take on responsibilities hitherto attributed to the State. In doing so, they and other local initiatives bridge between asylum seekers, political elites and residents. Yet, there is a danger of volunteers exhausting themselves and feeling abandoned by politicians12. Therefore, in order to put the principalsof the common good, of subsidiarity and of solidarity into practice, it is necessary for those responsible for government to better understand how social diversity among Syrians affects individual asylum seekers' and refugees' needs for protection and humanitarian assistance, to support voluntary faith-based and other organisations and to publicly recognize their contributions to social cohesion within a fast changing society. 
Acknowledgements: I am grateful to the Oxford Institute of Population Ageing for funding parts of this research between February and March 2016.

\section{Notes}

1 Silvestri, S. and J. Mayall. (2015). The Role of Religion in Conflict and Peacebuilding. London: The British Academy.

2 Godźiak, E. M. and D. J. Shandy. (2002). "Editorial Introduction: Religion and Spirituality in Forced Migration." Journal of Refugee Studies 15(2), p.129.

3 Mayer, J.-F. (2007). "Introduction. 'In God Have I Put My Trust': Refugees and Religion." Refugee Survey Quarterly 26(2), p. 10.

4 Fiddian Qasmiyeh, E. (2011). "Introduction: Faith-Based Humanitarianism in Contexts of Forced Displacement." Journal of Refugee Studies 24(3), p. 430.

5 Pope Francis. (2015). Laudato Si'. On Care for Our Common Home.Encyclical Letter. London: CTS, p. 77.

6 Eurostat. (2016). 'Asylum and first time asylum applicants by citizenship, age and sex Annual aggregated data (rounded)', http://ec.europa.eu/eurostat/statistics-

explained/index.php/File:Five main citizenships of \%28non-

EU\%29 asylum applicants, $2015 \% 28$ number of first time applic ants, rounded figures\%29 YB16.png

7 Amnesty International. (2015). QUO VADIS AUSTRIA? Die Situation in Traiskirchen darf nicht die Zukunft der 
Flüchtlingsbetreuung in Österreich werden. Vienna: Amnesty International.

8 Mokre, M. (2015). Solidarität als Übersetzung. Überlungen zum Refugee Protest Camp Vienna. Wien et al.: Transveral texts, pp. 217218.

9 MacIntyre, A. (2009). Dependent Rational Animals. Why Human Beings Need the Virtues. London: Duckworth, p. 102 10 Mokre, M. (2015)., pp. 176-178.

11 Pontifical Council for Justice and Peace.2012. Compendium of the Social Doctrine of the Church. London and New York: Burnes \& Oates, pp. 81-102.

12 Rosenberger, S. (2016). 'Freiwilligen-Organisationen als Integrationsmotoren' Interview with Jessica Richter, Uni:View Magazin, 23 March 2016, https://medienportal.univie.ac.at/uniview/semesterfrage/detailan sicht/artikel/freiwilligen-organisationen-alsintegrationsmotoren/]

Pia Jolliffe is a Fellow at Blackfriars Hall, University of Oxford, where she teaches Japanese History and member of ROR-n. She holds a Mag.Phil. in Japanese Studies, Sociology and Political Science from the University of Vienna (Austria) and a DPhil in International Development from the University of Oxford (United Kingdom). Pia has also worked as consultant for the United Nations High Commissioner for Refugees in Geneva (Switzerland). Her main research interests are: the nexus between migration, international development and life course transitions. 


\section{Civil Society in Izmir or how an elusive concept could become useful}

Denise Tan

Originally published in 11/3/2016

Izmir, close to several Greek islands in the Aegean, has become a refugee hotspot, with hundreds of thousands of forced migrants arriving in the last few years. I went to Izmir to conduct fieldwork on civil society organizations for my MA thesis in autumn 2015, when the UNHCR noted the highest number of refugees arriving in Greece so far. Several local NGOs were established in Izmir in reaction to the high influx of forced migrants especially since the Syrian war. I focused on these organizations from the perspective of civic society, not from a classic forced migration and refugee studies point of view. As Elena Fiddian-Qasmiyeh recently stated, international humanitarian organizations have been studied from a forced migration perspective but "South-South humanitarianism" or "refugee-refugee humanitarianism" [i] have mostly been ignored. Humanitarian activities from local organizations in the South were discredited as faith-based or ideological and therefore hardly studied. However, Ms Fiddian-Qasmiyeh sees the need to take these local organizations into consideration. Hence I hope focussing on local NGOs and civil society organizations will contribute not only to the literature on civil society, but also to the study of forced migration and refugees.

The term 'civil society' is hardly ever defined, but implicitly understood within a liberal approach to politics. This broadly defines civil society as voluntary, self-governing organisations which 
operate between the spheres of the individual and the state[ii]. These organisations work for the 'good of society' and boost liberal qualities like freedom, cooperation, democracy, tolerance and trust. Within academia, the concept of 'civil society' civil society is more ambiguous. Most articles start by outlining imprecise, elusive and highly ideologized character of this idea[iii]. However, an anthropological concept of civil society can be useful for studying social organization and structure.

The new NGOs in Izmir have different profiles and ideological backgrounds: Islamic, secular, leftist or human-rights based; professional or voluntary; office based or with a field outreach outreach; "refugee-specialized" or generally working with marginalized people; privately or internationally funded. Despite these differences, most offer similar humanitarian services. In that context, two local NGOs that provide legal assistance and medical support are exceptional. Besides these activities directed towards refugees themselves, local NGOs play a crucial role as intermediaries for international bodies, journalists, and academics. International organizations, and social scientists (including myself) depend on NGOs to gain access to the field and get in touch with refugees. During the time of my fieldwork, organizations like WASA or International Medical Corps tried to establish a foothold in Izmir. The first thing they did was to look for local, groups, observe their activities, and analyze how and with whom they could mingle. Thus, the ethnographic material suggests that international organisations depend on associations on the ground in order to establish themselves within a new field. The same may be true for social scientists and researchers. Also, journalists as well as representatives of the European Union ask NGOs for information on the current situation[iv]. 
Forced migrants often cannot identify who they received what aid from and have little knowledge about who is behind this aid. Urban migrants in Turkey face difficulties on several levels, especially in relation to housing, work, legal conditions, health and education. It is clear local NGOs can only reach a small part of the large number of refugees in Izmir, who are of course very grateful for their help. The ethnographic material revealed that informal networks and groups support refugees in finding work and housing (which are refugee priorities). Neighbours (often refugees but also others), Facebook groups and Syrian solidarity networks help organising and managing their new life conditions. They help with translations at work or in hospitals - and even more importantly - link refugees with local NGOs. Information concerning different NGO services is spread among these networks and leads refugees directly to NGO offices or places. NGOs benefit from this word of mouth communication, as they would otherwise have to put resources into communicating with migrants spread among the 4 million people in the Izmir province. Thus, these different social groupings - informal associations, local institutions and international organisations - are connected and interdependent.

Because of the "NGOization" of liberal political approaches to civil society, international and local NGOs are in the focus whereas informal networks receive less attention[v]. Additionally, these approaches define civil society as a normative concept bound to Western liberal values. Anthropologists criticised this Eurocentric dimension of civil society in the 1990s[vi], when the concept started to become popular again. Robert Layton offers a definition of civil society, which detaches it from this normative dimension: "One cannot include in the definition a moral requirement that civil society function to support or oppose the state, nor that it should exclusively promote individual liberty or group cohesion"[vii]. He 
understands civil society as a generic term for all kinds of organizations that operate between the household and the state and enable individuals to coordinate and manage resources and collective activities. Thus, both economic and non-economic activities belong to civil society such as associations, NGOs, churches, clubs, ethnic or kinship groups and (as I emphasise) informal networks.

One might argue in anthropological circles that the term social organisation theoretically already includes these associations and institutions. However, the focus remains mostly on local levels of the household, kinship, village or a defined urban environment in interaction with larger levels such as the state, transnational networks and connections[viii]. Explicitly naming civil society and emphasizing its role in addition to these well-known and established forms of social organisation helps to incorporate NGOs, neighbourhood networks, virtual groups, initiatives, clubs and other forms of informal bodies within the study of organization at local level.. These networks and groups not only work transnationally; they are much more innovative and fluid in that they arise spontaneously in reaction to specific situations. Refugee NGOs and associations developed as forced migrants settled in Izmir's central district of Basmane. A group of Syrian immigrant friends, became active, when they saw Syrian refugees couldn't communicate with doctors due to the language barrier.

This approach seems appealing for the study of forced migration and refugee as forced migrants are (partly) disconnected from their accustomed forms of local organisation when they are forced to stay in another country. In Turkey, the state hardly supports refugees in managing their new living conditions, let alone helping them to integrate into Turkish society. Instead, different forms of society formal and informal, local and transnational - become relevant. In 
Austria, where asylum procedures strictly regulate forced migrants' lives, formal bodies in civic society, mainly Christian NGOs, take care of asylum seekers and refugees. It would be interesting to study these organizations; see for example Pia Jolliffe's blog entry (http://www.ror-n.org/-blog/the-integration-of-syrian-asylumseekers-in-austria-in-the-light-of-catholic-social-teaching). At the same time, we shouldn't forget other informal groups within civil society, which may not be obvious at first sight, but which play important roles within forced migrants' social organisation.

\section{References}

[i] Fiddian-Qasmiyeh, E. (2016). Repressentations of Displacement from the Middle East and North Africa. Public Culture, 28 (3 80), 457 473. p.463

[ii] Ishkanian, A. (2007). Democracy promotion and civil society. In M. Albrow, M. Glasius, H. K. Anheier, \& M. Kaldor (Eds.), Global Civil Society 2007/8: Communicative Power and Democracy (pp. 58-85). London: SAGE.p. 60

[iii] Edwards, M. (2011). Introduction: Civil Society and the Geometry of Human Relations. In: M. Edwards (Ed.): The Oxford Handbook of Civil Society. Oxford: Oxford University Press. p. 7

\section{[iv] https://www.facebook.com/Izmirde-suriyeli-}

m\%C3\%BCltecilerle-dayani\%C5\%9Fma-derne\%C4\%9Fi$\underline{646585155366750 /}$ 
[v] Akkaya, G. (2012). Nichtregierungsorganisationen als Akteure der Zivilgesellschaft: Eine Fallstudie über die Nachkriegsgesellschaft im Kosovo. Wiesbaden: VS Verlag für Sozialwissenschaften. p. 59

[vi] See Hann, C., \& Dunn, E. (Eds.). (1996). Civil Society - Challenging western models. London: Routledge.; Comaroff, J. L., \& Comaroff, J. (Eds.). (1999). Civil Society and the Political Imagination in Africa: Critical Perspectives. Chicago: University of Chicago Press.; or Fisher, W. F. (1997). Doing Good? The Politics and Antipolitics of NGO Practices. Annual Review of Anthropology, 26, 439-464.

[vii] Layton, R. (2004). Civil Society and Social Cohesion - A reassessment. Working papers/Max Planck Institute for Social Anthropology, 63. p. 4

[viii]Eriksen, T. H. (2010). Small Places, Large Issues: An Introduction to Social and Cultural Anthropology (Vol. 3rd ed). London: Pluto Press. p.63ff

Denise Tan is an MA student at the Department of Social and Cultural Anthropology at the University of Vienna. Her MA thesis discusses NGOs and non-camp refugees in Izmir/Turkey from a civil society perspective. The thesis is based on ethnographic fieldwork conducted during autumn 2015 in Izmir, which was funded by the short-term grant abroad (KWA) from the University of Vienna. 


\section{The Ethics of Struggle: when refugees become hosts of other refugees}

Monika Halkort

Originally published in 3/24/2017

Studies about refugees and host societies often presume a relationship between strangers, who have little in common but their spatial proximity. The primary concern here is how time-honoured ideals of liberal government are mobilized for exclusivist projects to secure (white) privileges, using the social contract between citizens and their governments to restrict the rights and entitlements of refugees. Far less has been said about situations in which refugees themselves are cast in the role of hosts, taking in people with similar life trajectories and origins or even a shared common cause. Such is the case for about 450,000 Palestinians who have been living in Lebanon ever since their forced displacement (1948). With the outbreak of war in Syria, Palestinian camps have become a primary destination for refugees trying to escape the intense fighting in Damascus, Aleppo and other highly contested areas. Their presence has opened deep seated divisions within the exile population, and upset long-standing commitments to the ethics of struggle commitments that once defined Palestinians.

Palestinians make up only a tiny fraction of the 4.8 million people who have fled Syria since 2011. Of the 120,000 who made it across the border, about 30,000 ended up in neighbouring Lebanon (UNRWA, 2017). Not all of them live in camps, where rent is much cheaper. About $50 \%$ ended up in cities and villages across Lebanon. Palestinians from Syria are not the first generation of refugees to arrive in camps such as Nahr el Bared in the north, or 
Shatila, on the outskirts of Lebanon's capital Beirut. Both camps have taken in several generations of refugees over the decades, starting with the 15 year Lebanese civil war. The camps actively participated in the war, which erased two settlements completely. Nahr el Bared, close to the Syrian border, came under attack once again in 2007 after small groups of Islamist militants started a fierce battle with the Lebanese army in which the homes of about 30,000 people were destroyed.

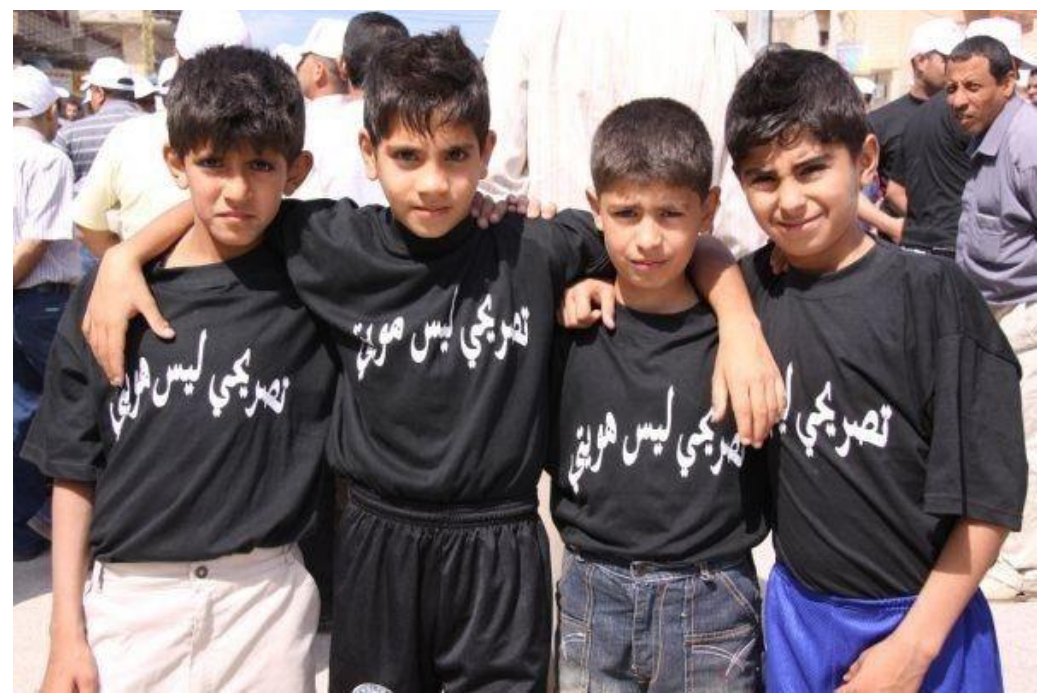

With each new crisis, Palestinians depended by and large upon themselves to accommodate the sudden influx of hundreds in need of food, shelter and clothing. International aid was made available, yet it was barely enough to cover the most basic needs. Together with natural population growth, that has turned the Palestinian camps into some of the most densely populated spaces in the world with less than 3.5 square metres per person. This is less than the 
minimum living space required for healthy living according to the Humanitarian Charter of International Relief (the Sphere Project, 2011). The need to rebuild Nahr el Bared provided a long overdue opportunity to ease the pressures on the overstretched housing conditions and to develop a sustainable living environment in line with contemporary standards of urban development. Yet the hope of improvement was short lived once, half way into the reconstruction, the main agency in charge of Palestinian refugees, UNRWA, ran out of funding leaving 12,000 people displaced until today. [1] Amid the ongoing crisis another 750 Palestinian families arrived from Syria, further increasing the competition for habitable space. The situation is equally bleak in Shatila, whose population grew from 10,000 to an estimated 30,000 people, including Lebanese and Syrian Palestinians, regular Syria citizens but also migrant workers from elsewhere.

The deeply impoverished living conditions in the camps made it inevitable tension and conflict would emerge between the original residents and the new arrivals. The past years have seen severe cut backs in social and medical support from UNRWA, due to the agency's chronic budget deficit of 100 Million US \$ per year. Shortterm emergency relief was available in the wake of the Syrian crisis, yet this aid was mostly spent on Syrian Palestinians, leaving their Lebanese counterparts watching with envy how some received basic goods and financial donations, while they were struggling to cope without support.

The uneven distribution of funds has sharpened social and cultural differences and narrowed lines of solidarity down to local entitlement, belonging and need. "We cannot live with them. They are not like us," is a common sentiment heard among Lebanese Palestinians. Their resentments are met with similar frustrations among the Syrian camp population, locking both sides in a vicious 
circle in which lines of mistrust harden, occasionally sliding into open aggression towards the "brothers" in need. As one Syrian mother of four explains: "They are simply jealous because we are smarter and better able to find jobs, in spite of our desperate circumstances." Members of the educated middle class, who no longer live in the camps, watch in horror how the relationship between camp residents and the new refugees is taking on racial outlines that bring the worst stereotypes into play. "We of all people should know what it means to be in the role of the outsider," one cultural activist complains. He has spent decades maintaining a sense of individual pride and collective identity, especially among young Palestinians, using methods of oral history and "Theatre of the Oppressed". "How can we treat our own as undesirable, backward or un-cultured. Refusing them the right to make themselves feel at home?"

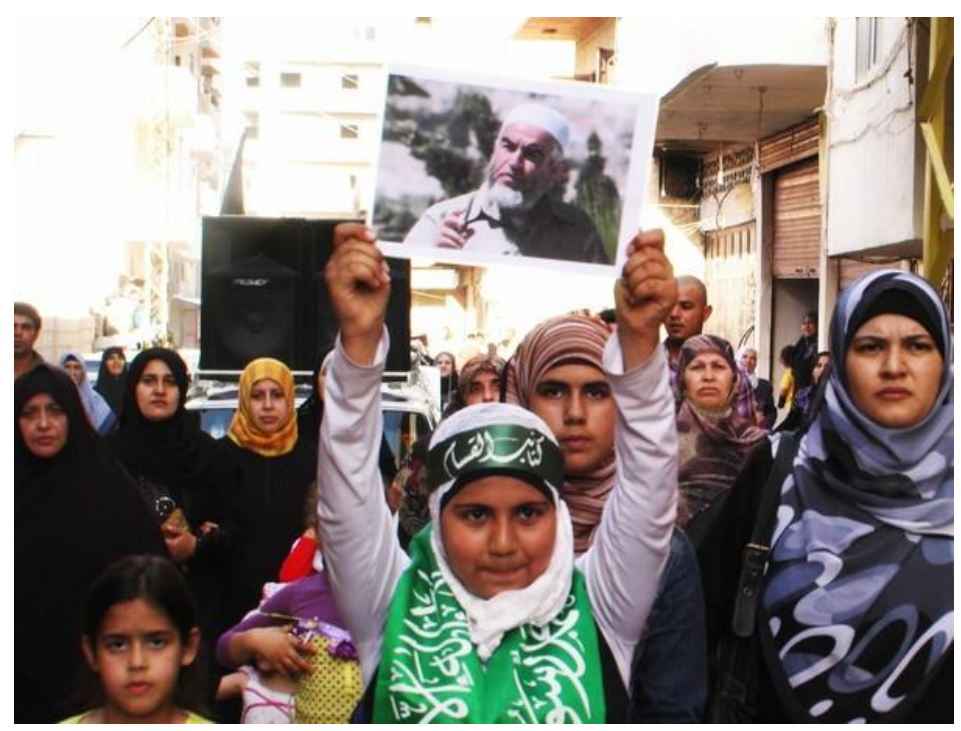


The current tensions have called into question long standing assumptions about what it means to be Palestinian. It has destabilized time honored ethics of struggle that once provided a core tenet of identity and belonging for Palestinians. Palestinian identity, as Karma Nabulsi (the representative of the PLO at the UN 1977-90) writes, is not based on nationalist individuality or sentimental attachment to the lost homeland. It is grounded in the general will of the people for independence that provides them with a sense of coherence and unity (Nabulsi, n.d.). What creates the idea of homeland, in this view, is neither land nor territory but the links between the Palestinian people as the core foundation of their sovereignty.

Nabulsi's remarks build upon Rousseau's (1913) reading of sovereignty as the living embodiment of the social contract. It rejects the Hobbesian idea that mutual commitments and obligations between people can be vested in some governmental body, viewing them as an expression of their general will instead. As George Douglas Howard Cole in his translation of Rousseau explains: "The general will is realized not whenever that is done which is best for the community, but when ... the community as a whole has willed the doing of it." (Cole, 1913). Rousseau's idea of the social contract, however, implies the ability to collectively invest in the material and affective infrastructures needed for translating a sense of togetherness and common good into a lived and felt social reality.

The war in Syria has clearly taken its toll on the social contract that once defined Palestinians as members in communities of struggle. Yet it is only the most recent episode in a long chain of events that have alienated the refugees from the wider national project, isolating them not only geographically but also emotionally and strategically from the centre of decision making about their future, and from a Palestinian state. 
The frustration is particularly pronounced among those who have lived through the siege of Yarmouk, on the outskirts of Damascus. They have endured months of continuous bombardment with little or no access to food and medicines and not a single gesture of political support. No one came to their rescue, they complain: not the Palestinian Authority, not the PLO nor the rest of the refugee community, or made any attempt to help their escape. The fall of Yarmouk, in their view, marked the end of a chapter of Palestinian history in exile. "It's the end of the idea of Return as a common political project, as one Youth Activist from Yarmouk summarised. "They abandoned us."

Up until recently such contempt would rarely be expressed in the open, in front of "strangers" with no historical links to the camp. Yet this young generation of Palestinians, born in exile, no longer feels bound to the unspoken contract of keeping disagreement concealed. "We were living a lie. We are not one group of people. We no longer share a common cause." Their sense of betrayal calls for a critical review of the ethics of struggle under enduring forced exile. Not only for those who have lived and endured its horrors but also for those who have witnessed and documented its suffering and plight. What binds us together is the painful question: what kind of obligations exist for political projects that have so far failed to yield any effective rewards?

\section{References}

Bitari, N. (2013/2014). Yarmuk Refugee Camp and the Syrian Uprising: A View from Within. Journal for Palestine Studies, 43(1), 61-78. 
Cole, G. D. (1913). Introduction. In J.-J. Rousseau, The Social Contract and the Discourses (p. xxxvi). London: Everyman Dent.

Nabulsi, K. (n.d.). Being Palestinian. Retrieved from Ted Honderich Website: http://www.ucl.ac.uk/ uctytho/Being_Palestinian.html Rousseau, J.-J. (1913). The Social Contract and the Discourses. London: Everyman Dent.

Steele, J. (2015, March 5). How Yarmouk refugee camp became the worst place in Syria. Retrieved from The Guardian: https://www.theguardian.com/news/2015/mar/05/howyarmouk-refugee-camp-became-worst-place-syria

The Sphere Project. (2011). Humanitarian Charter and Minimum Standards in Humanitarian Response. Retrieved from The Sphere Project: $\quad \underline{\text { http://www.spherehandbook.org/en/shelter-and- }}$ settlement-standard-3-covered-living-space/

UNRWA. (2017). PRS in Lebanon. Retrieved from United Nations Relief and Works Agency: https://www.unrwa.org/prs-lebanon

\section{Notes}

[1] Additional funds have recently been made available yet it will take another two years until all housing facilities will have been rebuilt. 
Monika Halkort is assistant professor of digital journalism and social communication at the Lebanese American University, Department of Communication Arts. Her research explores the social life of data, focusing in particular on the relationship between digital infrastructures and claim making in the context of political struggle and humanitarian governance. Her most recent work examines the bio politics of digital circulation in post conflict situations and how they facilitateand/or undermine struggles for political autonomy and selfdetermination among stateless populations and refugees. The main geographic focus of her work is the Arab World. 


\section{The Geopolitics of the Cloud}

Monika Halkort

Originally published in 5/19/2017

* This essay was originally published in Scores 10/16. SCORES is an interdisciplinary journal by the Tanzquartier Wien linking performance theory with critical practice across a wide range of artistic and intellectual fields.

Every year hundreds of refugees and undocumented migrants are kidnapped in Ethiopia, Sudan and the surrounding areas. Once captured they are sold to organised gangs in the Sinai desert, who trade their bodies in exchange for ransom from relatives and friends. Ninety-five per cent of the hostages are Eritreans desperate to escape the repressive and poor living conditions in their country. They include men, women, children and accompanying infants, in search for a better life in Europe or Israel. Their vulnerability makes them a particularly inviting target. Leaving Eritrea requires hard-toobtain travel visas, leading many to pay traffickers to smuggle them out. Once across the border they often deliberately burn their passports so as to avoid repatriation. Others are forcefully dispossessed of their IDs once they have been sold off to criminal gangs.

Relatives and friends rarely seek help from security forces for fear that the hostages will be arrested or killed in release operations. Human-rights activists have reported numerous occasions where captives have been shot by Egyptian or Israeli border police soon after they were freed (van Reisen, Estefanos, \& Rijken, 2012). This pervasive fear enables the kidnappers to operate by and large 
untroubled by unwanted attention. Demands for ransom can reach up to $\$ 50,000$ for each hostage held.

All this is well documented by human-rights activists, researchers and the news media, yet their reports have so far not produced any effective response. The Egyptian authorities reject any responsibility for the hostages, based on the fact that they have entered the country illegally. Going after the kidnappers themselves, on the other hand, has proven difficult, because of the ongoing conflict between the Egyptian military and the armed insurgency in Sinai.

The ineffectiveness of testimonial evidence in preventing crimes against humanity is of course nothing new in the history of humanrights violations. The lack of political intervention against the ethnic cleansing in Bosnia, Rwanda or Darfur comes as powerful reminder that visual or oral evidence is by no means a guarantee for mobilising political action or support. Yet the fateful trap of the Eritrean hostages points to a constitutive shift in the political economy of suffering and testimony, whose ethical implications have yet to be fully understood. In what follows I am reading this shift in context with the wider neo-liberal restructuring of political and moral publics and their articulation with new communicative domains. The current juncture of personalized mass communication and human mobility, I will suggest, introduced a whole new layer of sovereign authority upon the contemporary order, in which new states of exception can flourish and traditional domains of power over life are fundamentally transformed.

Visual or oral testimony are never self-evident or selfexplanatory. They require purposeful interpretation to produce cultural sensibilities for action or change. As Keenan (2002, p. 115) writes, left to itself the image compels nothing, nor does it dictate any particular response. It remains a cultural form without guarantees, 
just like the testimony; always available for reinterpretation, "where everything is open to abuse and appropriation .... shaking ground indeed" (ibid.). [1]

And yet the testimony persists as a primary medium through which ethical claims are negotiated. Human-rights activists heavily depend on the circulation of images, symbols and personal accounts of suffering to connect audiences to political projects and to evoke sympathy and compassion in support of bodies in need (McLagan, 2007, p.309). For most of the post-WWII era, this mobilisation of conscience has relied on the highly regulated networks of television. They have enabled groups such as Amnesty International, Médecins Sans Frontières and others to create political momentum for a humanitarian or moral cause. As McLagan (2007, pp. 309 - 310) suggests, the corporeality of the body has provided a critical vehicle for the strategic conscription of human empathy into political action. Confronting audiences with testimonial evidence of bodies in pain created a sensuous link between the bodies represented on screen and the bodies in the audience, enabling viewers to recognise themselves in the vulnerability of distant others on display. The shared human condition of embodied existence, in other words, provided the interpretative foil necessary to create an intersubjective space of exchange and identification. It made room for the account of individual suffering to reappear as a recognisable part of the shared human condition from which ethical responsibilities and obligations could be inferred.

The highly individualised landscape of contemporary mass selfcommunication has radically changed the conditions of possibility for the cultivation of ethical sensibilities through such crafted choreographies of affect. It invited a whole new range of actors to participate in the moral economy of mediated suffering, using far more flexible and targeted modes of assembly to create private 
publics that do not necessarily share common causes with the public domain. The propaganda machine of ISIS and the communication strategy of the Sinai kidnappers are just two examples here. They come as a harsh reminder of the fact that the persuasive power of testimony is no longer solely in the hands of the victims but rather has become an active instrument of war.

The Sinai kidnappers have proven extremely resourceful in exploiting the affective resonance of mediated suffering. They do not contact the family and relatives of their prisoners directly, but rather force the hostages themselves to call and beg for money in exchange for their release. The hostages are often tortured while still on the phone to increase the emotional pressure and to push for rapid payment. Those who cannot or do not pay risk being killed or harvested for organs that can be traded to make up for the outstanding sum. Emotional blackmail by phone is of course a tactic used in most hostage situations. The key difference here is that these calls do not come from secret or untraceable locations. They are made on regular phonelines registered with mobile service providers which, at least in theory, would allow anyone interested in freeing the hostages to locate and identify the kidnappers. What prevents their arrest is the legal and political impasse and complacency surrounding refugee and migrant populations. This impasse cannot be explained with the ineffectiveness of state and humanitarian actors alone. It requires taking a closer look at how long standing political and moral deficits articulate to the emergence of new forms of sovereign power as a direct result of global communication networks on a planetary scale.

The universal addressing scheme of cloud computing and mobile phone companies, as Benjamin Bratton (2012) suggests, has linked bodies, objects and events into an abyss-like field of information exchange in which the old Westphalian order of territorial 
jurisdiction is increasingly overwritten by new bio-political regimes. The flexible system of IP addresses and geo locators, in this view, confronts us with a new type of sovereign that shifts the ability to regulate movement, transactions and the well-being of populations away from inter-governmental organisations and the state.

Bratton's observation rests on the following assumption: for a thing or event to participate in the world it needs to have an address, a unique identity that makes it available for connections with other things. On its own, it is not present. It needs to be made into an "it", with a discrete location, to become recognisable, addressable and marked. This has traditionally been achieved by formal addressing tables, such as post codes, street addresses, or unique citizen ID numbers. Together they have provided the key political technologies for the organisation of political space in the modern era that has both demarcated and legitimated the sovereign authority of the state (Bratton, 2016, p. 193; Bratton, 2012). The global addressing scheme of mobile phone and internet providers no longer corresponds with the political geography inherited from this Westphalian order. It has superimposed a whole new layer of sovereign actors onto the territorial grid capable of transcending national borders and jurisdictions, leading incommensurate logics of governance and geography to overlap and collide.

Social media such as Facebook, Google Maps, or mobile phone apps do not distinguish between citizens, migrants, kidnappers or refugee populations. They are just as likely to provide their services irrespective of the user's legal or political status or circumstance. This is not to suggest that there are no authentication mechanisms and security checks built into the global communication infrastructure or to ignore the increasing encroachment on personal data by national and international security agencies. The paradoxical coexistence of ever tighter mechanisms of electronic surveillance 
and biometric regimes and the acceleration of unregulated population movements rather points to the asymmetrical mix of formal and informal jurisdictions that defines our current moment, and that lead public and private laws to feed off of each other in ways that render the nature and scope of sovereign jurisdictions ever more uncertain and unclear. As Bratton (2012) remarks, states are increasingly taking on the form of cloud-based platforms by extending their reach to far-flung data centres that are formally not part of their political control. Data and communication service providers, on the other hand, increasingly overrule the state's capacity to regulate and track social connectivity and participation, re-scripting the public sphere alongside the competitive market principles of corporate law. The result is an explosive mix of "productive accidents", Bratton (ibid.) concludes, in which new states of exception can flourish and new boundaries can be drawn.

Bearing this in mind it becomes possible to see how the tragic fate of the Eritrean refugees, stacked away in secretive desert prisons, stands for a far wider shift in the troubled history of publicity, indifference and mediated suffering. The fact that their testimony has so far not succeeded in attracting sufficient attention is not simply the effect of the political and moral deficits or the oversaturation of pain in human-rights discourse. It shows how the privatisation of political and moral publics through new addressing schemes articulates with the wider neoliberal restructuring of common interests, and recalibrates social and ethical imperatives alongside individual interests and capital gains. The result is a radical transformation of the public sphere into an infinitely scalable entity that enabled the kidnappers to cynically exploit the strategic purchase of human testimony and to perform the most inhuman acts of violence "live" in front of carefully crafted audiences, whose compassion has effectively fenced off unwanted public attention and 
drastically reduced the ability to mobilise action in support of the refugees. Being able to contain the persuasive power of testimony within the private networks of family and friends has left the decision to let live or let die safely in the hands of the kidnappers, conjuring up a system of affective capture in which the distinction between lives to be saved and lives to be abandoned is made contingent on the availability of capital and private funds.

\section{References}

Bratton, B. (2012), "The Cloud, the State, and the Stack: Metahaven in Conversation with Benjamin Bratton", Metahaven interview, retrieved 15 May 2016, from: http://mthvn.tumblr.com/post/38098461078/thecloudthestatean dthestack

Bratton, B. (2016), The Stack: On Software and Sovereignty, Cambridge, MA: MIT Press.

Keenan, T. (2002), "Publicity and Indifference (Sarajevo on Television) ", PMLA, 117 (1, Special Topic: Mobile Citizens, Media States ), pp. 104-116.

McLagan, M. (2007). "Human Rights, Testimony and Transnational Publicity", in M. Feher, G. Krikorian, \& Y. McKee, Non-Governmental Politics (pp. 304 - 317), New York: Zone Books.

van Reisen, M., Estefanos, M., \& Rijken, C. (2012), Human Trafficking in the Sinai: Refugees between Life and Death, Brussels: Wolf Legal Publishers (WLP). 


\section{Notes}

[1] The images of ethnic cleansing in Srebrenica, Bosnia, here are a powerful case in point. They eventually convinced the international community to intervene. Yet only through peace-keeping forces, without a legal mandate to stop or confront the warring groups. This allowed genocidal killings to persist right in front of the eyes of international peace keepers, leading to widespread condemnation of the UN's response.

Monika Halkort is assistant professor of digital journalism and social communication at the Lebanese American University, Department of Communication Arts. Her research explores the social life of data, focusing in particular on the relationship between digital infrastructures and claim making in the context of political struggle and humanitarian governance. Her most recent work examines the bio politics of digital circulation in post conflict situations and how they facilitateand/or undermine struggles for political autonomy and selfdetermination among stateless populations and refugees. The main geographic focus of her work is the Arab World. 



\section{Refugee Outreach}

\section{\& Research Network}
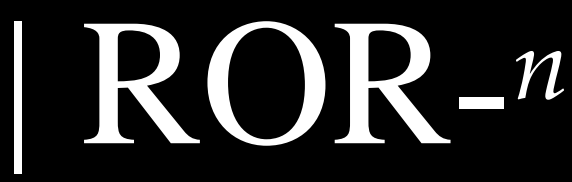

THIS BOOK IS A SELECTION OF CONTRIBUTIONS TO THE ROR-N BLOG. 30 AUTHORS COMING FROM DIVERSE DISCIPLINES DISCUSS FORCED MIGRATION-RELATED ISSUES. ALL 30 CONTRIBUTIONS OFFERED HERE WERE WRITTEN BY ACADEMICIANS, BASED ON INFORMED IN-DEPTH RESEARCH AND GEARED TO A WIDER PUBLIC. IN BRINGING TOGETHER THREE FIELDS OF INQUIRY, THE PRESENT VOLUME OPENS UP PROMISING APPROACHES TO FORCED MIGRATION. WE HOPE THAT THE RESEARCH QUESTIONS, METHODS AND PERSPECTIVES PRESENTED HERE WILL FACILITATE A FOCUSED AND PRODUCTIVE DISCUSSION ON THE ISSUES AT HAND.
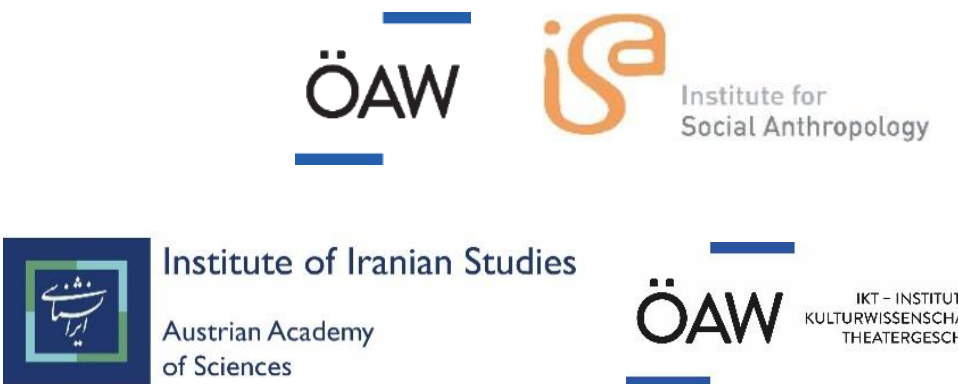

Institute of Iranian Studies

Austrian Academy of Sciences

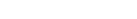

